Supplementary Information for:

\title{
Neocuproine as a Redox-Active Ligand Platform on Iron and Cobalt
}

\author{
Kate A. Jesse, Alexander S. Filatov, Jiaze Xie, and John S. Anderson* \\ Department of Chemistry, The University of Chicago, Chicago, IL 60637, United States \\ *Correspondence to: jsanderson@uchicago.edu
}




\section{Table of Contents}

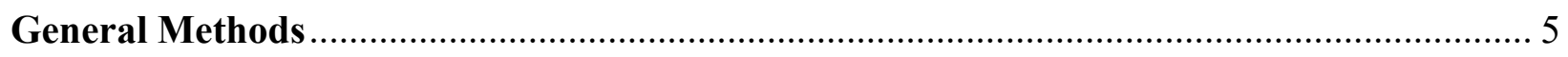

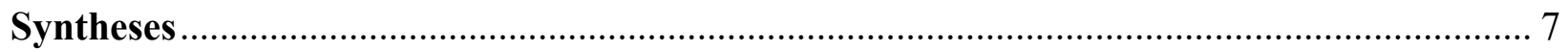

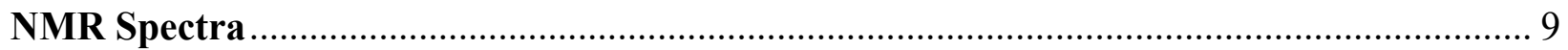

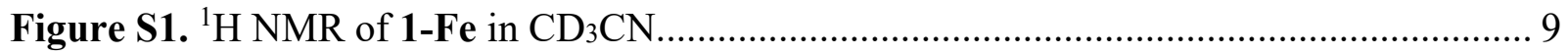

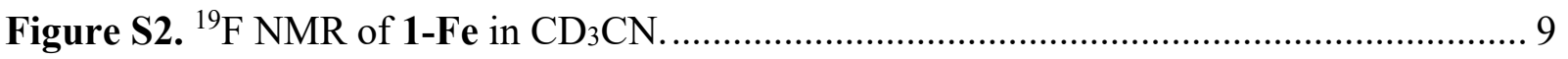

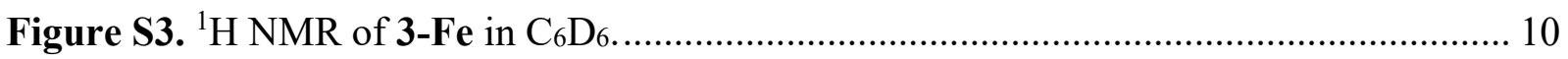

Figure S4. ${ }^{1} \mathrm{H}$ NMR of 3-Fe with excess AgOTf in $\mathrm{CD}_{3} \mathrm{CN}$ stacked with 1-Fe and 3-Fe. ..... 10

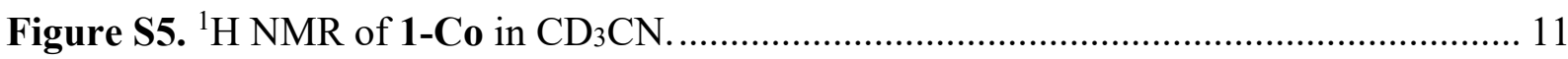

Figure S6. ${ }^{1} \mathrm{H}$ NMR of 1-Co and [Co(neocuproine)(OTf $\left.)_{2}(\mathrm{MeCN})\right]$ in $\mathrm{CD}_{3} \mathrm{CN}$..................... 11

Figure S7. ${ }^{19} \mathrm{~F}$ NMR of 1-Co and $\left[\mathrm{Co}(\right.$ neocuproine $\left.)(\mathrm{OTf})_{2}(\mathrm{MeCN})\right]$ in $\mathrm{CD}_{3} \mathrm{CN}$................... 12

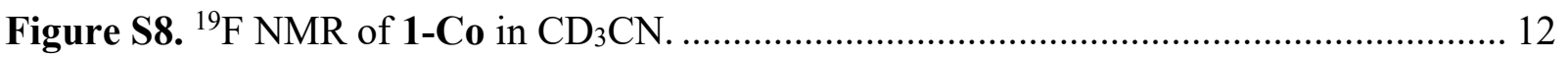

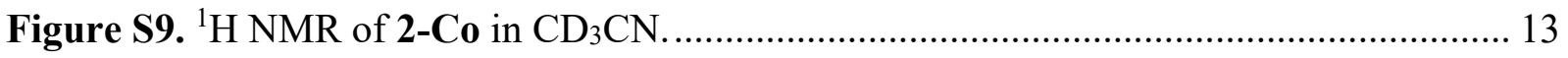

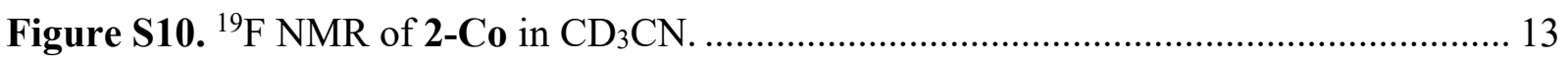

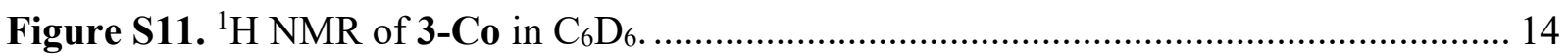

Figure S12. ${ }^{1} \mathrm{H}$ NMR of 3-Co with excess AgOTf in $\mathrm{CD}_{3} \mathrm{CN}$ stacked with 1-Co, 2-Co, and 3-

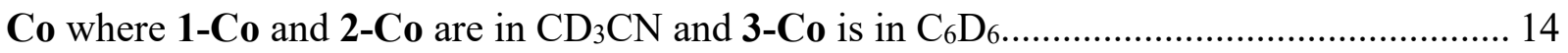

Figure S13. ${ }^{19} \mathrm{~F}$ NMR of 1-Fe with 3 equivalents of 1,2-difluorobenzene as an internal

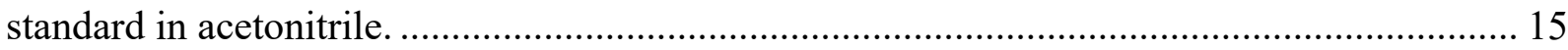

Figure S14. ${ }^{19} \mathrm{~F}$ NMR of 1-Co with 3 equivalents of 1,2-difluorobenzene as an internal

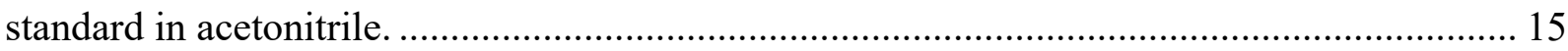

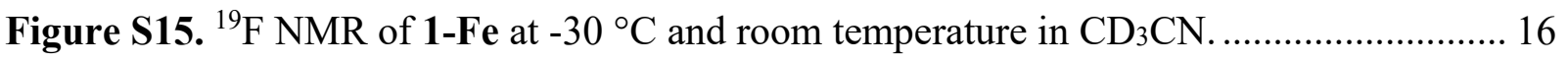

Figure S16. ${ }^{19} \mathrm{~F}$ NMR of 1-Fe at $-30{ }^{\circ} \mathrm{C}$ and room temperature in $\mathrm{CD}_{3} \mathrm{CN} \ldots \ldots \ldots \ldots \ldots \ldots \ldots \ldots . . . . . . . . . . . . . .16$

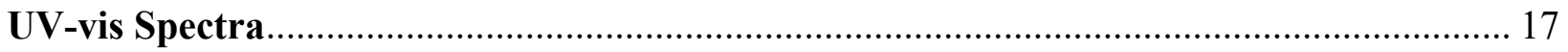

Figure S17. UV-vis spectrum of 1-Fe in acetonitrile..................................................... 17

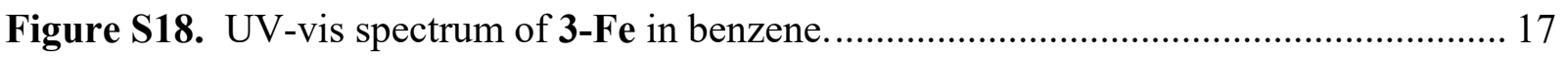

Figure S19. UV-vis spectrum of 1-Co in acetonitrile....................................................... 18

Figure S20. UV-vis spectrum of 2-Co in acetonitrile...................................................... 18

Figure S21. UV-vis spectrum of 3-Co in benzene........................................................ 19

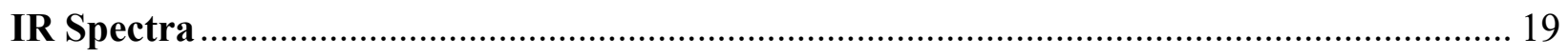

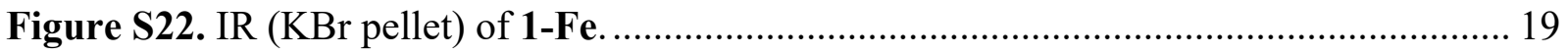

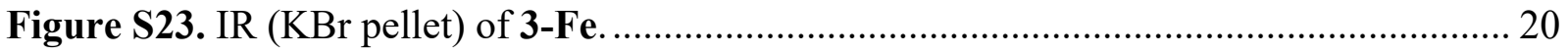

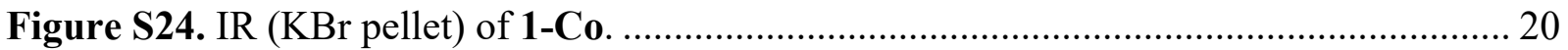




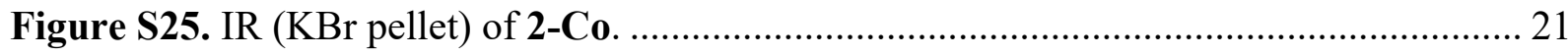

Figure S26. IR (KBr pellet) of 3-Co. ........................................................................ 21

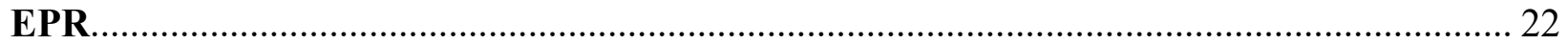

Figure S27. EPR spectrum of 1-Co in acetonitrile, RT................................................. 22

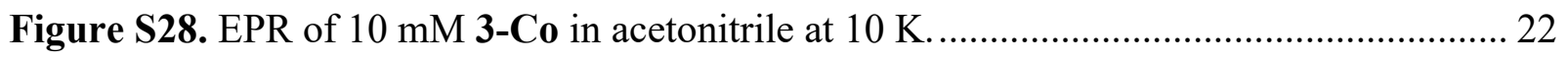

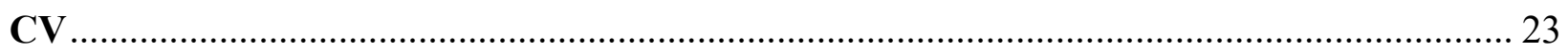

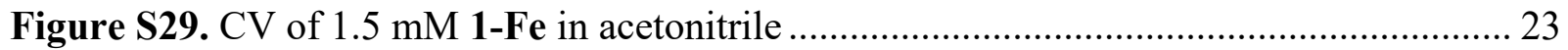

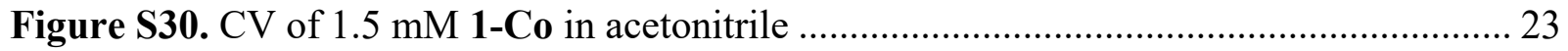

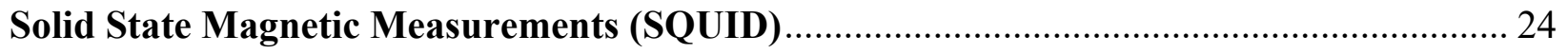

Figure S31. Variable temperature $\chi T$ data of 1-Fe at 1 Tesla. ........................................... 24

Figure S32. Variable temperature $\chi T$ data of 3-Fe at 1 Tesla. ............................................ 24

Figure S33. Variable temperature $\chi T$ data of 1-Co at 1 Tesla.......................................... 25

Figure S34. Variable temperature $\chi T$ data of 2-Co at 1 Tesla......................................... 25

Figure S35. Variable temperature $\chi T$ data of 3-Co at 1 Tesla.......................................... 26

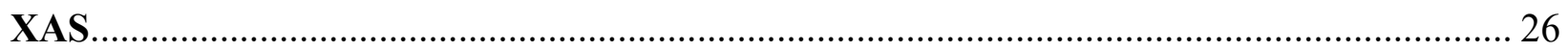

Figure S36. EXAFS spectrum in R-space at the Fe K-edge absorption of 3-Fe.................. 26

Figure S37. EXAFS spectrum in K-space at the Fe K-edge absorption of 3-Fe. ................. 27

Table S1. EXAFS Fit Parameters for 3-Fe.................................................................... 27

Figure S38. EXAFS spectrum in R-space at the Co K-edge absorption of 3-Co. ................ 28

Figure S39. EXAFS spectrum in K-space at the Co K-edge absorption of 3-Co................. 28

Table S2. EXAFS Fit Parameters for 3-Co ....................................................................... 29

Figure S40. XAS of 1-Fe, 3-Fe, $\mathrm{Fe}(\mathrm{MeCN})_{2}(\mathrm{OTf})_{2}$, and the $\mathrm{Fe}(0)$ foil............................. 29

Figure S41. XAS K-edge derivative plot of 1-Fe, 3-Fe, $\mathrm{Fe}(\mathrm{MeCN})_{2}(\mathrm{OTf})_{2}$, and the $\mathrm{Fe}(0)$ foil.

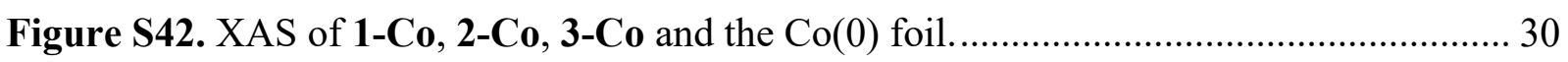

Figure S43. XAS K-edge derivative plot of 1-Co, 2-Co, 3-Co and the $\operatorname{Co}(0)$ foil................ 31

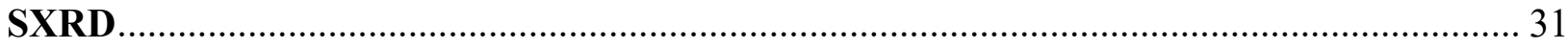

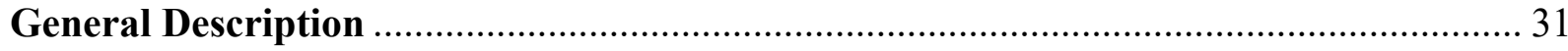

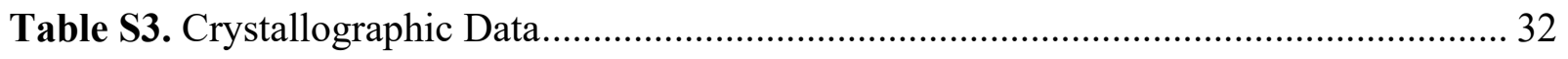

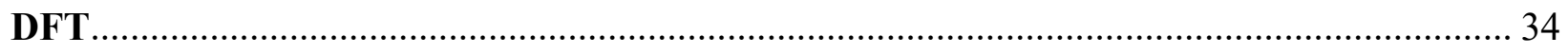

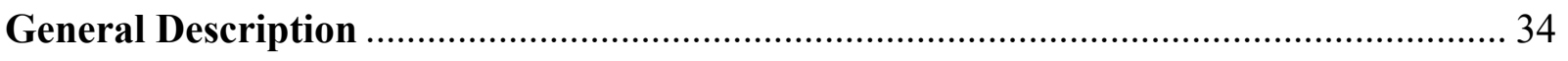

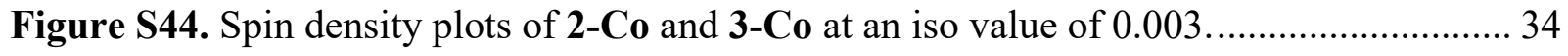

Table S4. Mulliken Spin Density on Ligand vs. Cobalt ....................................................... 34 
Table S5. Corresponding Orbital Overlap from Broken Symmetry Calculations.................. 34

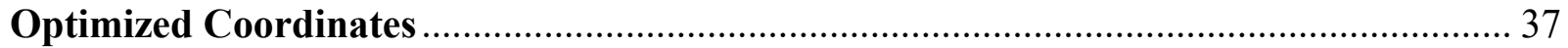

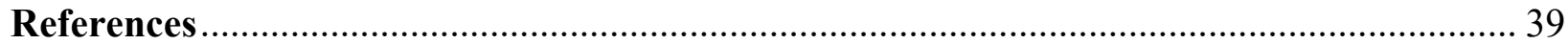




\section{General Methods}

All chemicals were purchased from commercial suppliers and used without further purification. All manipulations were carried out under an atmosphere of $\mathrm{N}_{2}$ using standard Schlenk and glovebox techniques. Glassware was dried at $180^{\circ} \mathrm{C}$ for a minimum of two hours and cooled under vacuum prior to use. Solvents were dried on a solvent purification system from Pure Process Technologies and stored over $4 \AA$ molecular sieves under $\mathrm{N}_{2}$. Tetrahydrofuran (THF) was stirred over $\mathrm{NaK}$ alloy and run through an additional alumina column prior to use to ensure dryness. Solvents were tested for $\mathrm{H}_{2} \mathrm{O}$ and $\mathrm{O}_{2}$ using a standard solution of sodium-benzophenone ketyl radical anion. $\mathrm{C}_{6} \mathrm{D}_{6}, \mathrm{CDCl}_{3}$, and $\mathrm{CD}_{2} \mathrm{Cl}_{2}$ were dried over $4 \AA$ molecular sieves under $\mathrm{N}_{2} .{ }^{1} \mathrm{H}$ and ${ }^{13} \mathrm{C}\left\{{ }^{1} \mathrm{H}\right\}$ NMR spectra were recorded on Bruker DRX 400 or 500 spectrometers. Chemical shifts are reported in ppm units referenced to residual solvent resonances for ${ }^{1} \mathrm{H}$ and ${ }^{13} \mathrm{C}\left\{{ }^{1} \mathrm{H}\right\}$ spectra. UV-Vis Spectra were recorded on a Bruker Evolution 300 spectrometer and analyzed using VisionPro software. Experiments requiring a dip probe utilized Hellma Analytics Excalibur Standard Tauchsonde Granzquarz-Tauchsonde (serial no. 13594). IR spectra were obtained on a Bruker Tensor II spectrometer with the OPUS software suite. All IR samples were prepared as $\mathrm{KBr}$ pellets in a homemade press. EPR spectra were recorded on an Elexsys E500 Spectrometer with an Oxford ESR 900 X-band cryostat and a Bruker Cold-Edge Stinger. EPR data was fit using a least-squares fit in SpinCount. Electrochemical measurements were performed using a BAS Epsilon potentiostat and analyzed using BAS Epsilon software version 1.40.67NT. Cyclic voltammetry measurements were made using a glassy carbon working electrode, platinum wire counter electrode, and silver wire pseudo-reference electrode, and referenced to internal $\mathrm{Fc} / \mathrm{Fc}^{+}$. Magnetic measurements were performed on either a Quantum Design MPMS 3 equipped with a superconducting quantum interference device (SQUID) or using a Quantum Design MPMS-XL SQUID magnetometer. Corrections were made for the diamagnetic contributions from the polycarbonate capsules and eicosane used to secure the sample by measuring field vs. moment in duplicate for each to determine a moment per gram correction. The $\chi$ values reported are the molar magnetic susceptibilities. Magnetic data ( $\chi T$ vs. T) plots and reported values have been normalized to one formula unit. Zero-field ${ }^{57} \mathrm{Fe}$ Mössbauer spectra were obtained at $80 \mathrm{~K}$ using a ${ }^{57} \mathrm{Co} /$ rhodium source. Samples were prepared in an MBraun nitrogen glove box. A typical sample contained approximately $60 \mathrm{mg}$ of compounds suspended in a plastic cap. Another cap with a slightly smaller diameter was squeezed into the previous sample cap to completely encapsulate the solid sample mixture. All spectra were analyzed using the WMOSS Mössbauer Spectral Analysis Software. Complex 1-Fe was fit with a Voigt line shape. Note that the accuracy of the fit parameters may be overestimated as the error in the Fe foil calibration is $0.01 \mathrm{~mm} / \mathrm{s}$. Single crystal X-ray diffraction data were collected in-house using Bruker D8 Venture diffractometer equipped with Mo microfocus X-ray tube $(\lambda=0.71073 \AA)$ or at the Advanced Photon Source of Argonne National Laboratory (beamline 15 -ID-B,C,D) using X-ray radiation with a wavelength of $\lambda=0.41328 \AA$. $\mathrm{X}$-ray near-edge absorption spectra (XANES) and X-ray absorption fine structure (XAFS) spectra were employed to probe the local environment around Fe. Data were acquired at the Advanced Photon Source at Argonne National Labs with a bending magnet source with ring energy at 7.00 GeV. Fe K-edge data were acquired at the MRCAT 10- BM beam line. EXAFS data were collected in the fluorescence mode using fluorescence ion chamber in Stern-Heald geometry. Absorption was calibrated and concurrently referenced during measurement to a Fe foil. Data collected was 
processed using the Demeter software suite ${ }^{1}$ by extracting the EXAFS oscillations $\chi(\mathrm{k})$ as a function of photoelectron wavenumber $\mathrm{k}$. The theoretical paths were generated using FEFF6 and the models were done in the conventional way using the fitting program Artemis. The initial model was taken from an X-ray crystal structures of the Fe and Co compounds. EXAFS data were modelled in R-space with k-weights of 1,2 and 3 until a satisfactory fit describing the system was obtained. 


\section{Syntheses}

[Fe(neocuproine)2(OTf)][OTf] (1-Fe)

$\mathrm{Fe}(\mathrm{MeCN})_{2}(\mathrm{OTf})_{2}(1.60 \mathrm{~g}, 3.67 \mathrm{mmol})$ and neocuproine $(1.54 \mathrm{~g}, 7.37 \mathrm{mmol})$ were dissolved separately in acetonitrile $(7 \mathrm{~mL}$ each). The solutions were combined with stirring for 30 minutes to form a deep yellow solution. The reaction mixture was concentrated under vacuum to a saturated solution in acetonitrile $(4 \mathrm{~mL})$ and crystallized via two layer crystallization with $\mathrm{Et}_{2} \mathrm{O}(13 \mathrm{~mL})$

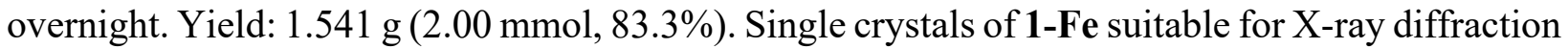
were obtained by vapor diffusion of $\mathrm{Et}_{2} \mathrm{O}$ into a concentrated solution of 1-Fe in acetonitrile. ${ }^{1} \mathrm{H}$ $\operatorname{NMR}\left(400 \mathrm{MHz}, \mathrm{CD}_{3} \mathrm{CN}, \mathrm{RT}\right): \delta=55.5(\mathrm{~s}, 4 \mathrm{H}), 32.6(\mathrm{~s}, 4 \mathrm{H}), 1.1(\mathrm{~s}, 4 \mathrm{H}),-34.3(\mathrm{bs}, 12 \mathrm{H}) .{ }^{19} \mathrm{~F}\left\{{ }^{1} \mathrm{H}\right\}$ NMR (500 MHz, CD 3 CN, RT): $\delta$-64 (bs). Magnetic Susceptibility: Evans' Method $\left(\mathrm{CD}_{3} \mathrm{CN}, \mathrm{RT}\right.$, $\left.\mu_{\mathrm{B}}\right): \mu_{\text {eff }}=5.06$; SQUID: $\chi T=3.65 \mathrm{~cm}^{3} \mathrm{~K} / \mathrm{mol}$. IR $\left(\mathrm{KBr}\right.$ pellet, $\left.\mathrm{cm}^{-1}\right): 3066(\mathrm{C}-\mathrm{H}, \mathrm{w}), 1594(\mathrm{~m})$, $1500(\mathrm{~m})$. Mössbauer $(80 \mathrm{~K}, \mathrm{~mm} / \mathrm{s}) \delta=1.186(2) ; \Delta E_{\mathrm{Q}}=3.404(3)$. UV-vis, $\mathrm{nm}$ in acetonitrile, $(\varepsilon$, $\left.\mathrm{M}^{-1} \mathrm{~cm}^{-1}\right)$ : 450 (140). Anal. Calc. C, 46.76; H, 3.14; N, 7.26; Found: C, 46.58; H, 3.30; N, 7.08.

$\left[\mathrm{Co}(\text { neocuproine })_{2}(\mathrm{OTf})\right][\mathrm{OTf}](\mathbf{1 - C o})$

$[\mathrm{Co}(\mathrm{MeCN})]_{6}\left[(\mathrm{OTf})_{2}\right](1.70 \mathrm{~g}, 2.18 \mathrm{mmol})$ and neocuproine $(2.70 \mathrm{~g}, 12.96 \mathrm{mmol})$ were dissolved separately in acetonitrile $(7 \mathrm{~mL}$ each). The solutions were combined with stirring overnight to form a deep purple solution. The reaction mixture was concentrated under vacuum to a saturated solution in acetonitrile $(4 \mathrm{~mL})$ and washed with benzene $(10 \mathrm{~mL} \times 5)$ to remove excess neocuproine. This was then crystallized via two layer crystallization using a concentrated solution of 1-Co in acetonitrile $(4 \mathrm{~mL})$ with $\mathrm{Et}_{2} \mathrm{O}(13 \mathrm{~mL})$ overnight. Yield: $1.10 \mathrm{~g}(1.42 \mathrm{mmol}, 50.5 \%)$. Single crystals of 1-Co suitable for X-ray diffraction were obtained by vapor diffusion of $\mathrm{Et}_{2} \mathrm{O}$ into a concentrated solution of 1-Co in acetonitrile. ${ }^{1} \mathrm{H}$ NMR $\left(400 \mathrm{MHz}, \mathrm{CD}_{3} \mathrm{CN}, \mathrm{RT}\right): \delta=58.5$ (s, 4H), 44.9 (s, 4H), 13.2 (s, 4H), -65.6 (bs, 12H). ${ }^{19} \mathrm{~F}\left\{{ }^{1} \mathrm{H}\right\}$ NMR $\left(500 \mathrm{MHz}, \mathrm{CD}_{3} \mathrm{CN}, \mathrm{RT}\right): \delta=-$ 75 (bs). Note: when excess neocuproine is present in solution, a single, very broad peak at $\delta=12$ $\mathrm{ppm}$ can be seen in the ${ }^{1} \mathrm{H}$ NMR spectrum. Magnetic Susceptibility: Evans' Method $\left(\mathrm{CD}_{3} \mathrm{CN}\right.$, RT, $\left.\mu_{\mathrm{B}}\right): \mu_{\text {eff }}=4.30$; SQUID: $\chi T=2.78 \mathrm{~cm}^{3} \mathrm{~K} / \mathrm{mol}$. EPR $\left(\mathrm{g}_{\mathrm{z}}, \mathrm{g}_{\mathrm{x}}, \mathrm{g}_{\mathrm{y}}\right): 2.35,2.08,1.87$. IR (KBr pellet, $\left.\mathrm{cm}^{-1}\right): 3076(\mathrm{C}-\mathrm{H}, \mathrm{w}), 1598(\mathrm{~m}), 1503(\mathrm{~m})$. UV-vis, $\mathrm{nm}$ in acetonitrile, $\left(\varepsilon, \mathrm{M}^{-1} \mathrm{~cm}^{-1}\right): 427(620)$, 521 (210), 541 (210), 577 (250). Anal. Calc. C, 46.57; H, 3.13; N, 7.24; Found: C, 46.38; H, 3.29; N, 7.21 .

[Fe(neocuproine-radical) 2$](3-\mathrm{Fe})$

1-Fe $(210 \mathrm{mg}, 0.27 \mathrm{mmol})$ and $\mathrm{KC}_{8}(70 \mathrm{mg}, 0.52 \mathrm{mmol})$ were stirred in $\mathrm{Et}_{2} \mathrm{O}(15 \mathrm{~mL})$ to form a suspension, which turned deep red-black over 30 minutes. The reaction was allowed to stir overnight, then condensed to a solid under vacuum. This was taken up in benzene $(200 \mathrm{~mL})$ and filtered through dry Celite to remove graphite and salt byproducts. This was condensed under vacuum to produce a pure, dark maroon powder. Yield: $45 \mathrm{mg}(0.095 \mathrm{mmol}, 34.9 \%)$. Crystals used to confirm connectivity by SXRD were obtained by vapor diffusion of petroleum ether into a concentrated solution of 3-Fe in THF. ${ }^{1} \mathrm{H}$ NMR $\left(400 \mathrm{MHz}, \mathrm{C}_{6} \mathrm{D}_{6}, \mathrm{RT}\right): \delta=119.9(\mathrm{~s}, 4 \mathrm{H}), 25.5$ (s, 
4H), -78.6 (bs, 12H). Magnetic Susceptibility: Evans' Method $\left(\mathrm{C}_{6} \mathrm{D}_{6}, \mathrm{RT}, \mu_{\mathrm{B}}\right): \mu_{\mathrm{eff}}=2.90$; SQUID: $\chi T=1.05 \mathrm{~cm}^{3} \mathrm{~K} / \mathrm{mol}$. IR (KBr pellet, $\left.\mathrm{cm}^{-1}\right): 2919(\mathrm{C}-\mathrm{H}, \mathrm{w}), 1615(\mathrm{~m}), 1590(\mathrm{~m}), 1503$ (s). Mössbauer ( $80 \mathrm{~K}): \delta=0.787(1) ; \Delta E_{\mathrm{Q}}=1.427(3)$. UV-vis, $\mathrm{nm}$ in benzene, $\left(\varepsilon, \mathrm{M}^{-1} \mathrm{~cm}^{-1}\right): 365(4700)$, 397 (3400), 487 (4100), 523 (3200), 782 (1400). Anal. Calc. C, 71.20; H, 5.12; N, 11.86; Found: C, 71.19; H, 5.18; N, 11.88 .

[Co(neocuproine-radical)2] (3-Co)

1-Co $(1.00 \mathrm{~g}, 1.29 \mathrm{mmol})$ and $\mathrm{KC}_{8}(350 \mathrm{mg}, 2.59 \mathrm{mmol})$ were stirred in a mixture of $\mathrm{Et}_{2} \mathrm{O}: \mathrm{THF}$ $(3: 1,15 \mathrm{~mL})$ to form a suspension that began to turn deep red-black immediately. The reaction was allowed to stir 1 hour, filtered through dry Celite to remove graphite, then condensed to a solid under vacuum. This was taken up in benzene $(700 \mathrm{~mL})$ and filtered to remove salt byproducts. This was condensed under vacuum to produce a dark maroon powder. Yield: $169 \mathrm{mg}(0.35 \mathrm{mmol}$, $27.5 \%$ ). Crystals used to confirm connectivity by SXRD were obtained by vapor diffusion of petroleum ether into a concentrated solution of 3-Co in THF. ${ }^{1} \mathrm{H}$ NMR (400 MHz, $\left.\mathrm{C}_{6} \mathrm{D}_{6}, \mathrm{RT}\right): \delta=$ 59.4 (s, 4H), 20.1 (s, 8H), -54.3 (bs, $12 \mathrm{H}$ ). Magnetic Susceptibility: Evans' Method ( $\mathrm{C}_{6} \mathrm{D}_{6}, \mathrm{RT}$, $\mu_{\text {B }}: \mu_{\text {eff }}=2.08$; SQUID: $\chi T=0.56 \mathrm{~cm}^{3} \mathrm{~K} / \mathrm{mol}$. EPR $\left(\mathrm{g}_{\mathrm{z}}, \mathrm{g}_{\mathrm{x}}, \mathrm{g}_{\mathrm{y}}\right): 2.70,2.36,2.063$. IR (KBr pellet, $\left.\mathrm{cm}^{-1}\right)$ : $3036(\mathrm{C}-\mathrm{H}, \mathrm{w}) ; 2916(\mathrm{C}-\mathrm{H}, \mathrm{w}), 1617$ and 1590 (s), 1494 (s). UV-vis, nm in benzene, $\left(\varepsilon, \mathrm{M}^{-}\right.$ $\left.{ }^{1} \mathrm{~cm}^{-1}\right)$ : 358 (2500), 400 (1600), 500 (3600), 634 (1200), $884\left(1500 \mathrm{M}^{-1} \mathrm{~cm}^{-1}\right)$. Anal. Calc. C, 55.77; H, 3.87; N, 8.97; Found: C, 55.04; H, 4.17; N, 8.24. Note that the combustion analysis for this compound is slightly off of the predicted value. We anticipate that this is due to the sensitivity of this reduced complex.

[Co(neocuproine-radical)(neocuproine)][OTf] (2-Co)

3-Co (20 mg, $0.04 \mathrm{mmol})$ was dissolved in THF (10 mL) and a solution of AgOTf (11 mg, 0.04 $\mathrm{mmol})$ in THF $(5 \mathrm{~mL})$ was added slowly with stirring. This was allowed to stir for an hour, filtered to remove $\mathrm{Ag}^{0}$, then concentrated under vacuum to a black powder. Yield: $18 \mathrm{mg}(0.03 \mathrm{mmol}$, $66.7 \%$ ). Single crystals suitable for X-ray diffraction could be obtained via vapor diffusion of petroleum ether into a concentrated solution of 2-Co in THF or via vapor diffusion of $\mathrm{Et}_{2} \mathrm{O}$ into a concentrated solution of 2-Co in acetonitrile. SXRD data reported was obtained from the latter conditions of $\mathrm{Et}_{2} \mathrm{O}$ and acetonitrile. ${ }^{1} \mathrm{H}$ NMR ( $400 \mathrm{MHz}, \mathrm{CD}_{3} \mathrm{CN}, \mathrm{RT}$ ): $\delta=48.4,47.4$ (two s, $8 \mathrm{H}$ ), $23.0(\mathrm{~s}, 4 \mathrm{H}),-29.8(\mathrm{bs}, 12 \mathrm{H}) .{ }^{19} \mathrm{~F}\left\{{ }^{1} \mathrm{H}\right\}$ NMR $\left(500 \mathrm{MHz}, \mathrm{CD}_{3} \mathrm{CN}, \mathrm{RT}\right): \delta=-79$. Magnetic Susceptibility: Evans' Method $\left(\mathrm{CD}_{3} \mathrm{CN}, \mathrm{RT}, \mu \mathrm{B}\right): \mu_{\text {eff }}=2.94$; SQUID: $\chi T=1.54 \mathrm{~cm}^{3} \mathrm{~K} / \mathrm{mol}$. IR $\left(\mathrm{KBr}\right.$ pellet, $\left.\mathrm{cm}^{-1}\right): 3065(\mathrm{C}-\mathrm{H}, \mathrm{w}), 1593(\mathrm{~m}), 1498(\mathrm{~m})$. UV-vis, $\mathrm{nm}$ in acetonitrile, $\left(\varepsilon, \mathrm{M}^{-1} \mathrm{~cm}^{-1}\right)$ : 508 (2000), 826 (2000). Anal. Calc. C, 70.73; H, 5.09; N, 11.78; Found: C, 70.18; H, 5.19; N, 11.09. Note that the combustion analysis for this compound is slightly off of the predicted value. We anticipate that this is due to the sensitivity of this reduced complex. 


\section{NMR Spectra}
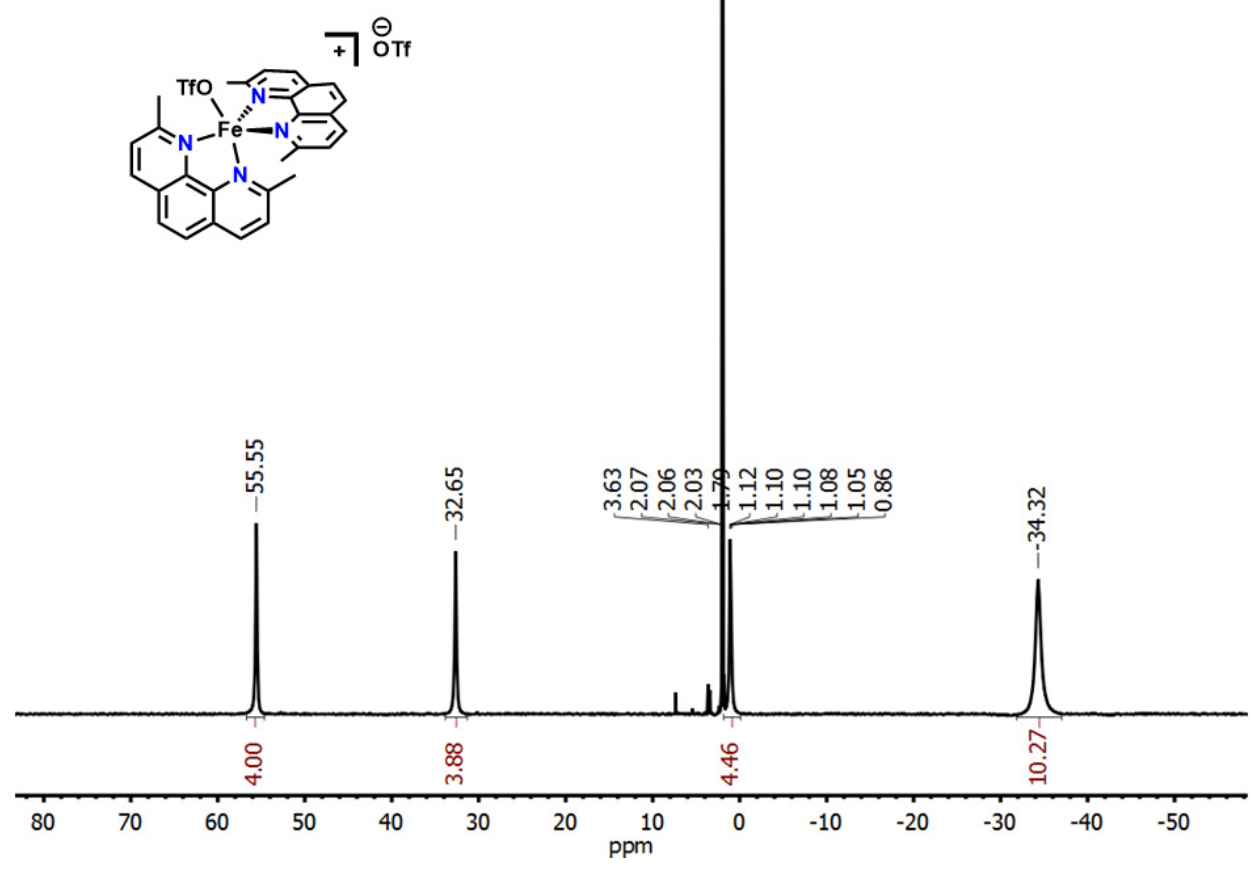

Figure S1. ${ }^{1} \mathrm{H}$ NMR of $\mathbf{1 - F e}$ in $\mathrm{CD}_{3} \mathrm{CN}$.
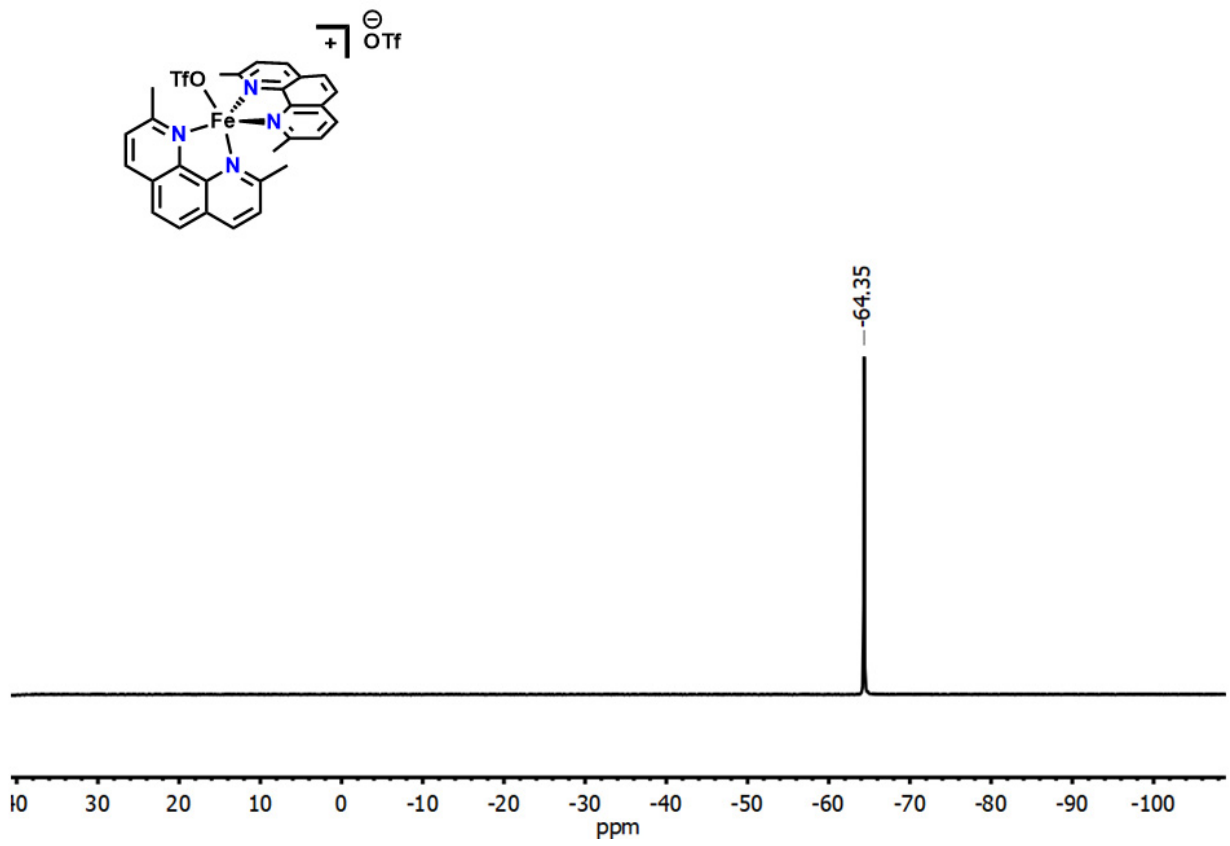

Figure S2. ${ }^{19} \mathrm{~F}$ NMR of 1-Fe in $\mathrm{CD}_{3} \mathrm{CN}$. 


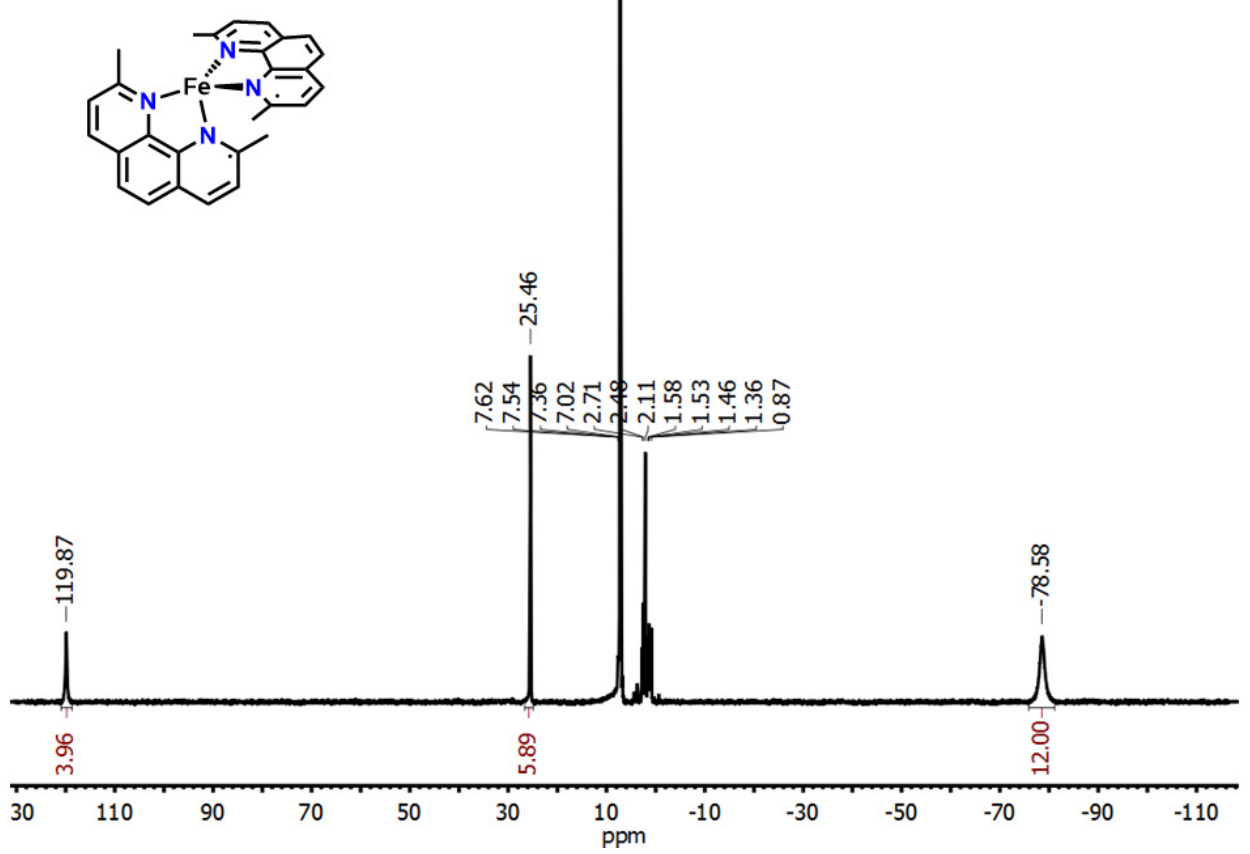

Figure S3. ${ }^{1} \mathrm{H}$ NMR of 3-Fe in $\mathrm{C}_{6} \mathrm{D}_{6}$.

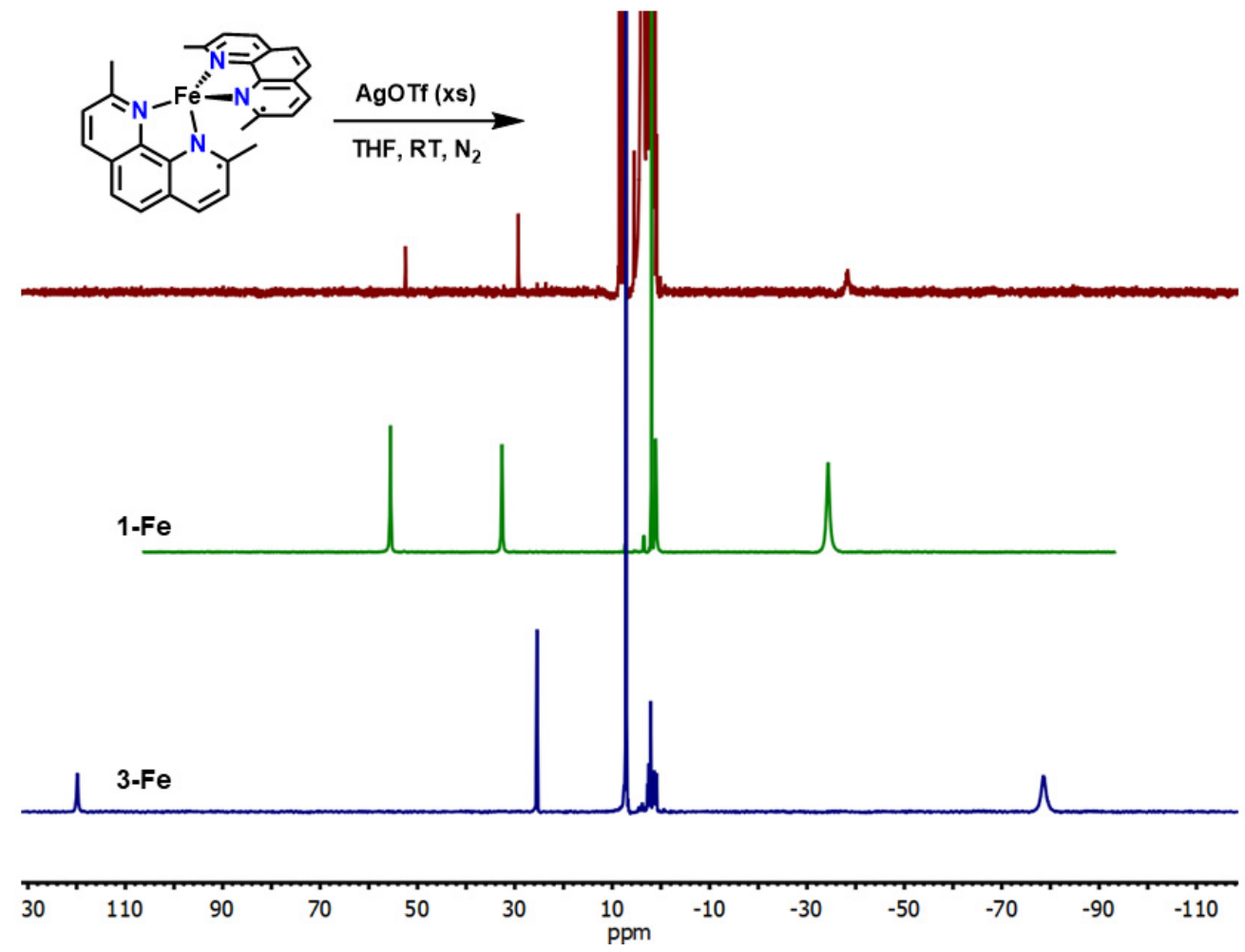

Figure S4. ${ }^{1} \mathrm{H}$ NMR of 3-Fe with excess AgOTf in $\mathrm{CD}_{3} \mathrm{CN}$ stacked with 1-Fe and 3-Fe. 


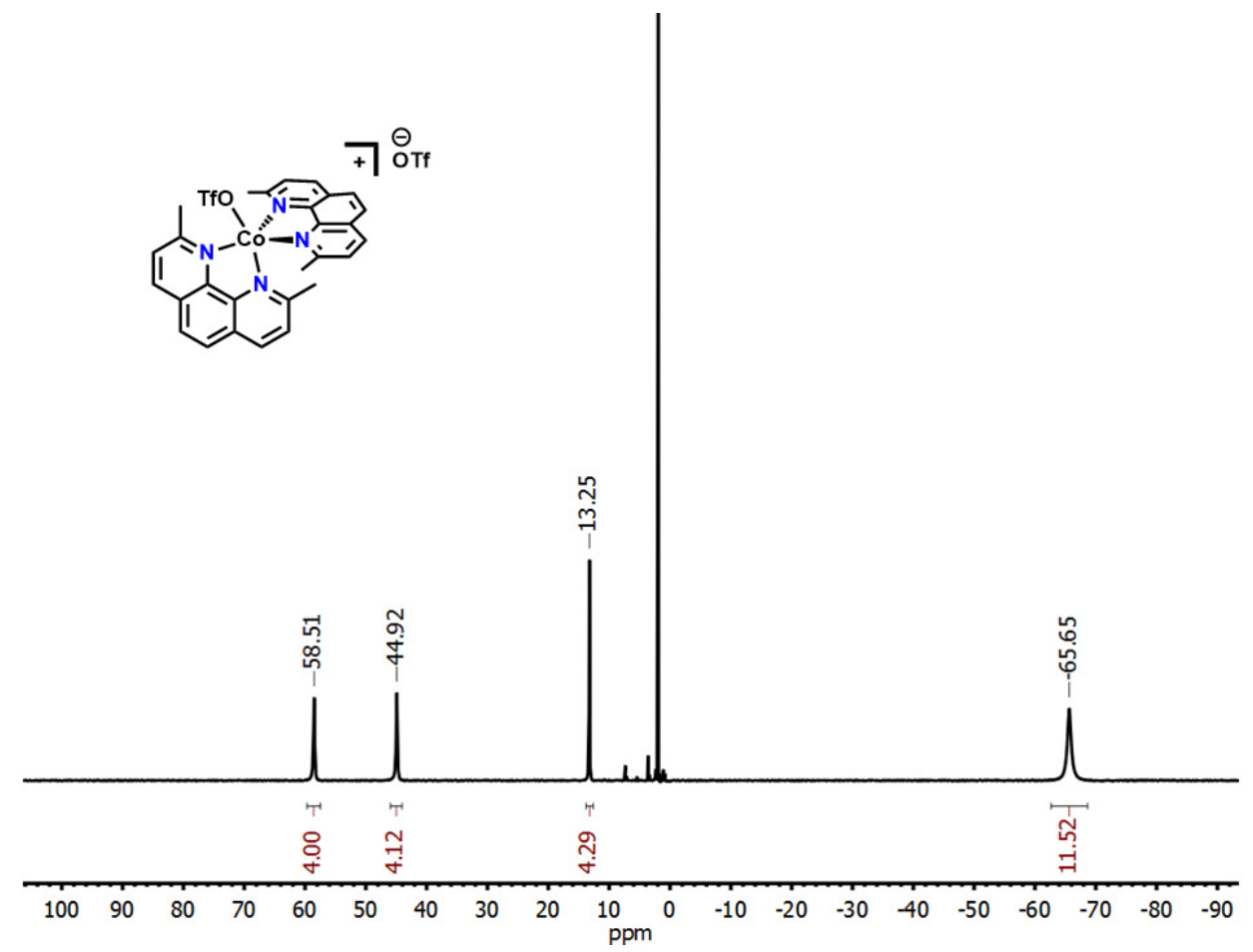

Figure S5. ${ }^{1} \mathrm{H} \mathrm{NMR}$ of $\mathbf{1 - C o}$ in $\mathrm{CD}_{3} \mathrm{CN}$.
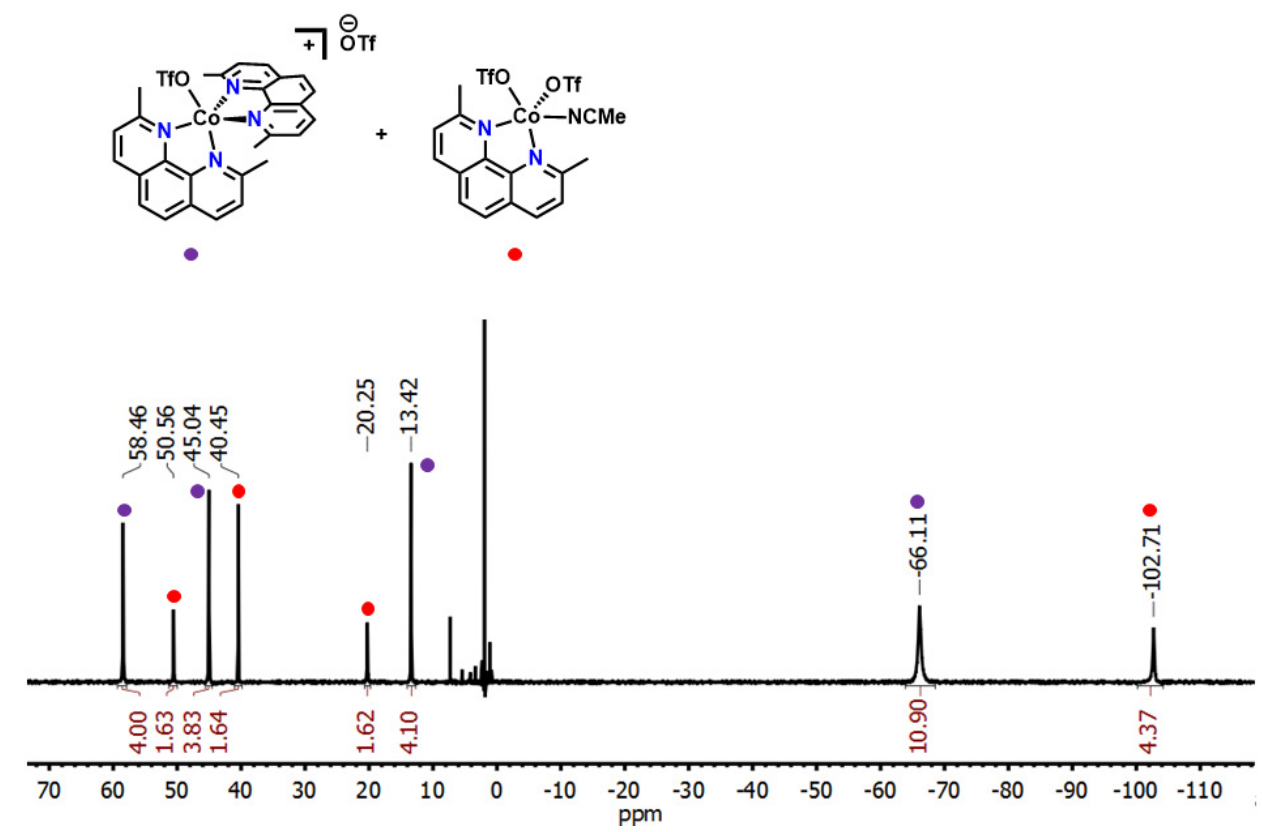

Figure S6. ${ }^{1} \mathrm{H}$ NMR of 1-Co and $\left[\mathrm{Co}(\right.$ neocuproine $\left.)(\mathrm{OTf})_{2}(\mathrm{MeCN})\right]$ in $\mathrm{CD}_{3} \mathrm{CN}$ 

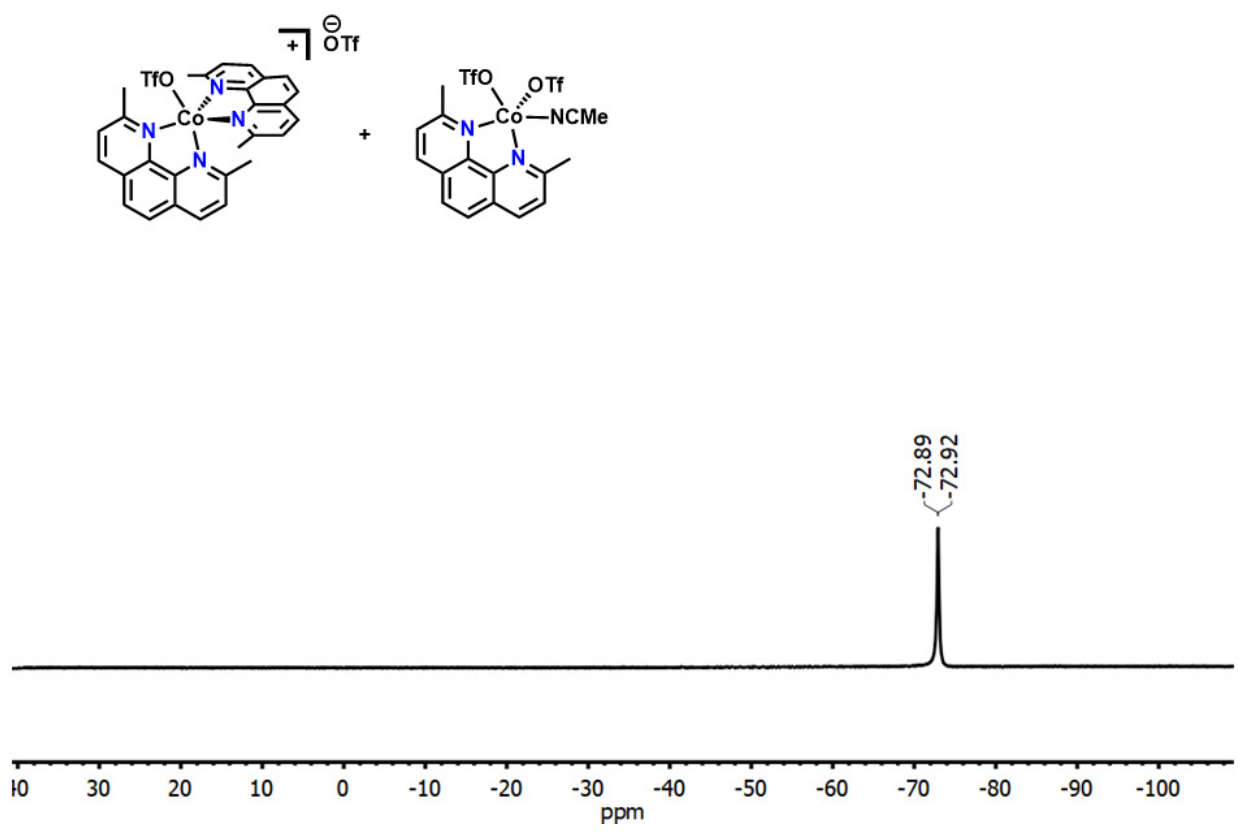

Figure S7. ${ }^{19} \mathrm{~F}$ NMR of 1-Co and $\left[\mathrm{Co}(\right.$ neocuproine $\left.)(\mathrm{OTf})_{2}(\mathrm{MeCN})\right]$ in $\mathrm{CD}_{3} \mathrm{CN}$
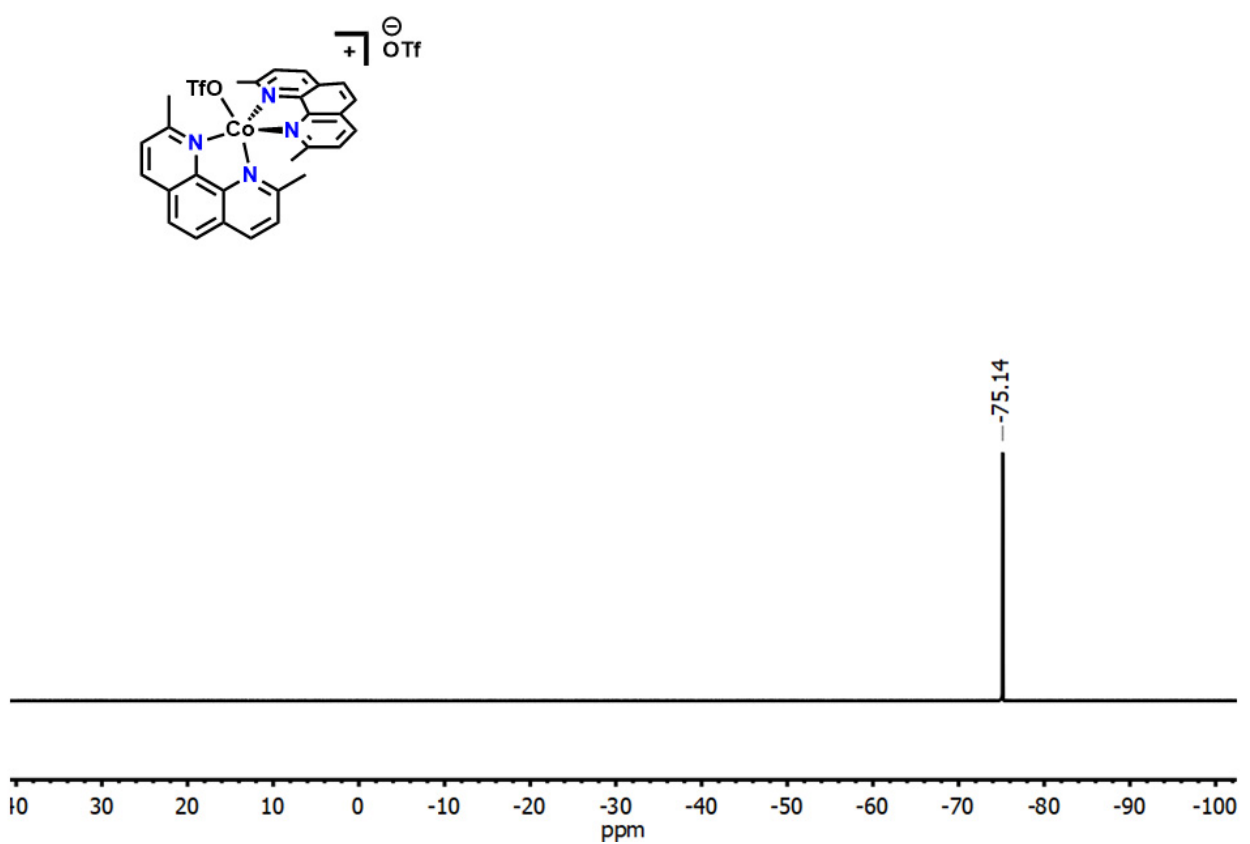

Figure S8. ${ }^{19} \mathrm{~F}$ NMR of $\mathbf{1 - C o}$ in $\mathrm{CD}_{3} \mathrm{CN}$. 


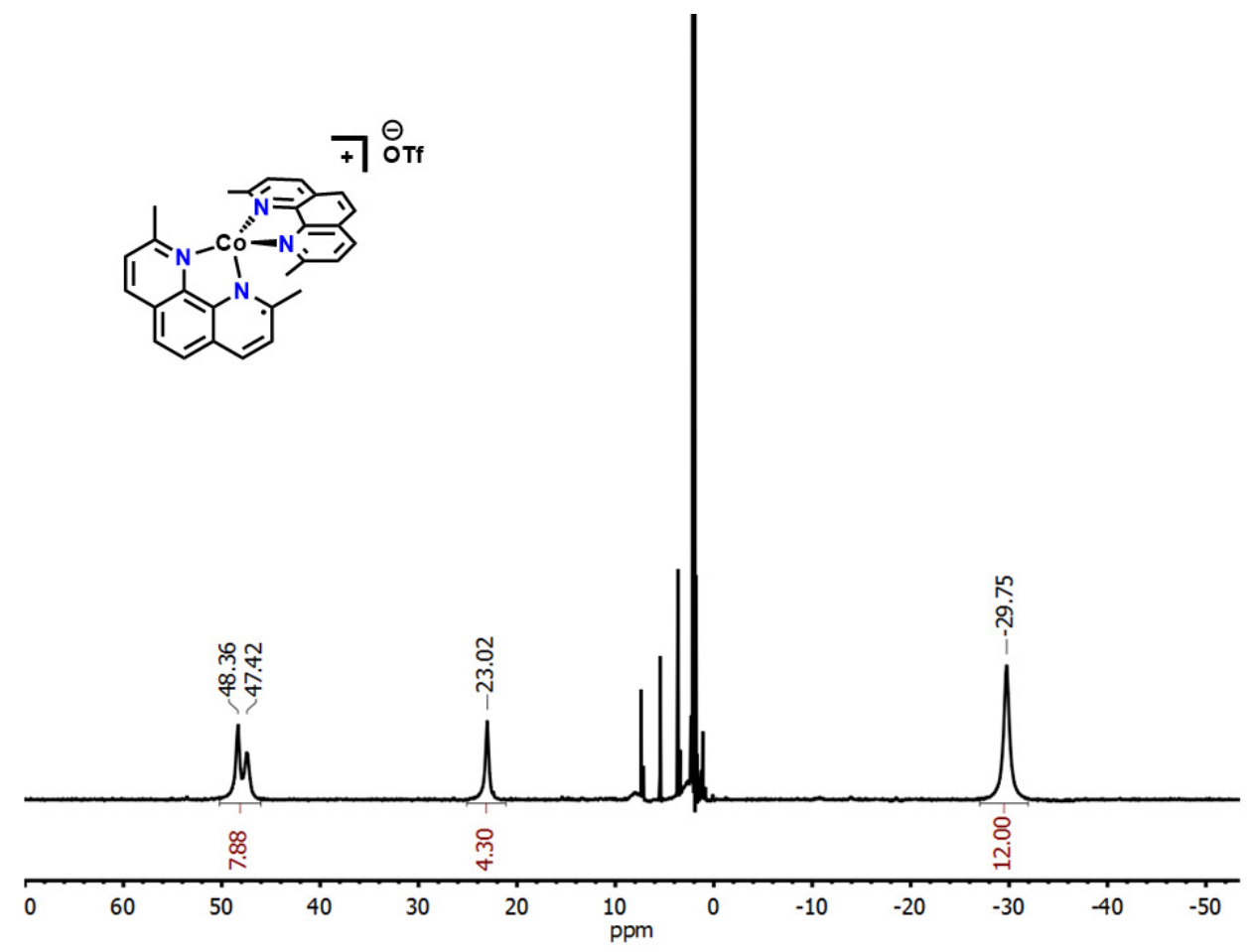

Figure 59. ${ }^{1} \mathrm{H} \mathrm{NMR}$ of 2-Co in $\mathrm{CD}_{3} \mathrm{CN}$.
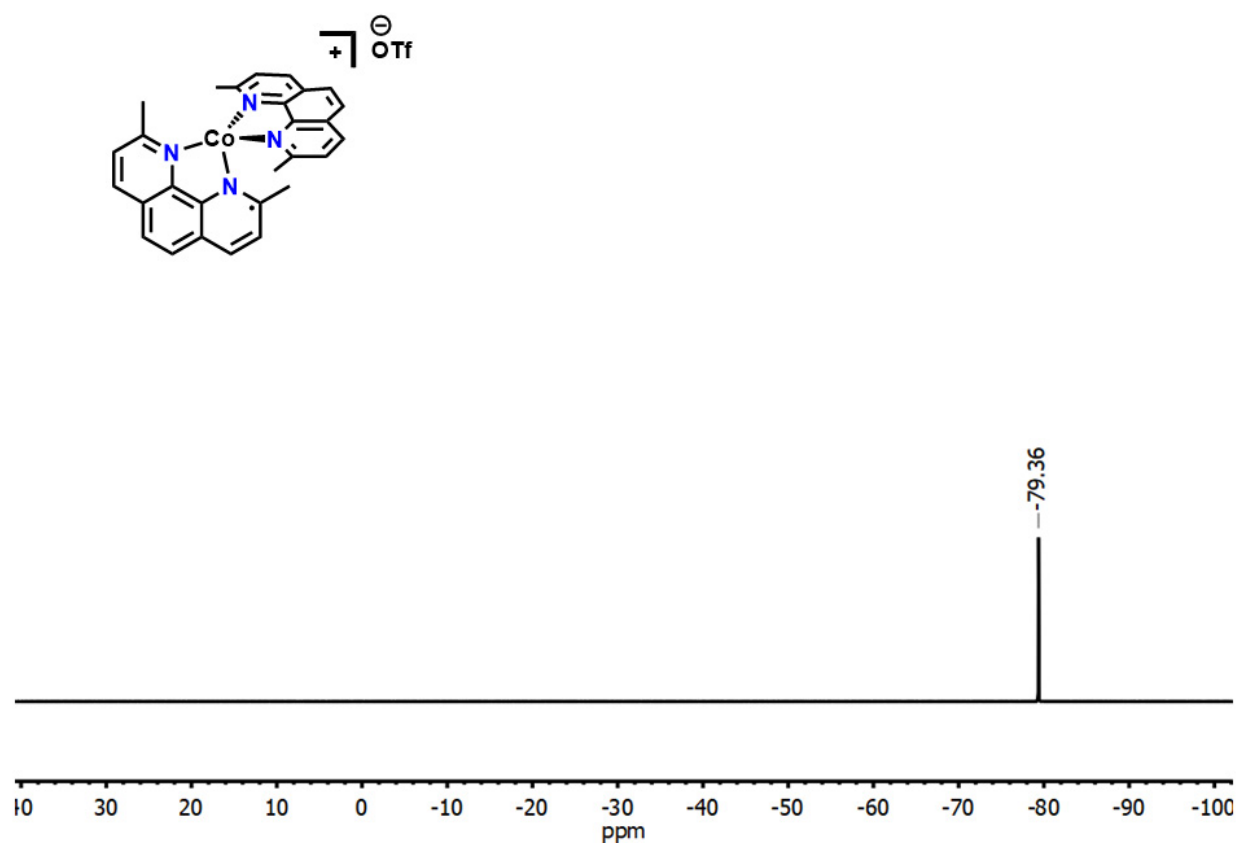

Figure S10. ${ }^{19} \mathrm{~F}$ NMR of 2-Co in $\mathrm{CD}_{3} \mathrm{CN}$. 


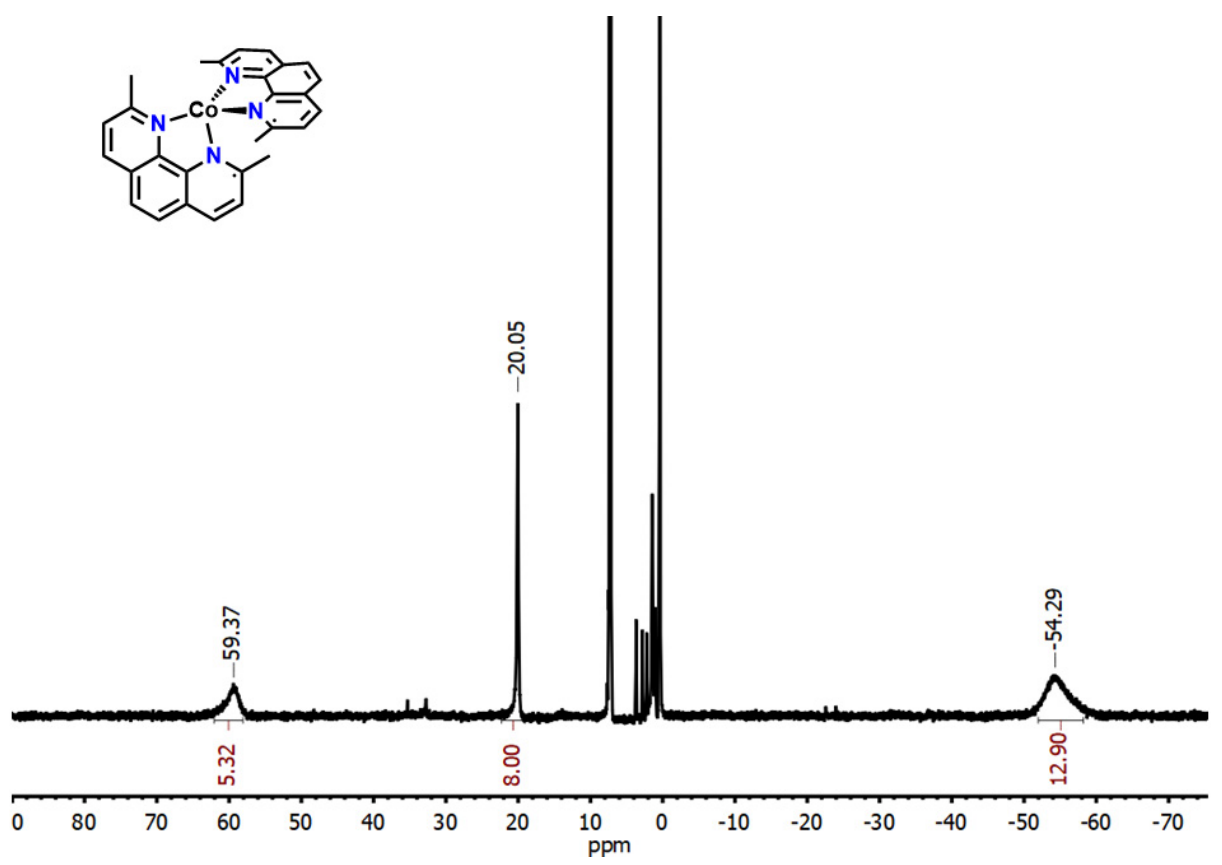

Figure S11. ${ }^{1} \mathrm{H}$ NMR of 3-Co in $\mathrm{C}_{6} \mathrm{D}_{6}$.

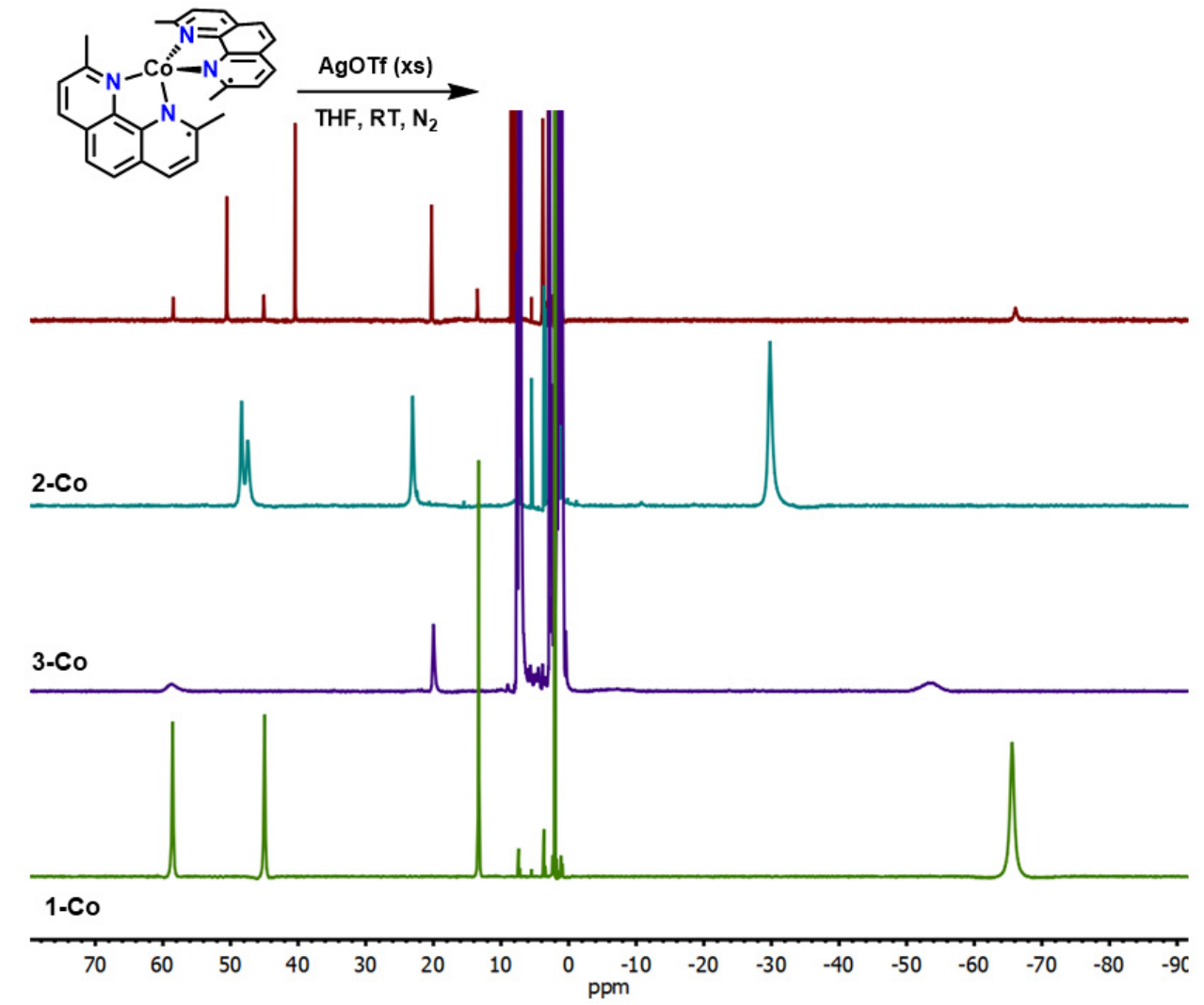

Figure S12. ${ }^{1} \mathrm{H}$ NMR of 3-Co with excess AgOTf in $\mathrm{CD}_{3} \mathrm{CN}$ stacked with 1-Co, 2-Co, and 3-Co where 1-Co and 2-Co are in $\mathrm{CD}_{3} \mathrm{CN}$ and 3-Co is in $\mathrm{C}_{6} \mathrm{D}_{6}$. 


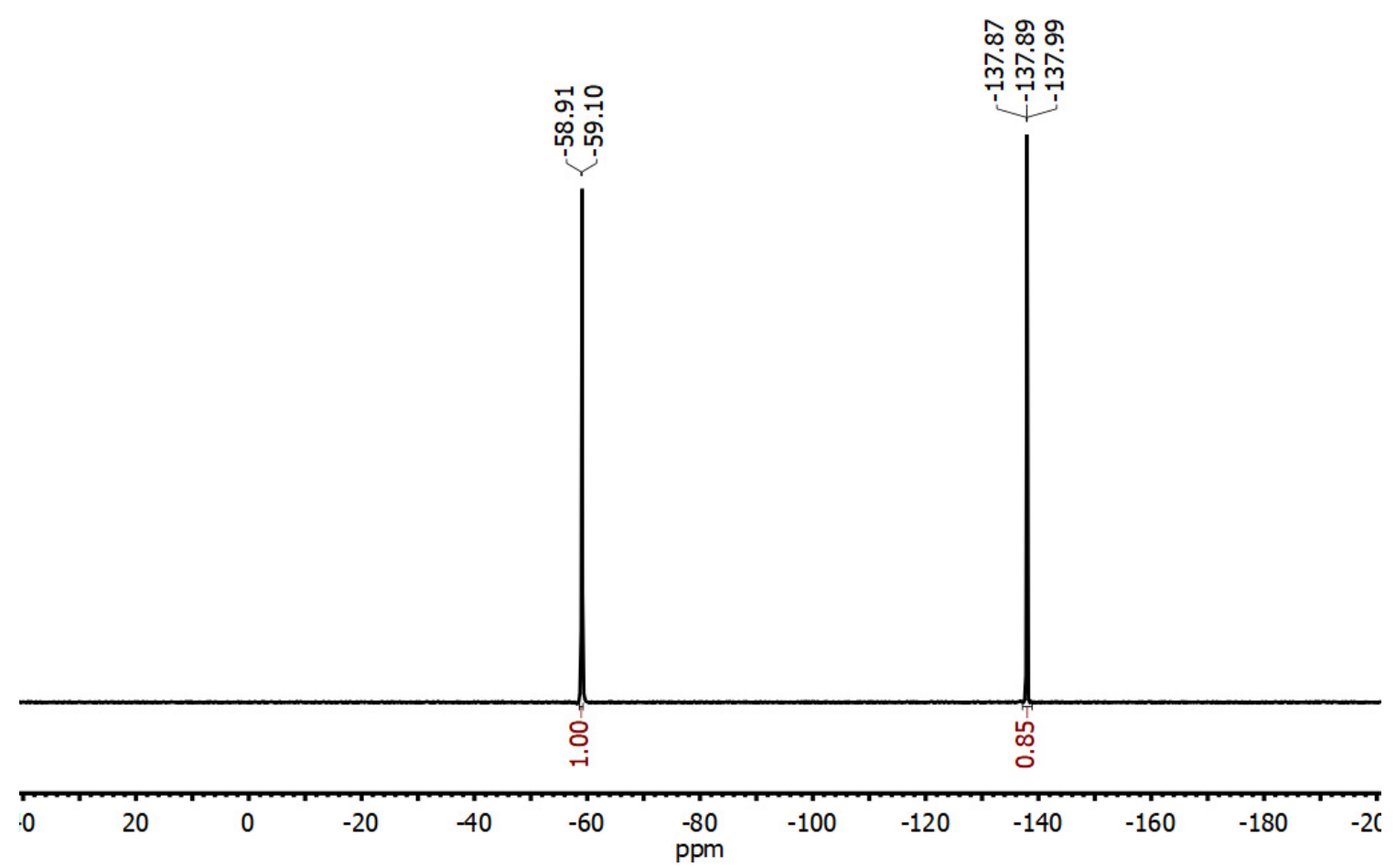

Figure S13. ${ }^{19} \mathrm{~F}$ NMR of 1-Fe with 3 equivalents of 1,2-difluorobenzene as an internal standard in acetonitrile.

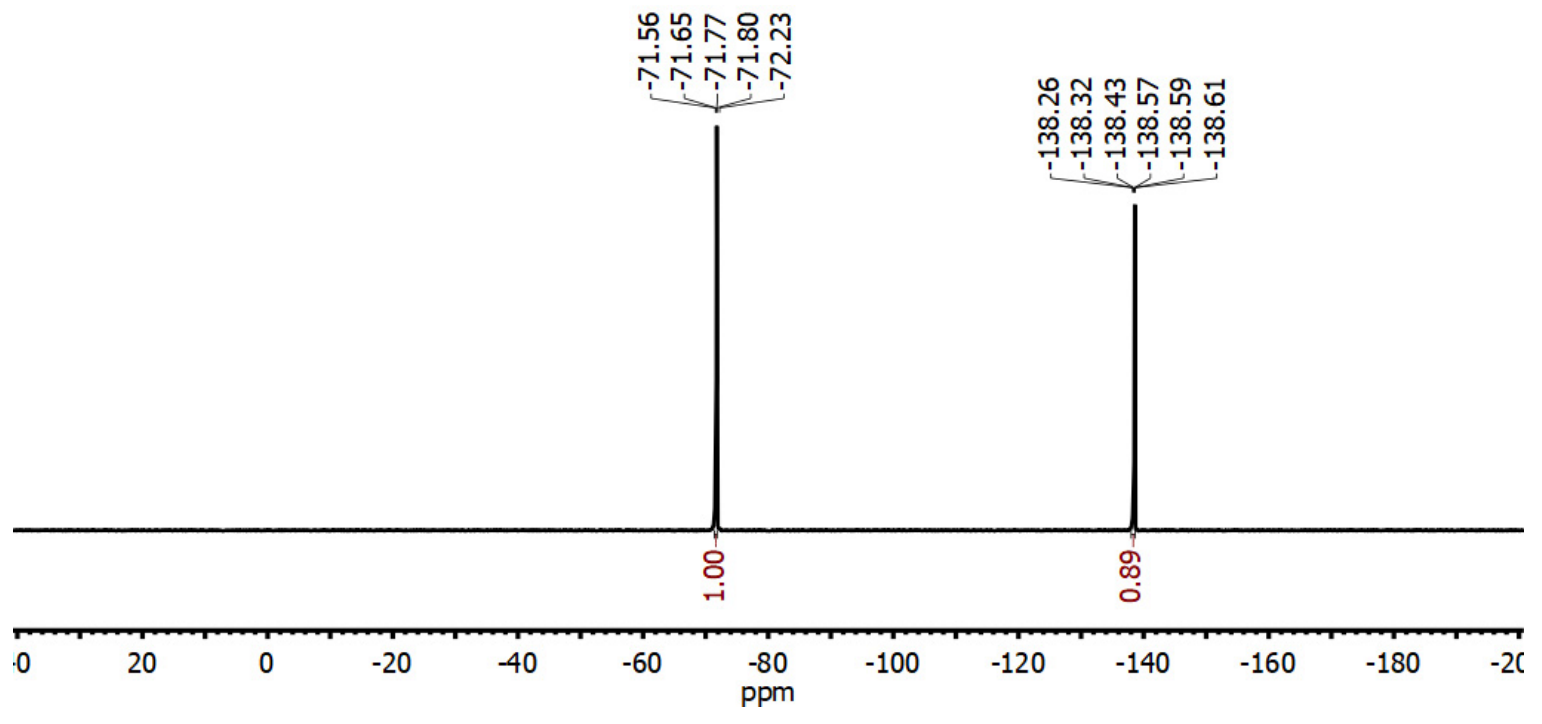

Figure S14. ${ }^{19} \mathrm{~F}$ NMR of 1-Co with 3 equivalents of 1,2-difluorobenzene as an internal standard in acetonitrile. 

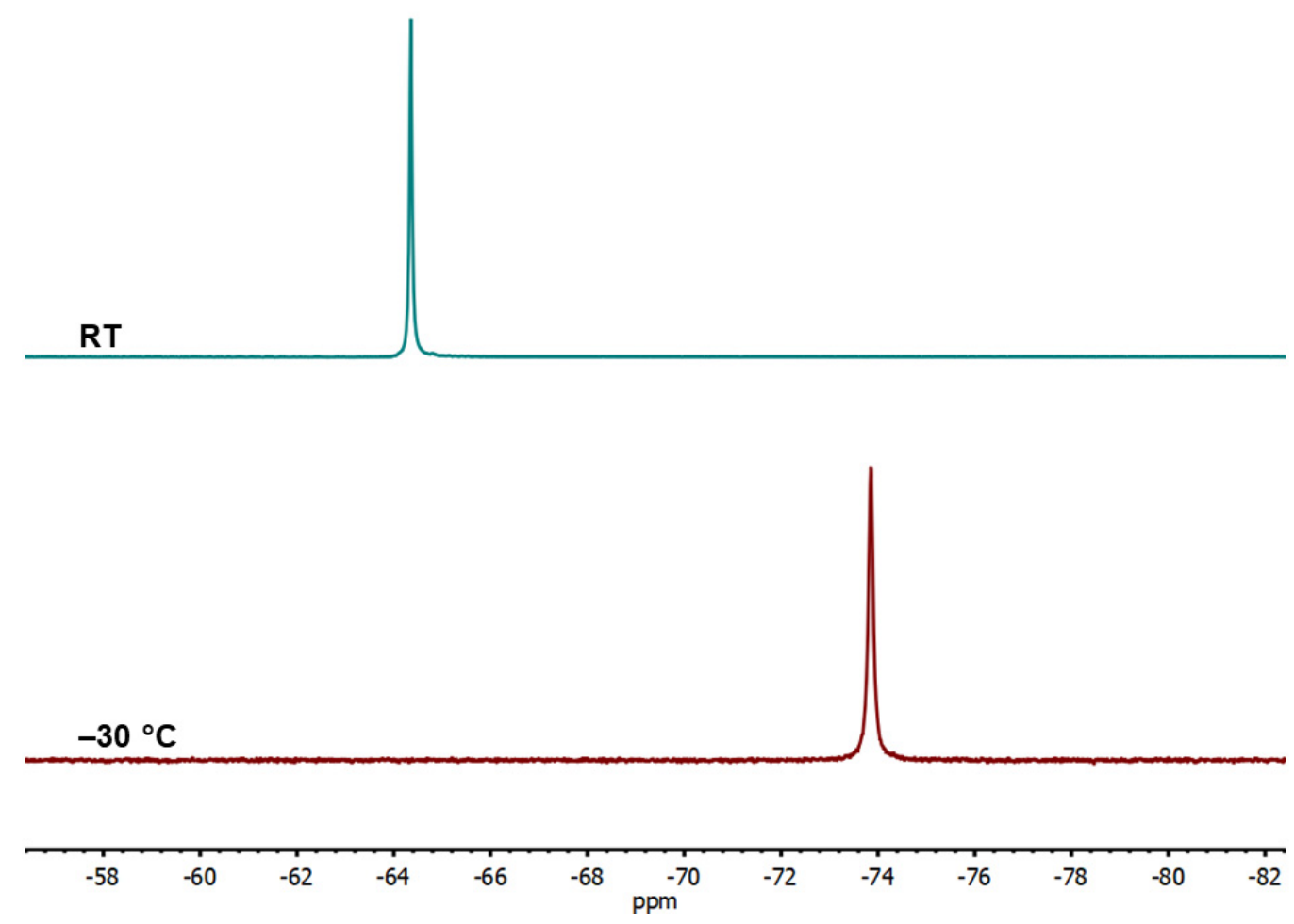

Figure S15. ${ }^{19} \mathrm{~F}$ NMR of $\mathbf{1 - F e}$ at $-30{ }^{\circ} \mathrm{C}$ and room temperature in $\mathrm{CD}_{3} \mathrm{CN}$.

RT

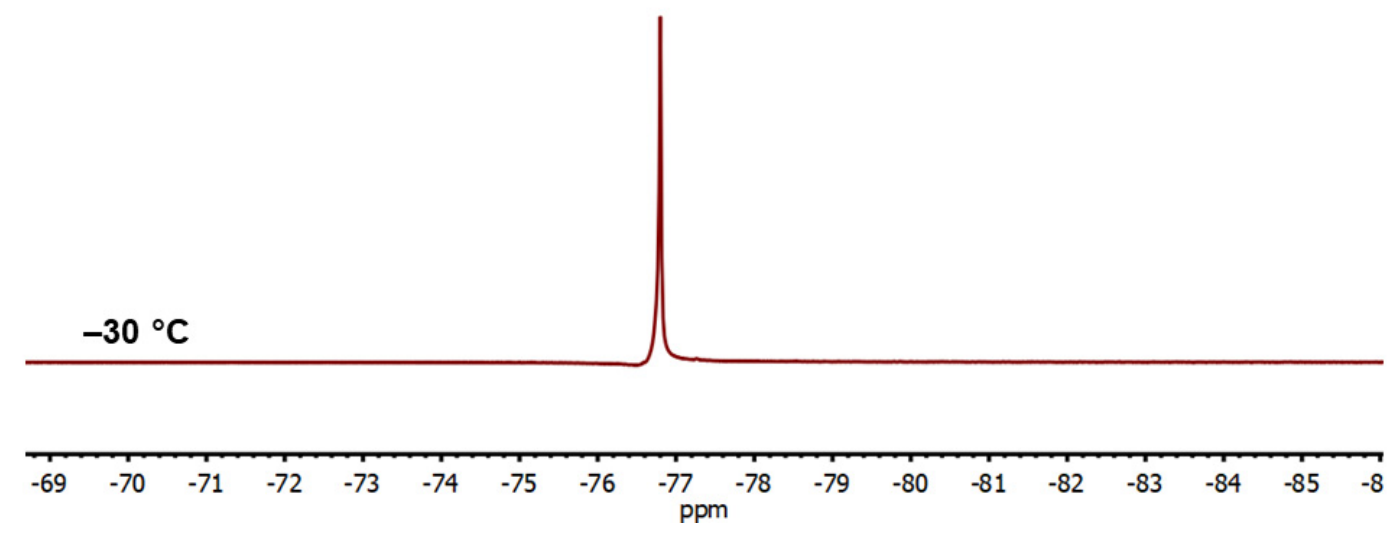

Figure S16. ${ }^{19} \mathrm{~F}$ NMR of $\mathbf{1 - F e}$ at $-30{ }^{\circ} \mathrm{C}$ and room temperature in $\mathrm{CD}_{3} \mathrm{CN}$. 


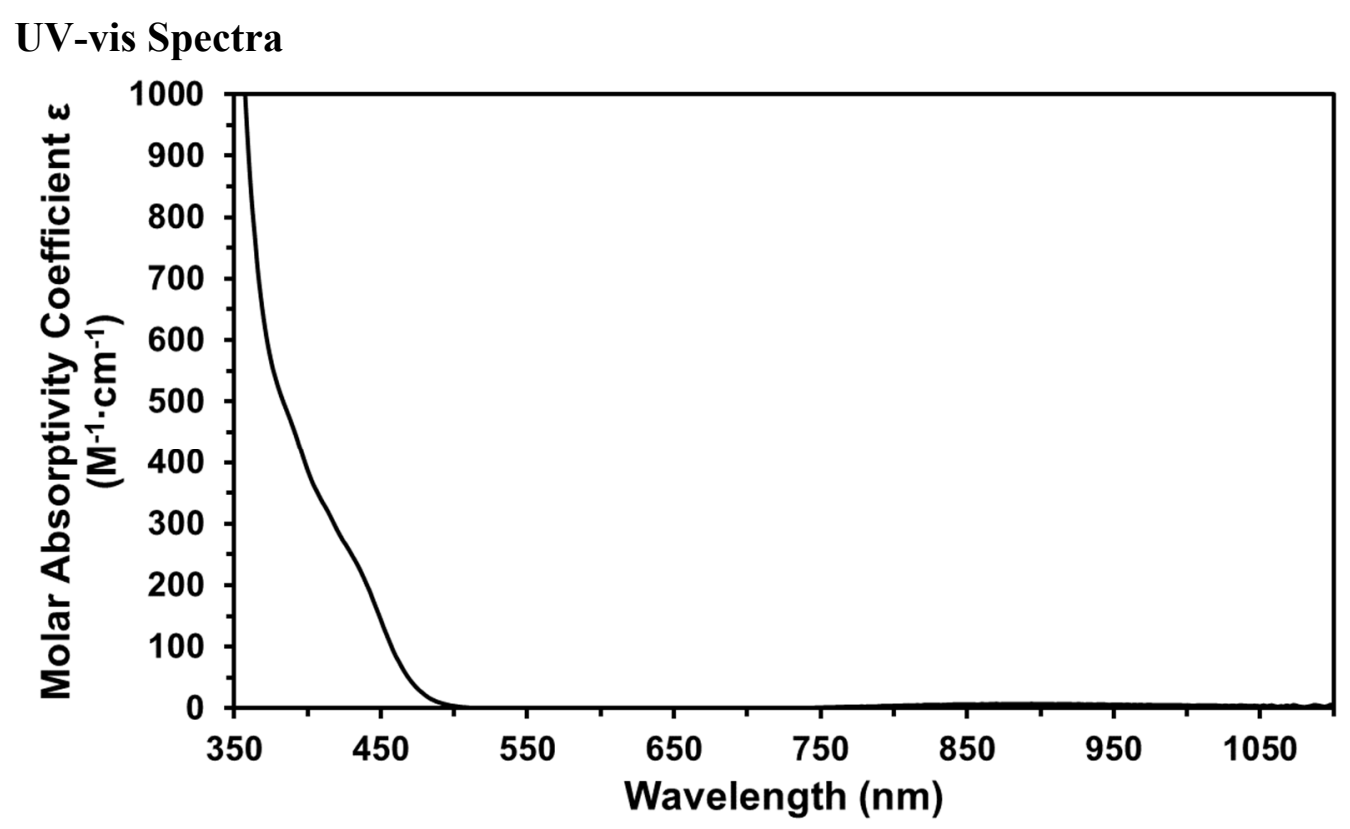

Figure S17. UV-vis spectrum of 1-Fe in acetonitrile.

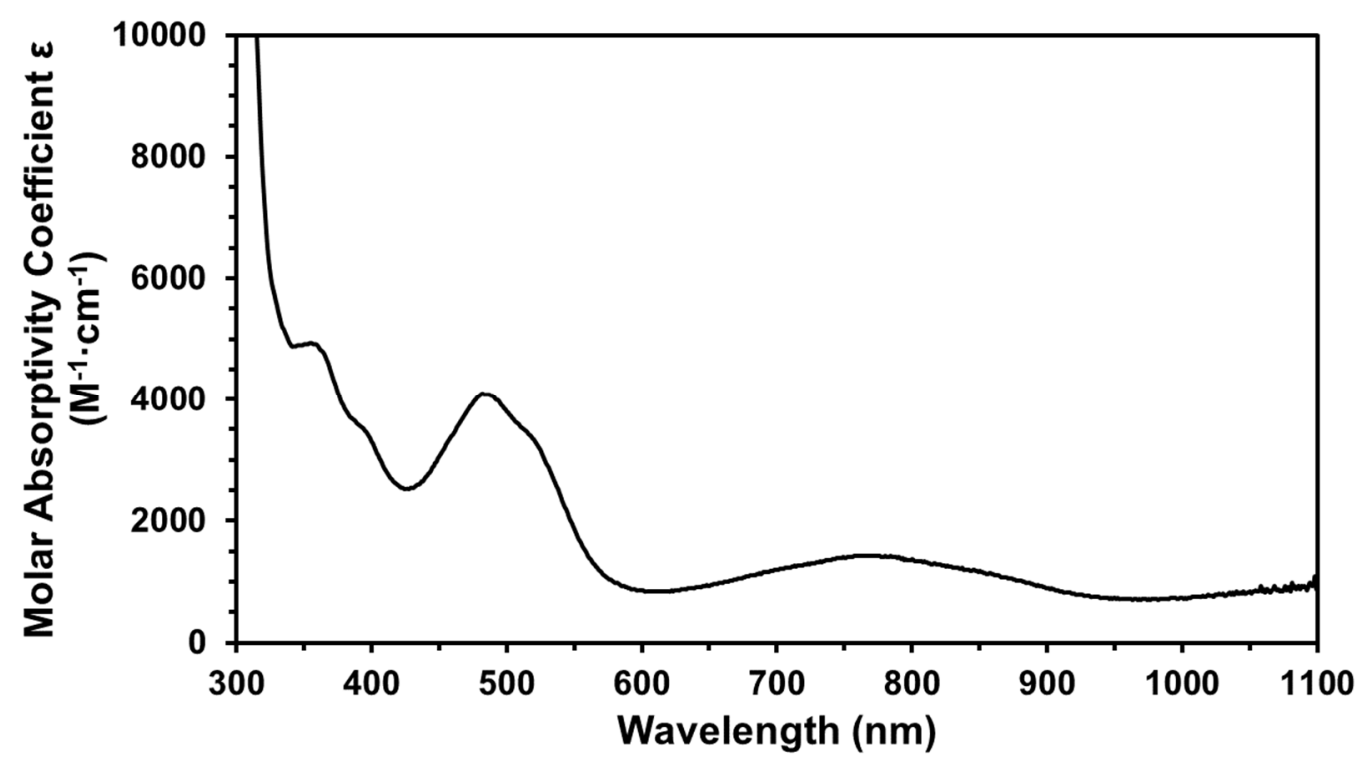

Figure S18. UV-vis spectrum of 3-Fe in benzene. 


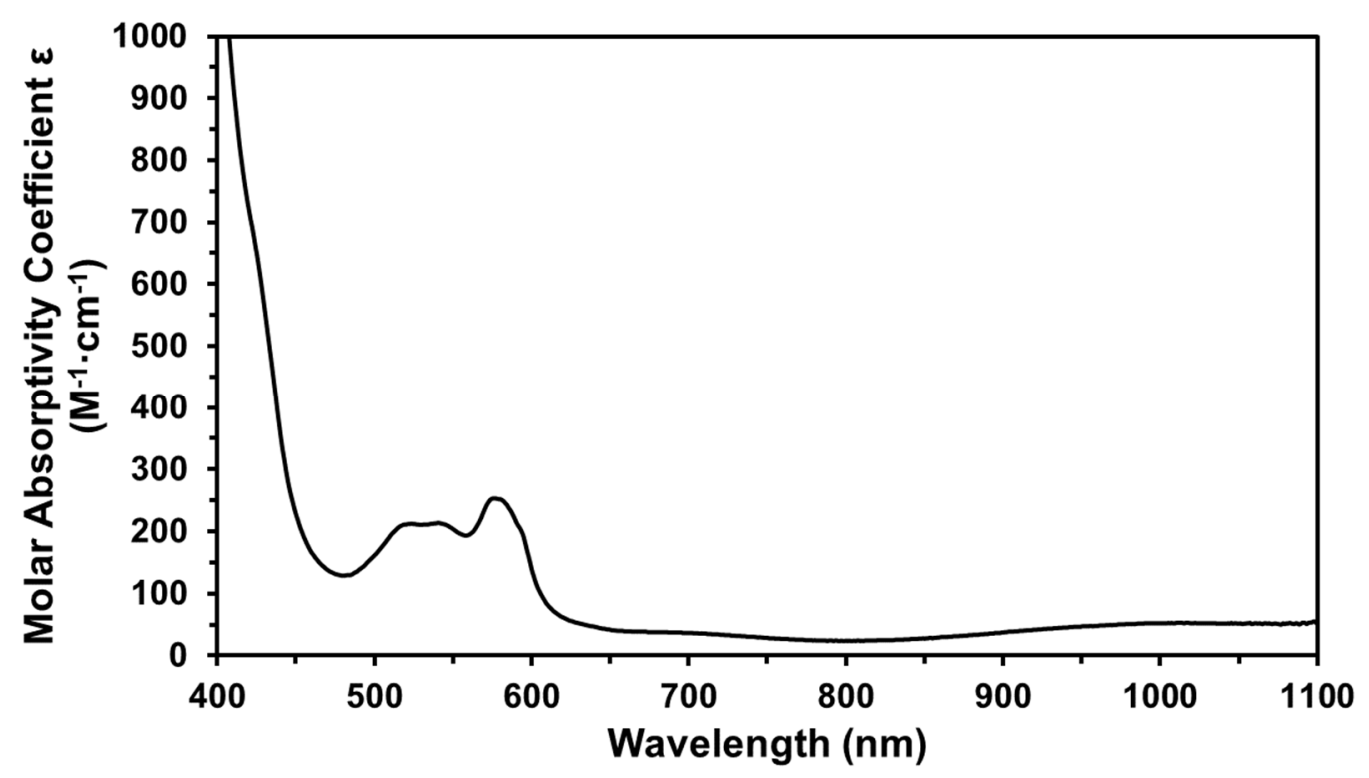

Figure S19. UV-vis spectrum of 1-Co in acetonitrile.

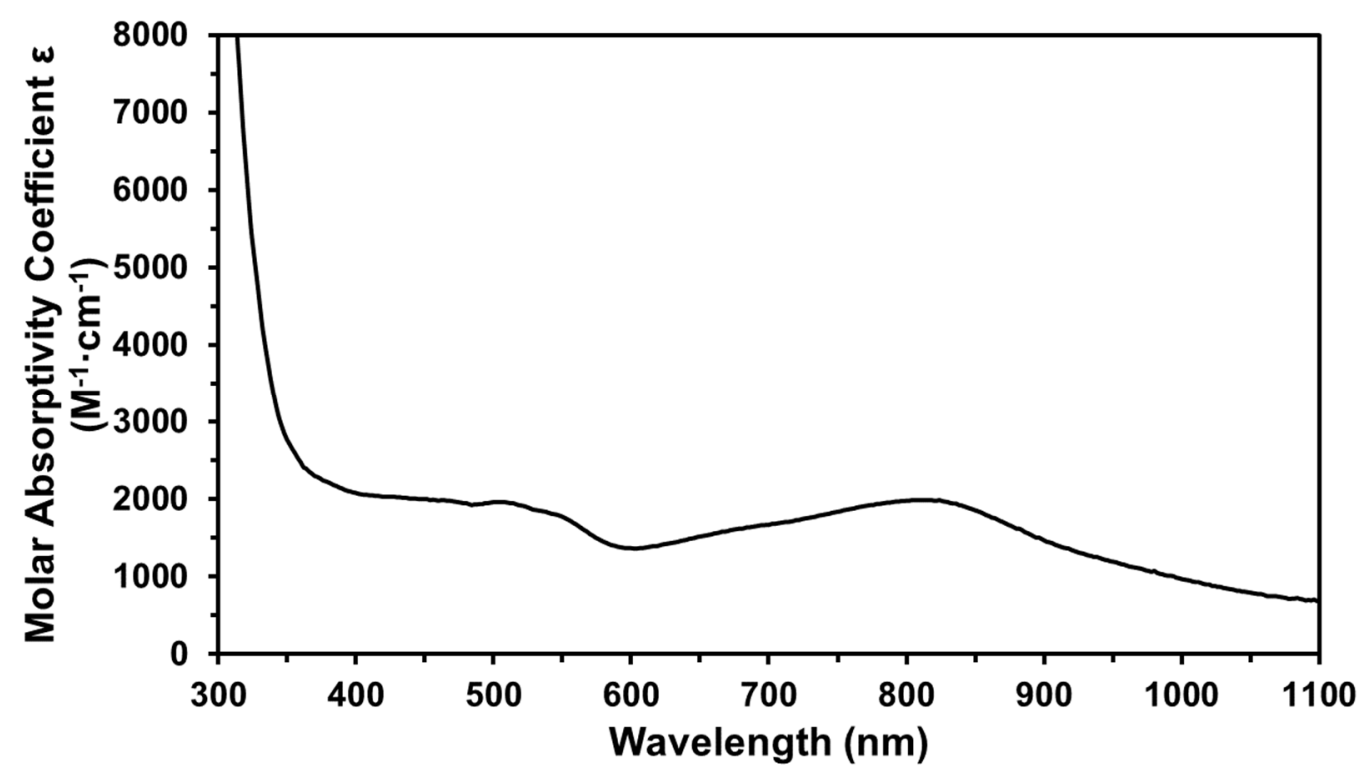

Figure S20. UV-vis spectrum of 2-Co in acetonitrile. 


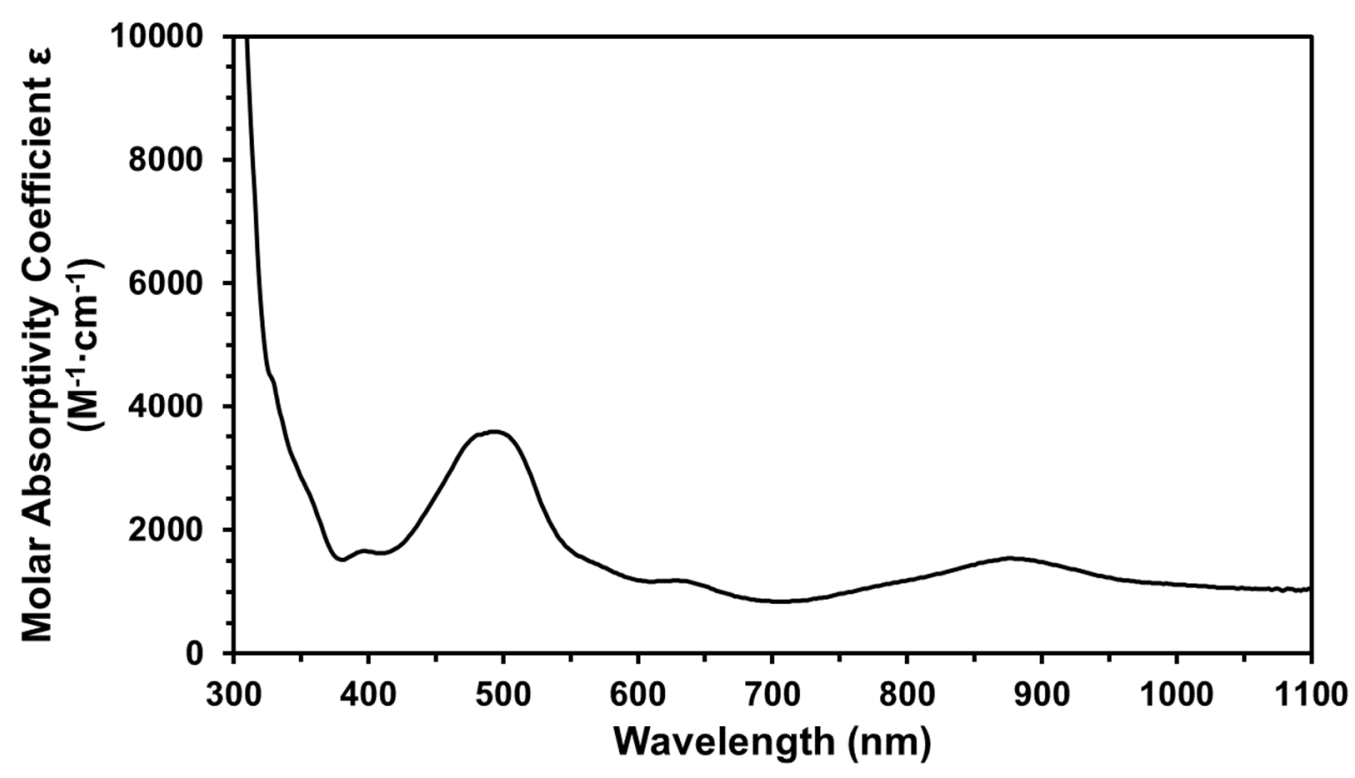

Figure S21. UV-vis spectrum of 3-Co in benzene.

\section{IR Spectra}

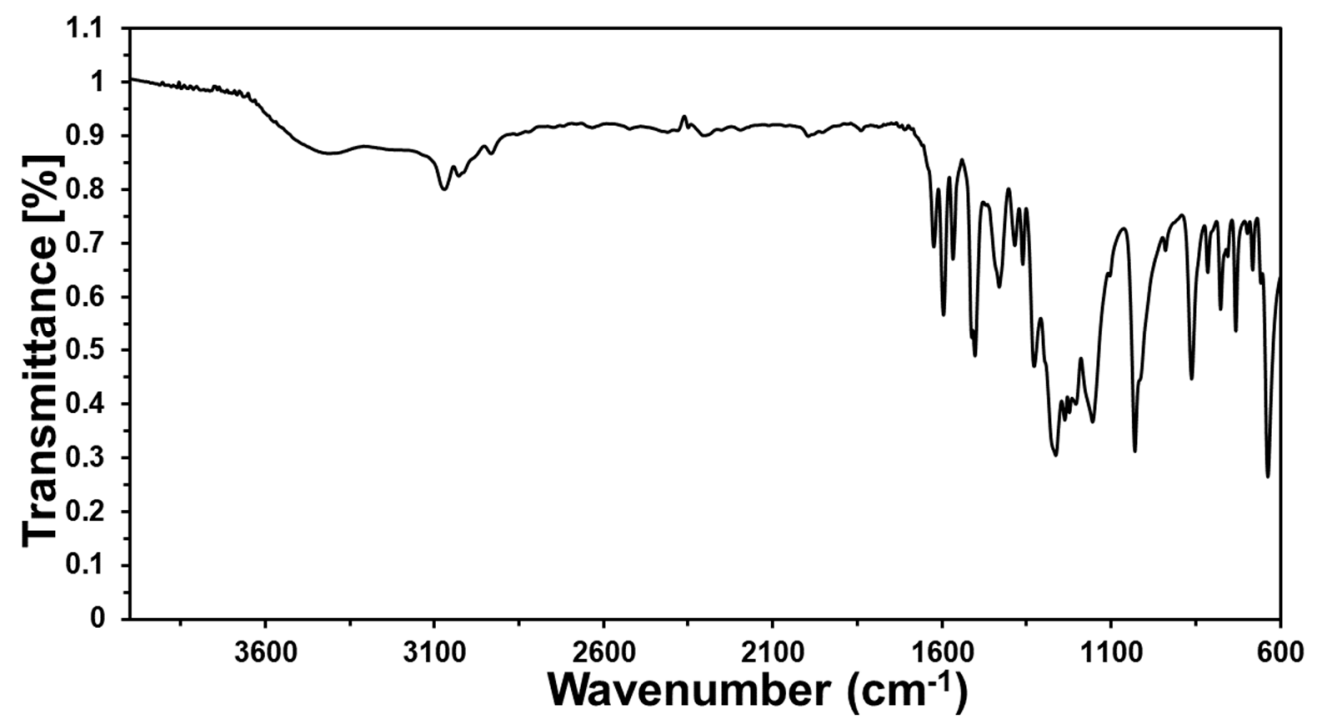

Figure S22. IR (KBr pellet) of 1-Fe. 


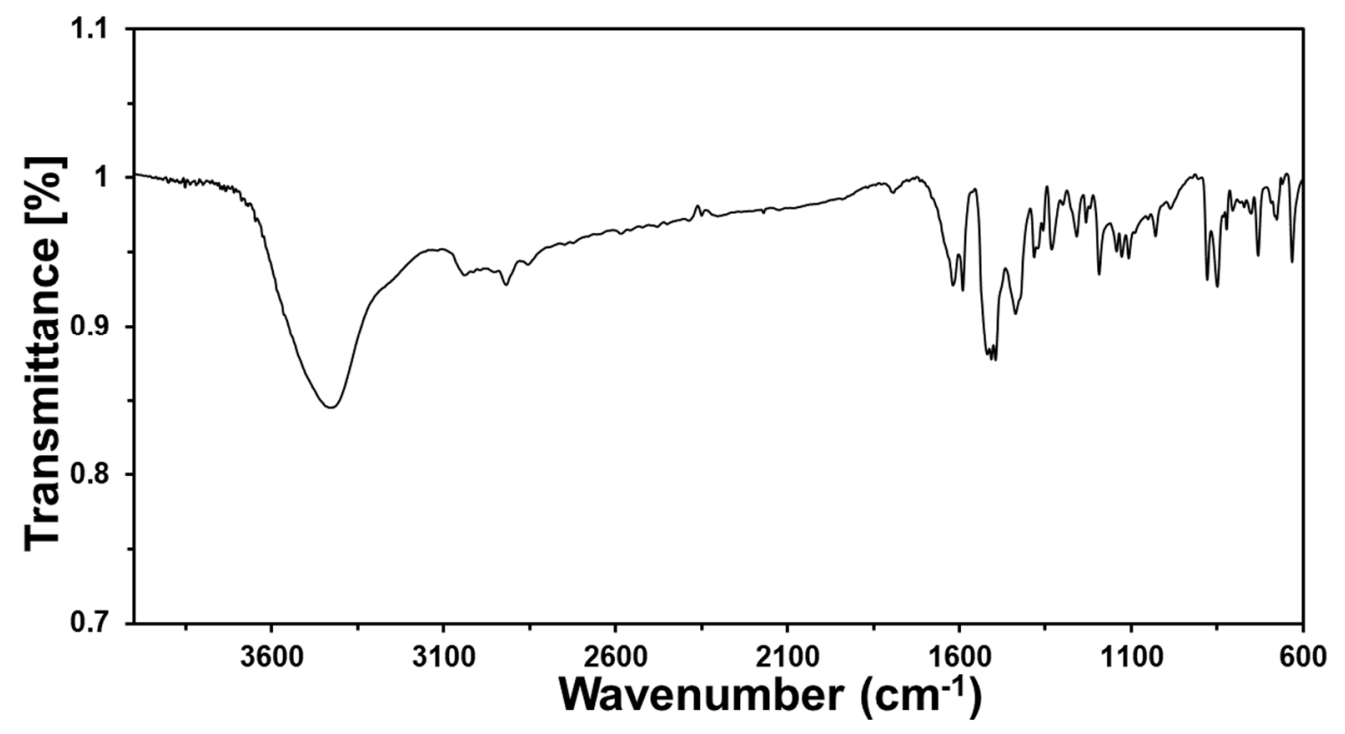

Figure S23. IR ( $\mathrm{KBr}$ pellet) of 3-Fe.

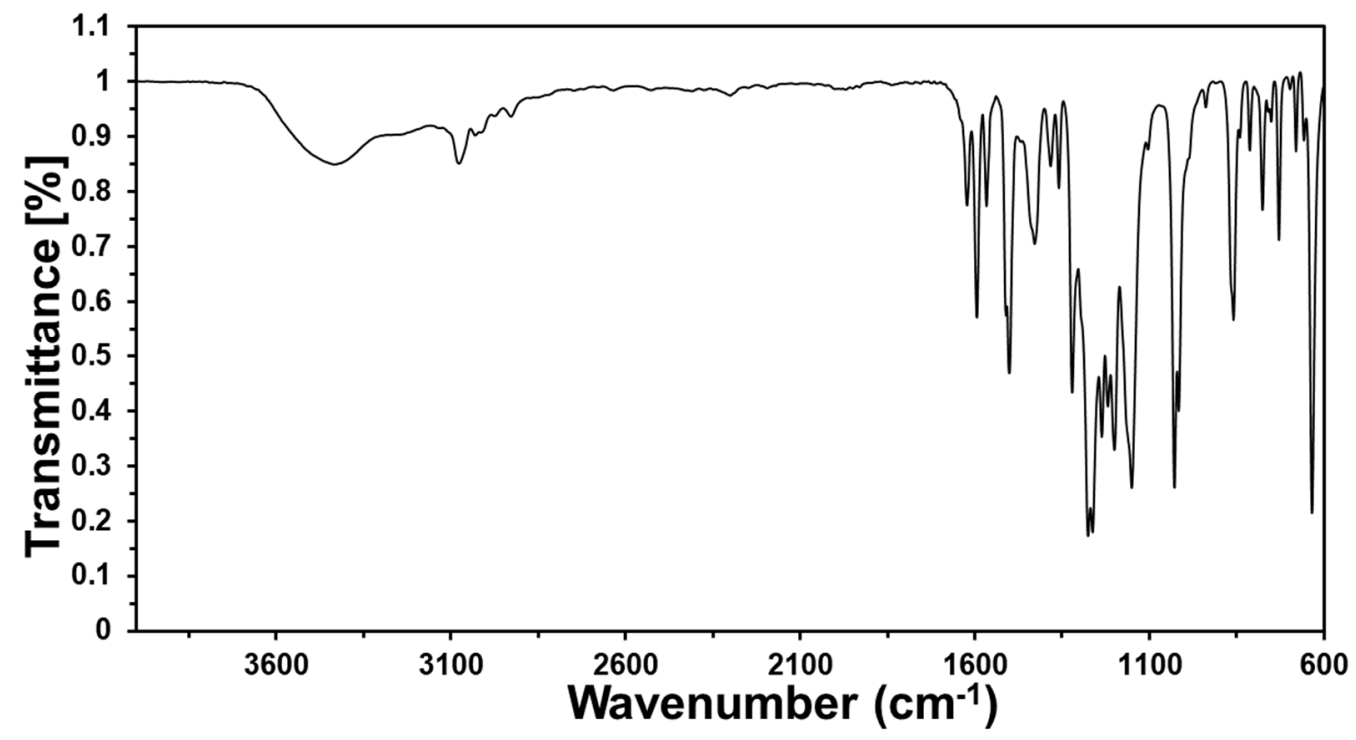

Figure S24. IR ( $\mathrm{KBr}$ pellet) of 1-Co. 


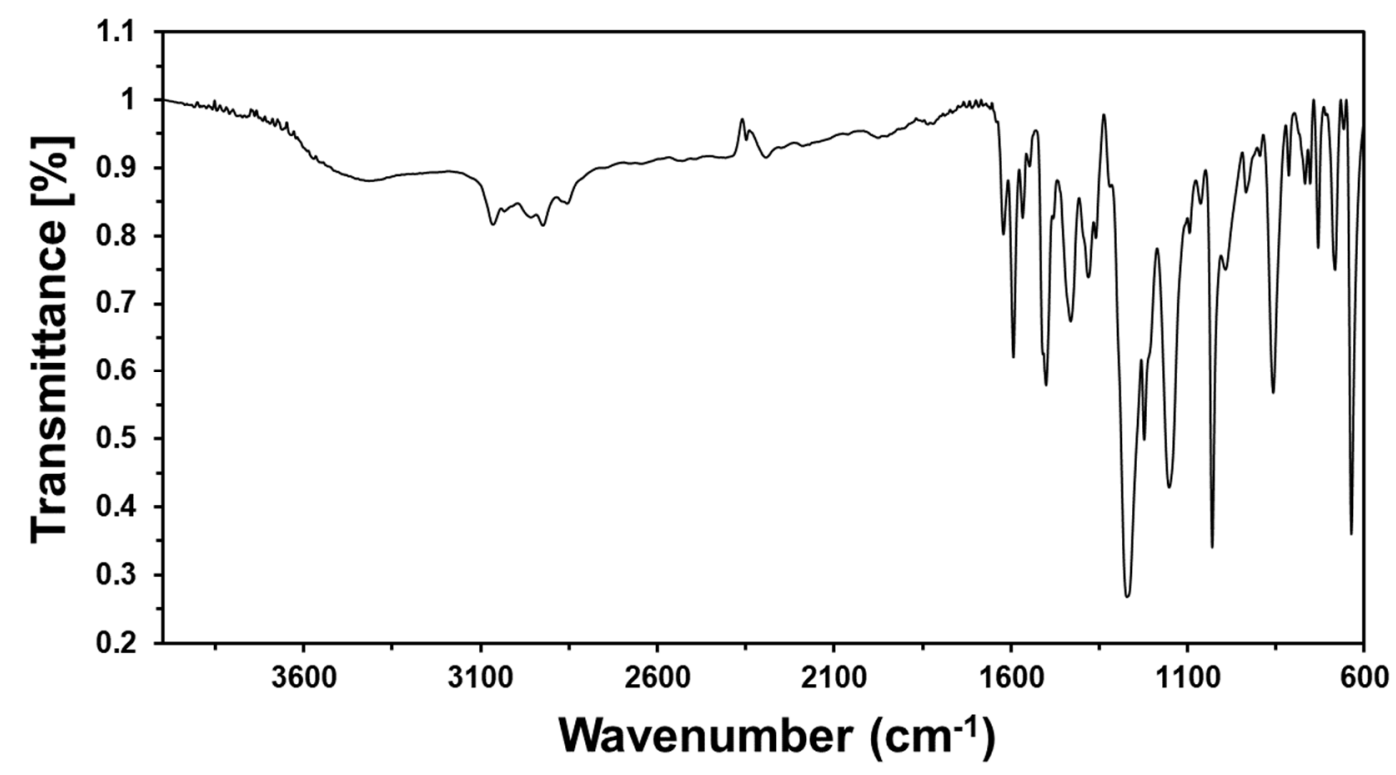

Figure S25. IR ( $\mathrm{KBr}$ pellet) of 2-Co.

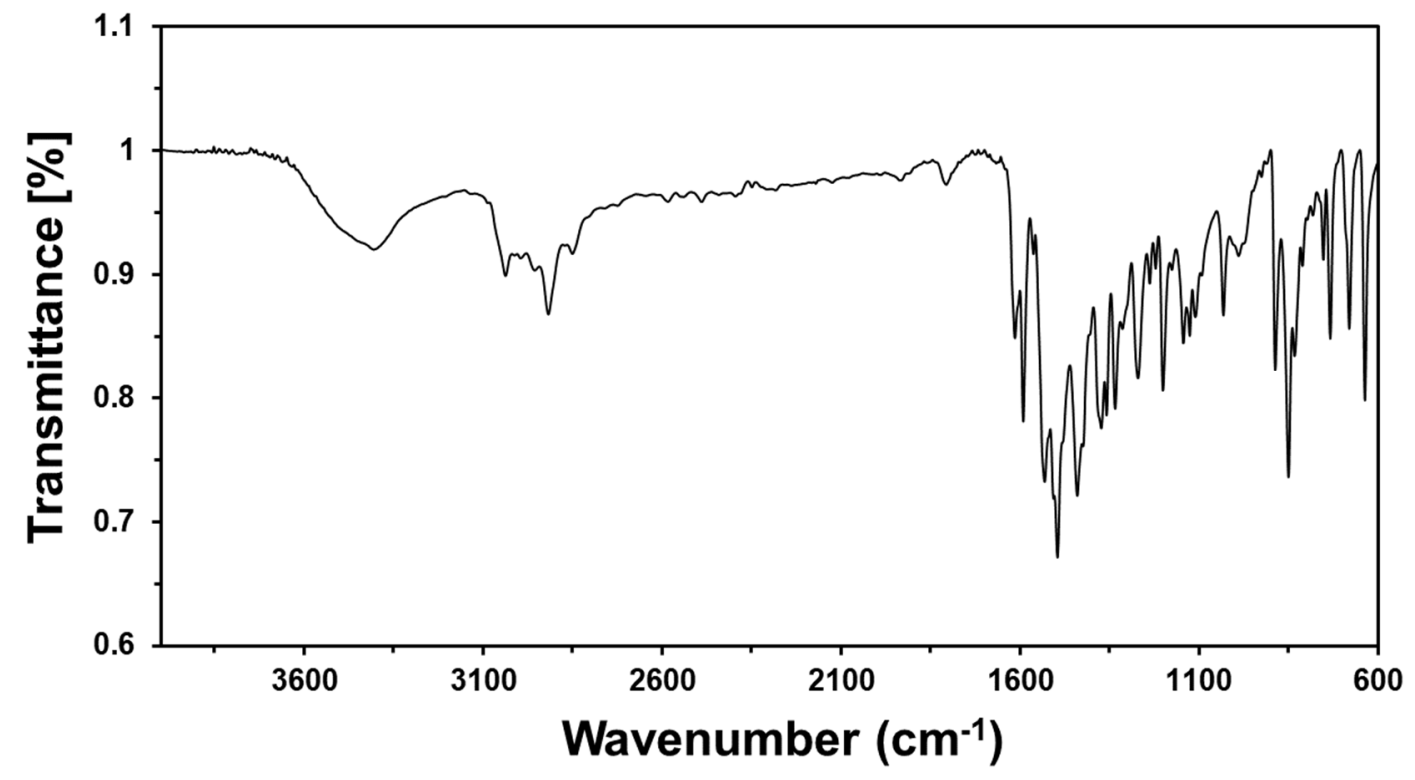

Figure S26. IR ( $\mathrm{KBr}$ pellet) of 3-Co. 


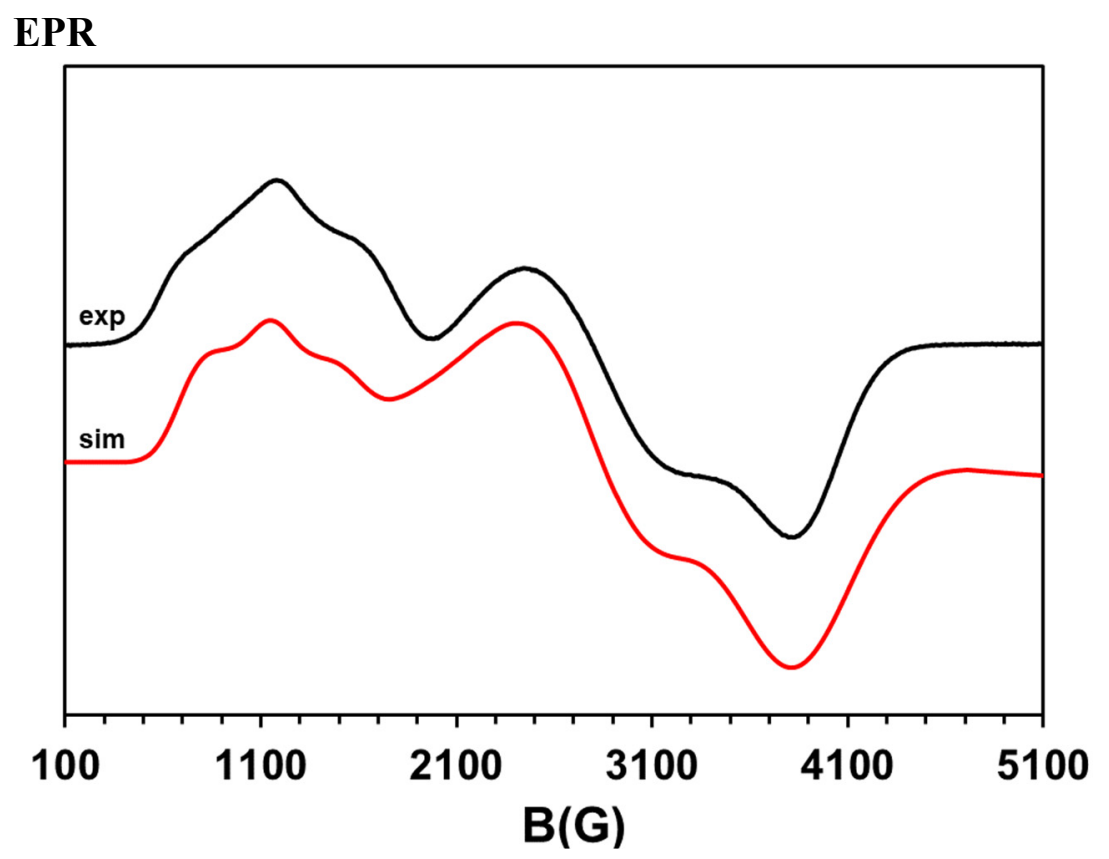

Figure S27. EPR spectrum of 1-Co in acetonitrile, RT. MW power $=0.63 \mathrm{~mW}, \mathrm{MW}$ frequency $=$ $9.63 \mathrm{GHz}$. Simulated parameters: $g_{\mathrm{z}}=2.35, g_{\mathrm{y}}=2.08, g_{\mathrm{x}}=1.87, A_{\mathrm{z}}=380, A_{\mathrm{y}}=30, A_{\mathrm{x}}=1$, D $=$ $3.2, \mathrm{E} / \mathrm{D}=0.22, \mathrm{sD}=0.026, \mathrm{sE} / \mathrm{D}=0.055$, Linewidth $=100$. Co hyperfine splitting is in MHz. The nuclear spin of ${ }^{59} \mathrm{Co}$ is $7 / 2$.

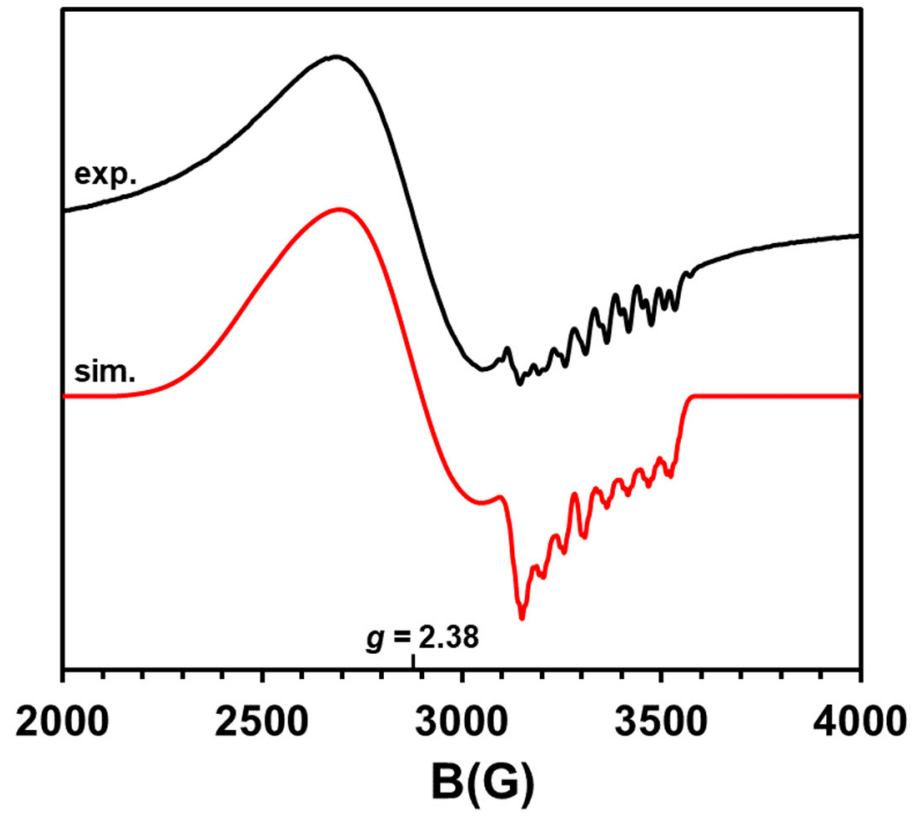

Figure S28. EPR of $10 \mathrm{mM} \mathrm{3-Co} \mathrm{in} \mathrm{acetonitrile} \mathrm{at} 10 \mathrm{~K}$ (black) and a simulation of the data (red). $g_{\mathrm{z}}=2.700, g_{\mathrm{y}}=2.360, g_{\mathrm{x}}=2.063, g 1_{\mathrm{z}}=0.15, g 1_{\mathrm{y}}=0.1, g 1_{\mathrm{x}}=0.003$. Co hyperfine coupling parameters (MHz): $A_{\mathrm{x}}=153, A_{\mathrm{y}}=10, A_{\mathrm{z}}=10$. N hyperfine coupling parameters (4 equivalent centers, MHz): $A_{\mathrm{x}}=31.60, A_{\mathrm{y}}=0.78, A_{\mathrm{z}}=0.63 . \mathrm{MW}$ Frequency $=9.631 \mathrm{GHz}$. MW Power $=2.00$ $\mathrm{mW}$. Linewidth $=2$. The nuclear spin of ${ }^{59} \mathrm{Co}$ and ${ }^{14} \mathrm{~N}$ is $7 / 2$ and 1 respectively. 


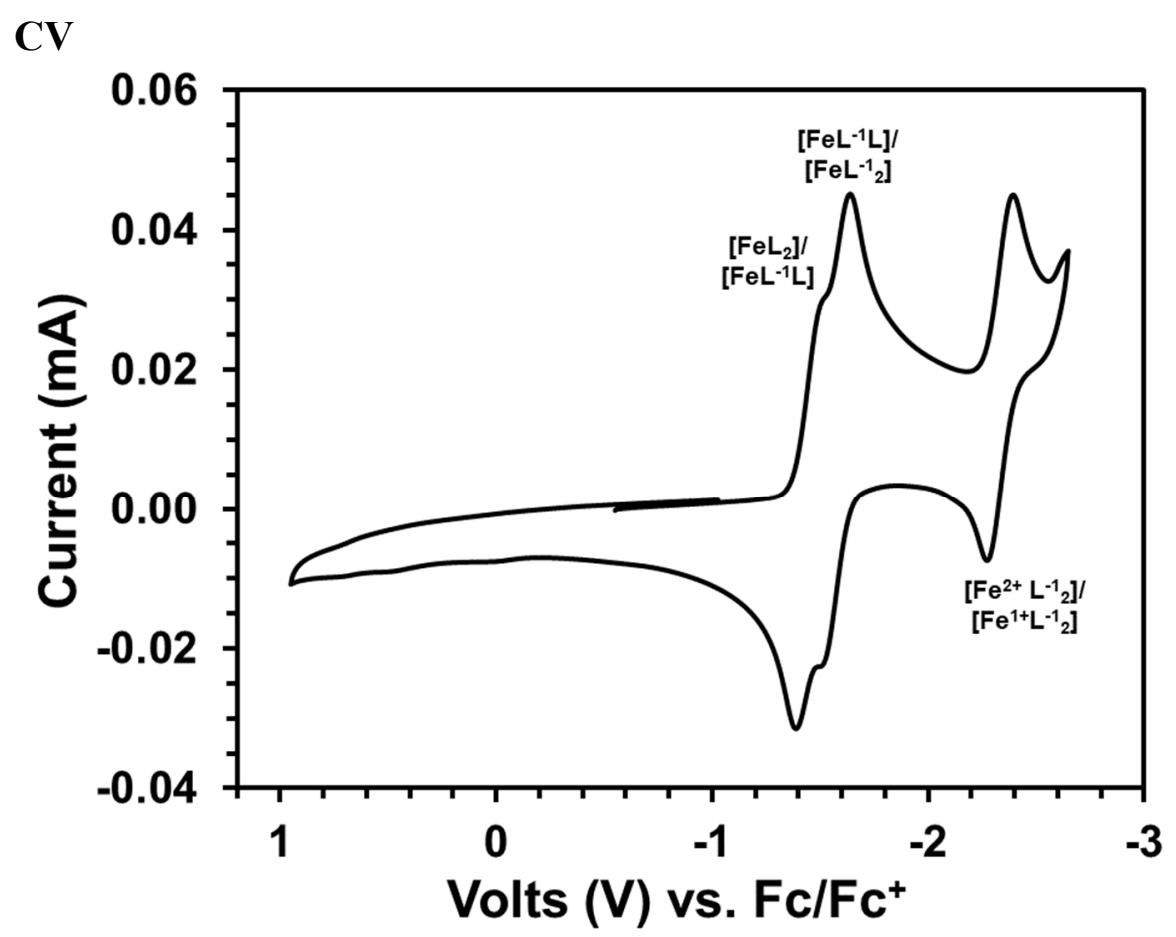

Figure S29. CV of $1.5 \mathrm{mM}$ 1-Fe in acetonitrile where $\mathrm{L}=$ neocuproine and $\mathrm{L}^{-1}=$ neocuproine radical ligand. Electrolyte: $5 \mathrm{mM}\left[\mathrm{Bu}_{4} \mathrm{~N}\right]\left[\mathrm{PF}_{6}\right]$, Scan rate: $100 \mathrm{mV} / \mathrm{s}$. Scanning oxidatively.

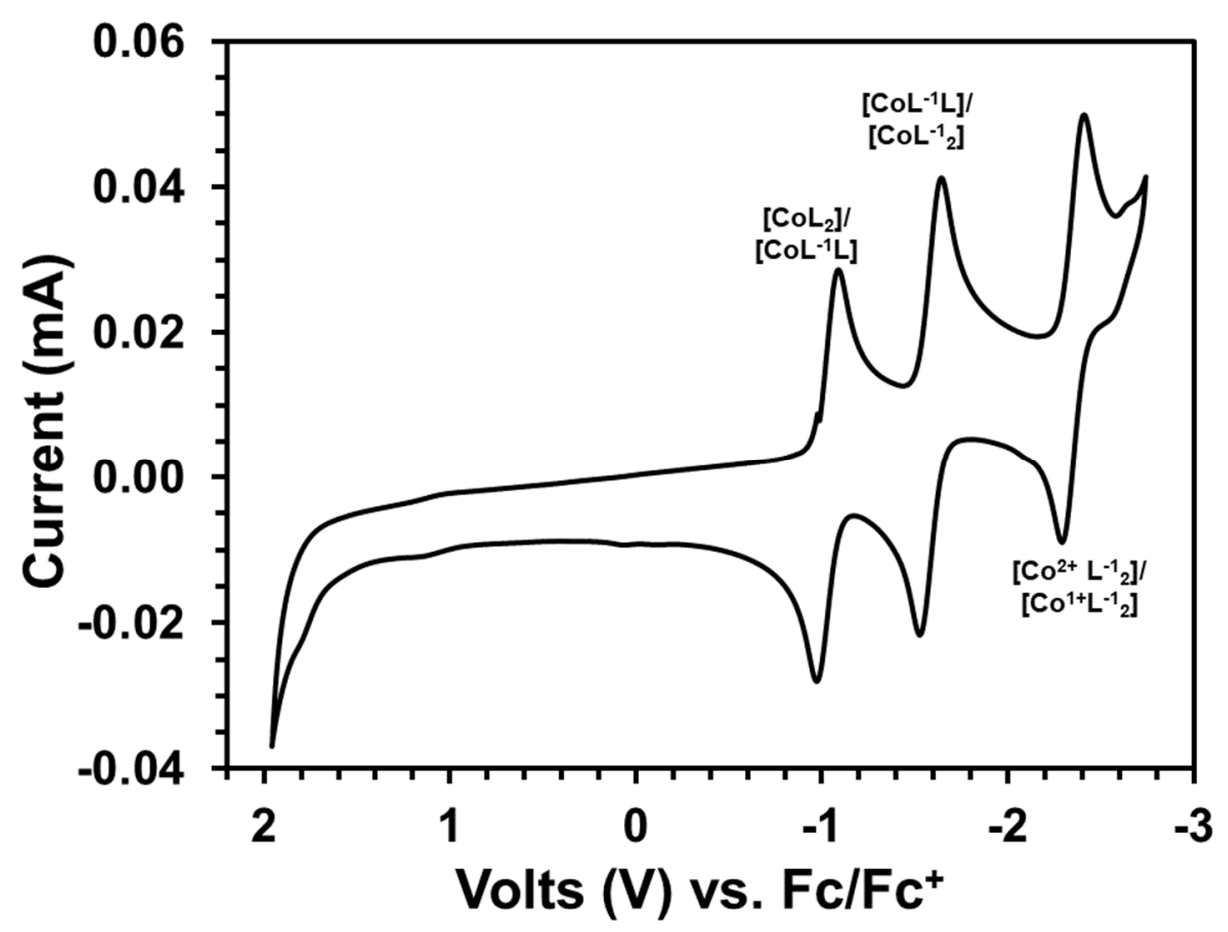

Figure S30. CV of $1.5 \mathrm{mM}$ 1-Co in acetonitrile where $\mathrm{L}=$ neocuproine and $\mathrm{L}^{-1}=$ neocuproine radical ligand. Electrolyte: $5 \mathrm{mM}\left[\mathrm{Bu}_{4} \mathrm{~N}\right]\left[\mathrm{PF}_{6}\right]$, Scan rate: $100 \mathrm{mV} / \mathrm{s}$. Scanning oxidatively. 
Solid State Magnetic Measurements (SQUID)

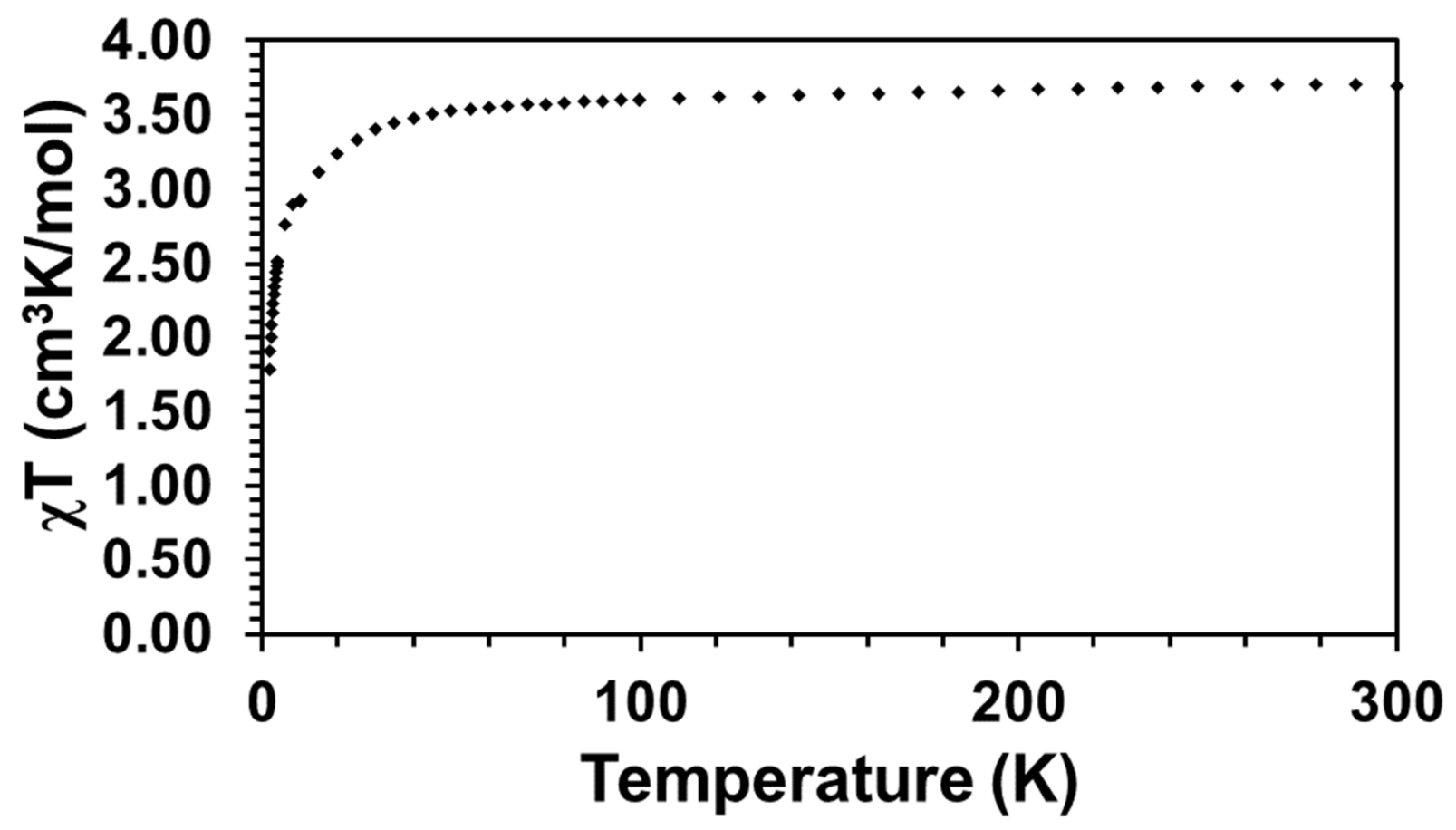

Figure S31. Variable temperature $\chi T$ data of $\mathbf{1 - F e}$ at 1 Tesla.

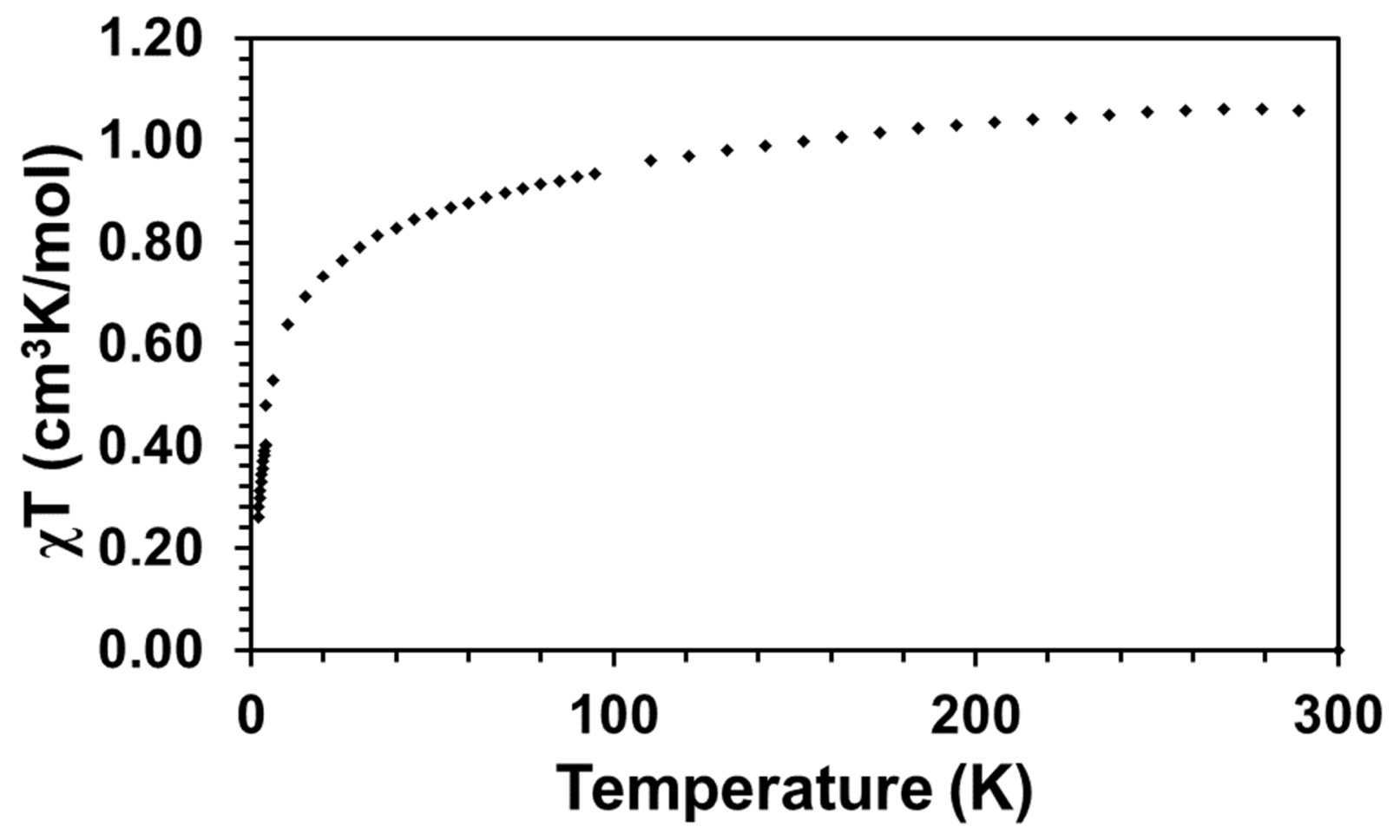

Figure S32. Variable temperature $\chi T$ data of 3-Fe at 1 Tesla. 


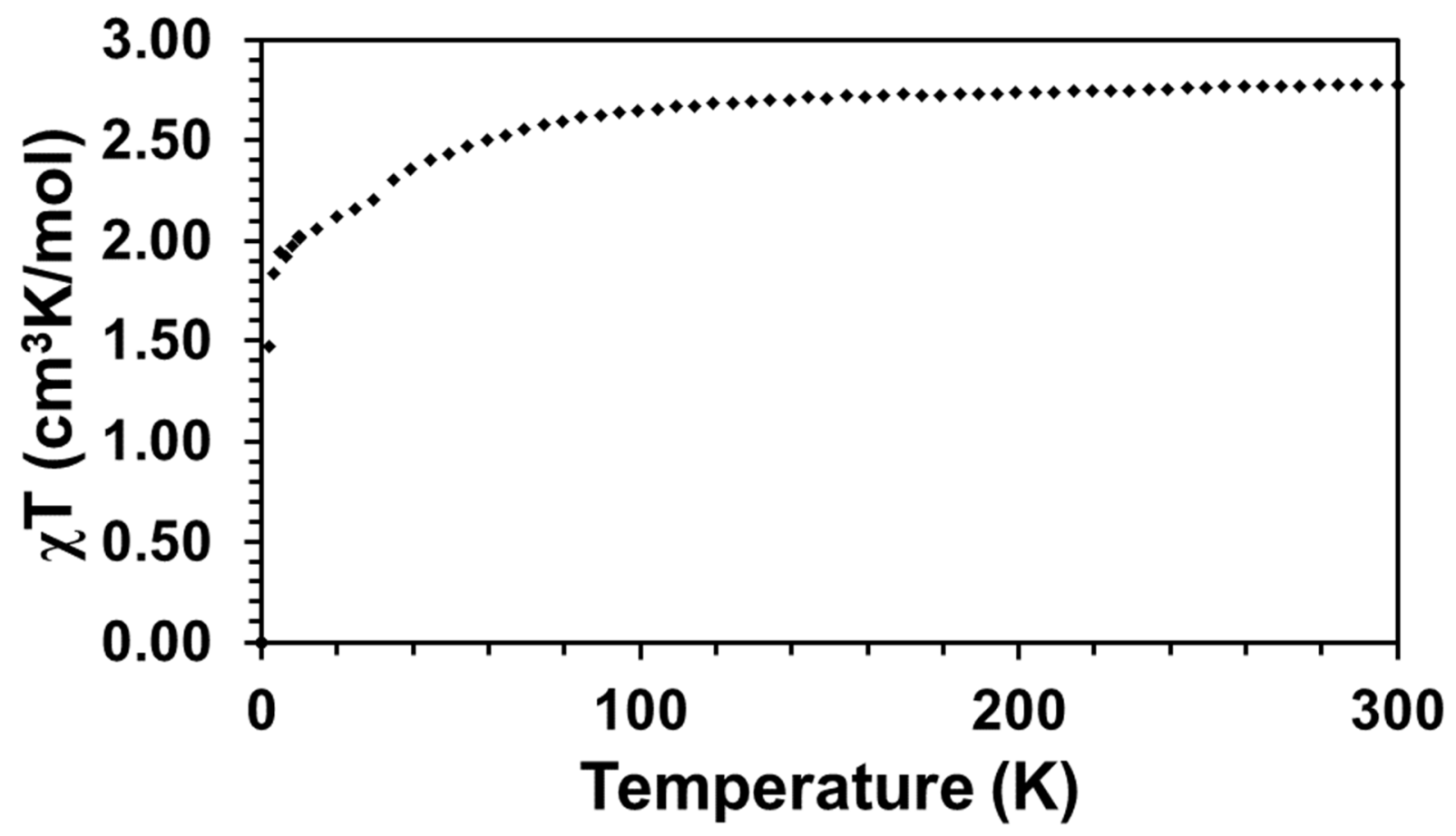

Figure S33. Variable temperature $\chi T$ data of 1-Co at 1 Tesla.

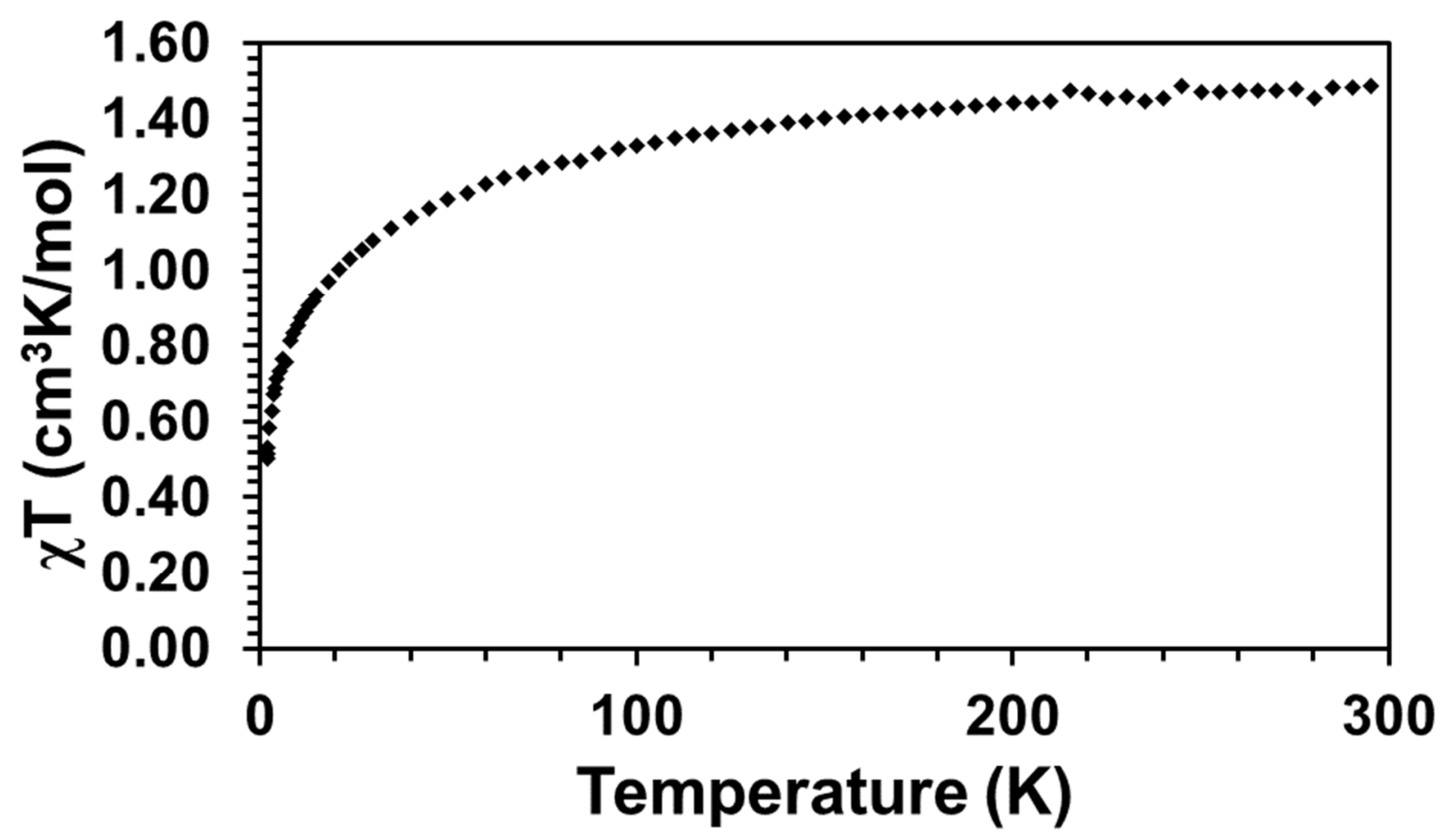

Figure S34. Variable temperature $\chi T$ data of 2-Co at 1 Tesla. 


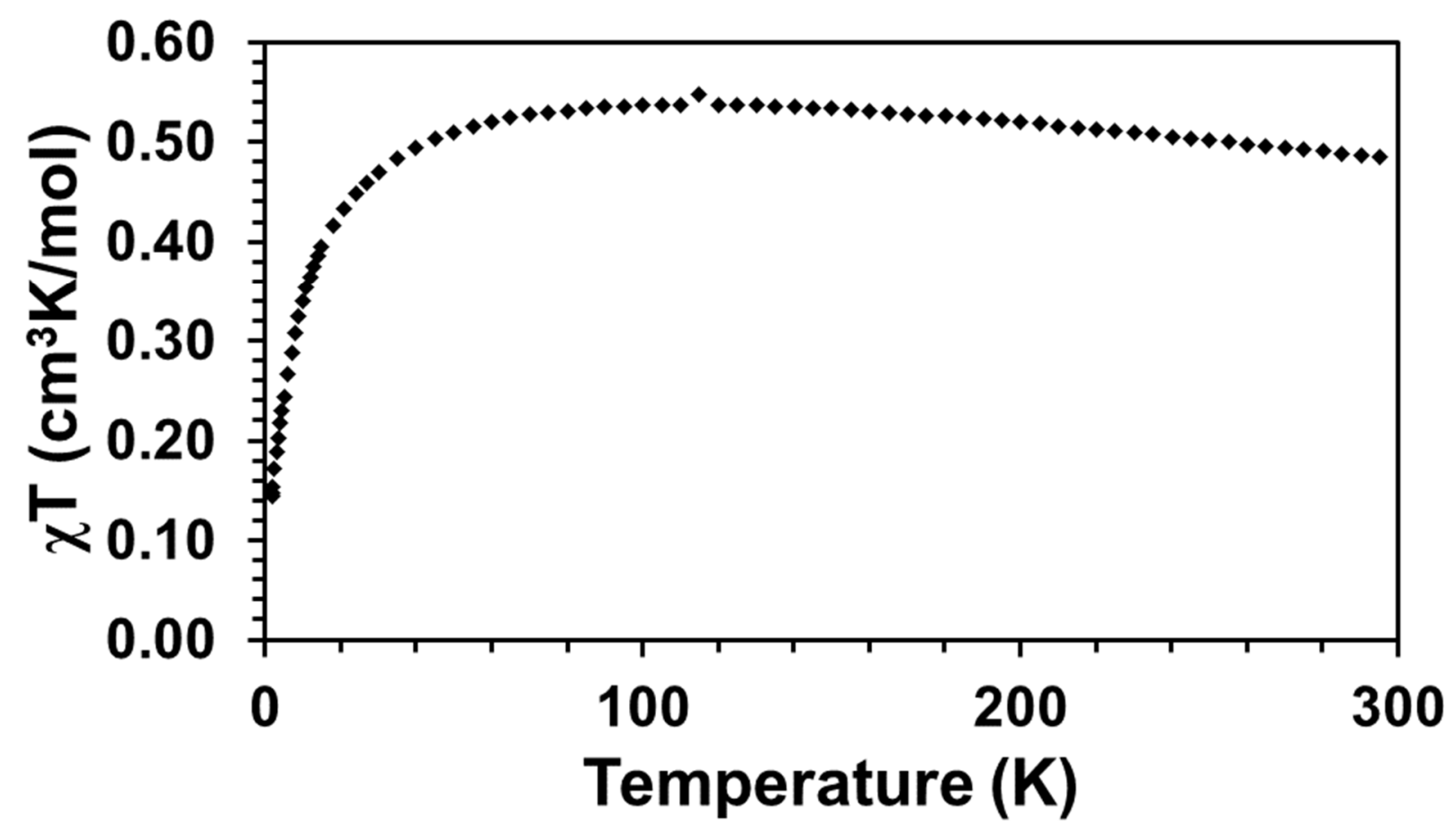

Figure S35. Variable temperature $\chi T$ data of 3-Co at 1 Tesla.

XAS

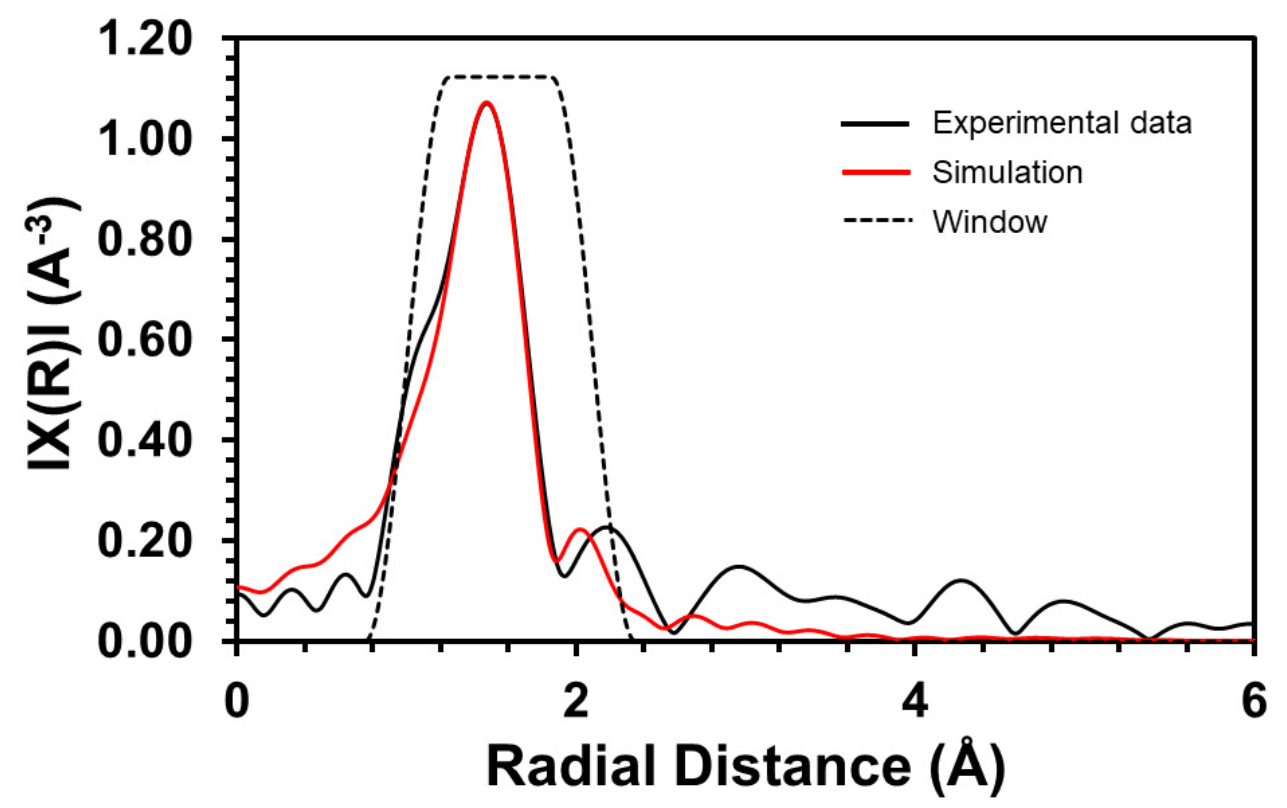

Figure S36. EXAFS spectrum in R-space at the Fe K-edge absorption of 3-Fe. The experimental data (black), simulated fit (red), and window (dashed) are shown. 


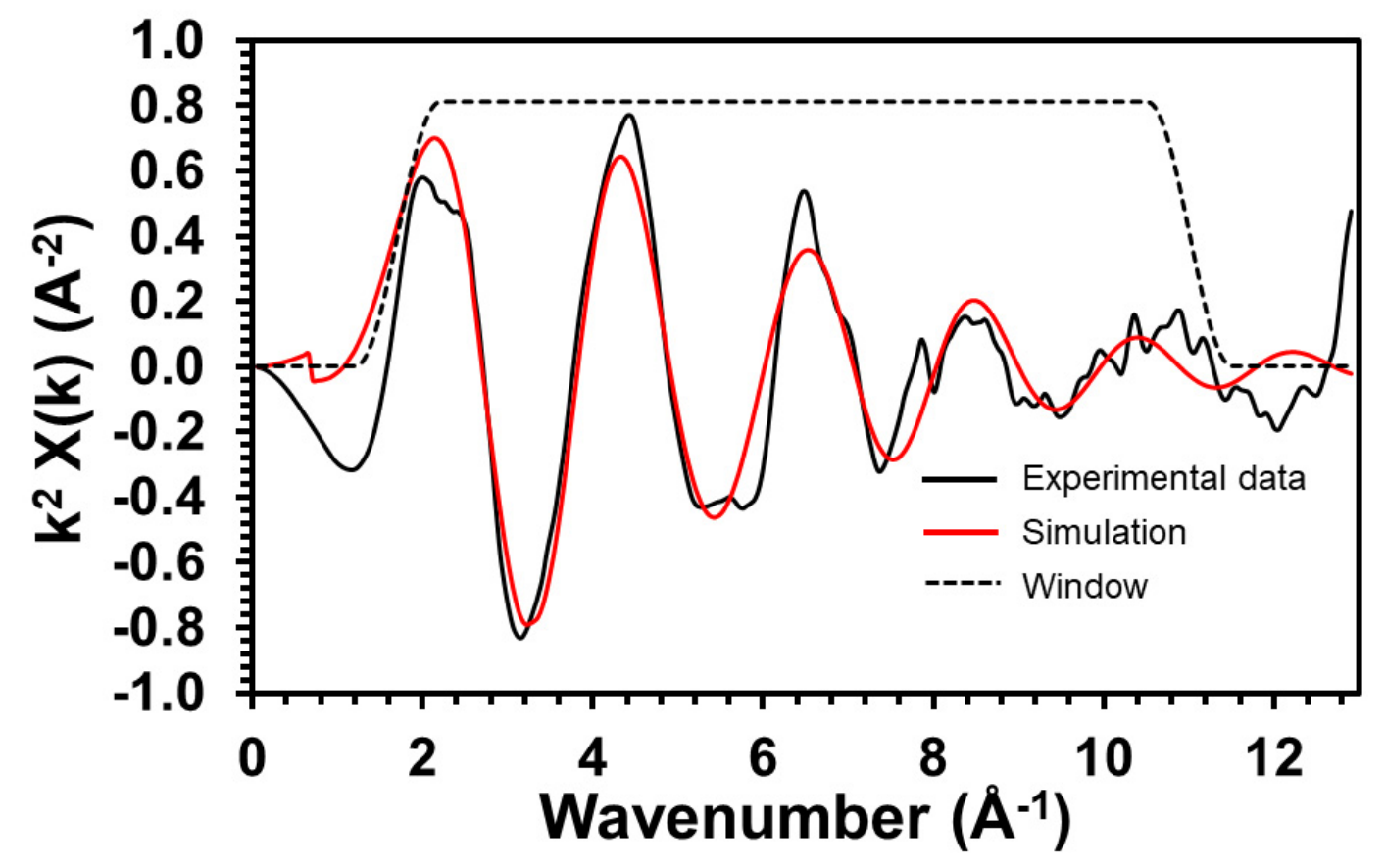

Figure S37. EXAFS spectrum in K-space at the Fe K-edge absorption of 3-Fe. The experimental data (black), simulated data (red), and window (dashed) are shown.

Table S1. EXAFS Fit Parameters for 3-Fe

\begin{tabular}{cccccc}
\hline${ }^{*}$ Complex 3-Fe & $\mathrm{N}$ & $\mathrm{R}(\AA)$ & $\sigma^{2}\left(\AA^{2}\right)$ & R-factor & Reduced chi-square \\
\hline Fe-N1 & 2 & $1.95(1)$ & $0.006(2)$ & 0.014 & 5873 \\
Fe-N2 & 2 & $2.02(1)$ & & & \\
\hline$\Delta \mathrm{E}_{0}=1.771 \mathrm{eV} ; \mathrm{S}_{0}^{2}=0.882$; Independent Points: 6; Fitting Range: k: 1.7-11 $\AA^{-1} ; \mathrm{R}: 1.0-2.1 \AA$
\end{tabular}

*N, Coordination numbers; $\mathrm{R}$, interatomic distances; $\sigma^{2}$, Debye-Waller factors (the mean-square deviations in interatomic distance). The values in parentheses are the estimated standard deviations; $\Delta \mathrm{E}_{0}$, change in the photoelectron energy; $\mathrm{S}_{0}^{2}$, amplitude reduction factor. 


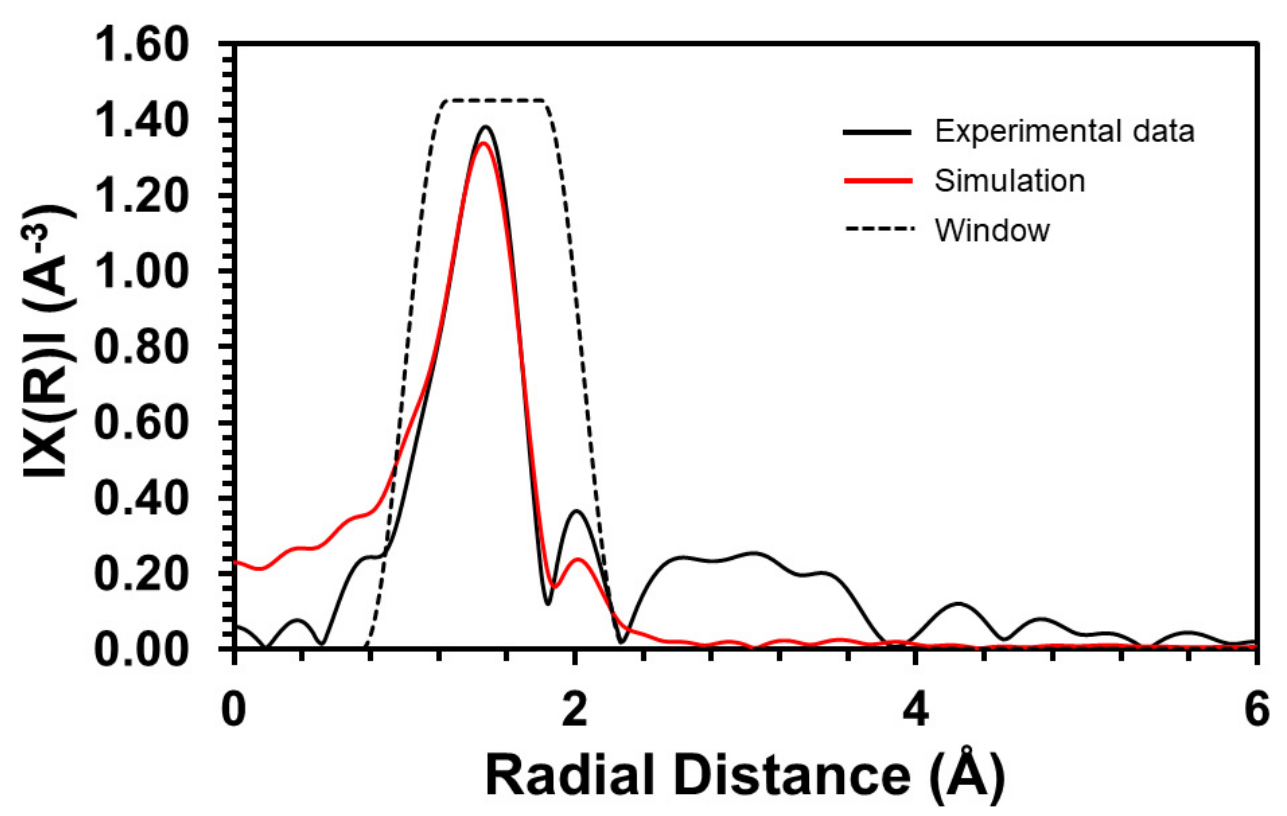

Figure S38. EXAFS spectrum in R-space at the Co K-edge absorption of 3-Co. The experimental data (black), simulated fit (red), and window (dashed) are shown.

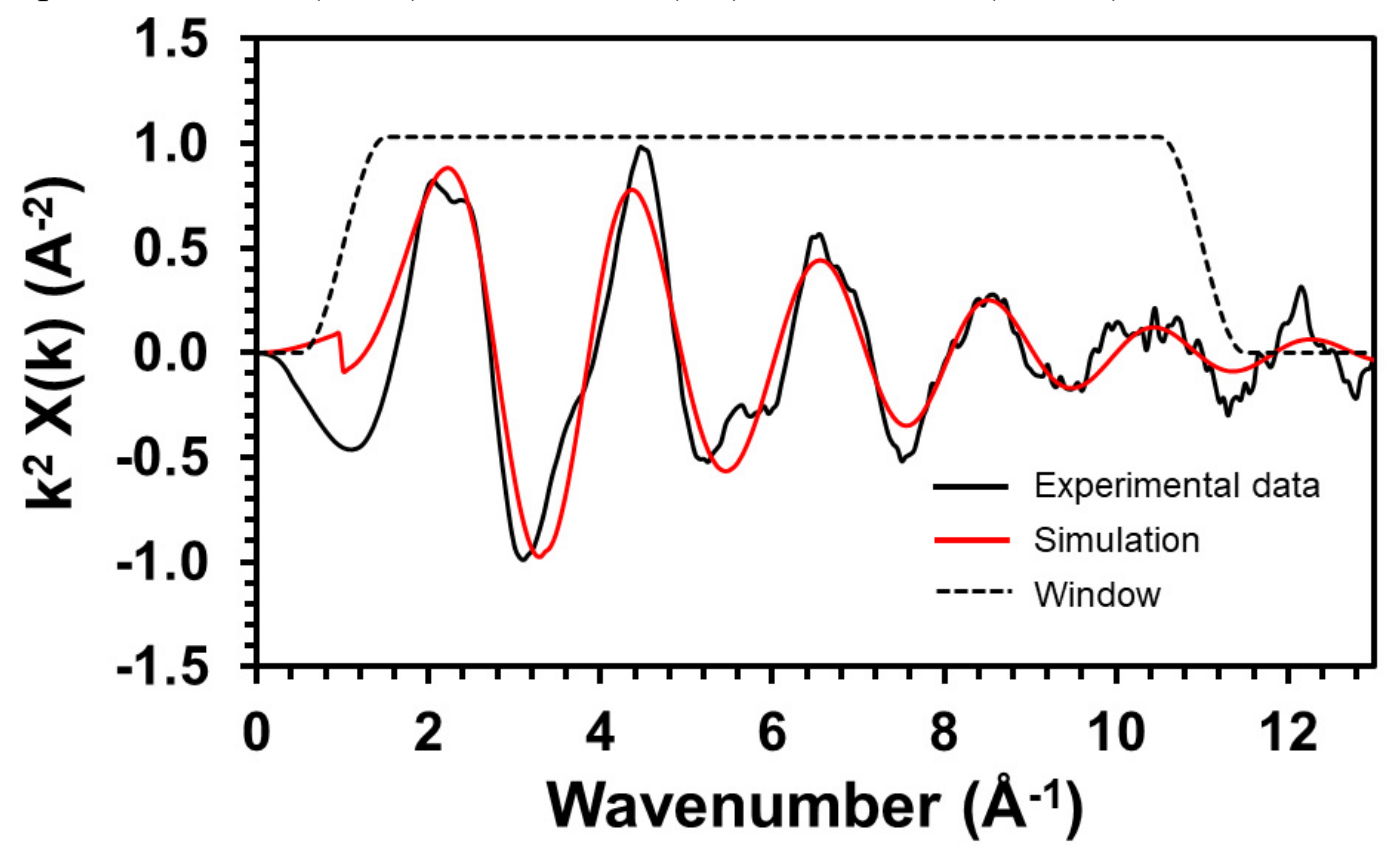

Figure S39. EXAFS spectrum in K-space at the Co K-edge absorption of 3-Co. The experimental data (black), simulated data (red), and window (dashed) are shown. 
Table S2. EXAFS Fit Parameters for 3-Co

\begin{tabular}{cccccc}
\hline${ }^{*}$ Complex 3-Co & $\mathrm{N}$ & $\mathrm{R}(\AA)$ & $\sigma^{2}\left(\AA^{2}\right)$ & R-factor & Reduced chi-square \\
\hline Co-N1 & 2 & $1.96(2)$ & $0.006(3)$ & 0.020 & 481 \\
Co-N2 & 2 & $2.00(2)$ & & & \\
\hline
\end{tabular}

$\Delta \mathrm{E}_{0}=3.764 \mathrm{eV} ; \mathrm{S}_{0}^{2}=0.995$; Independent Points: 6; Fitting Range: k: $1.0-11 \AA^{-1} ; \mathrm{R}: 1.0-2.05 \AA$

*N, Coordination numbers; $\mathrm{R}$, interatomic distances; $\sigma^{2}$, Debye-Waller factors (the mean-square deviations in interatomic distance). The values in parentheses are the estimated standard deviations; $\Delta \mathrm{E}_{0}$, change in the photoelectron energy; $\mathrm{S}_{0}^{2}$, amplitude reduction factor.

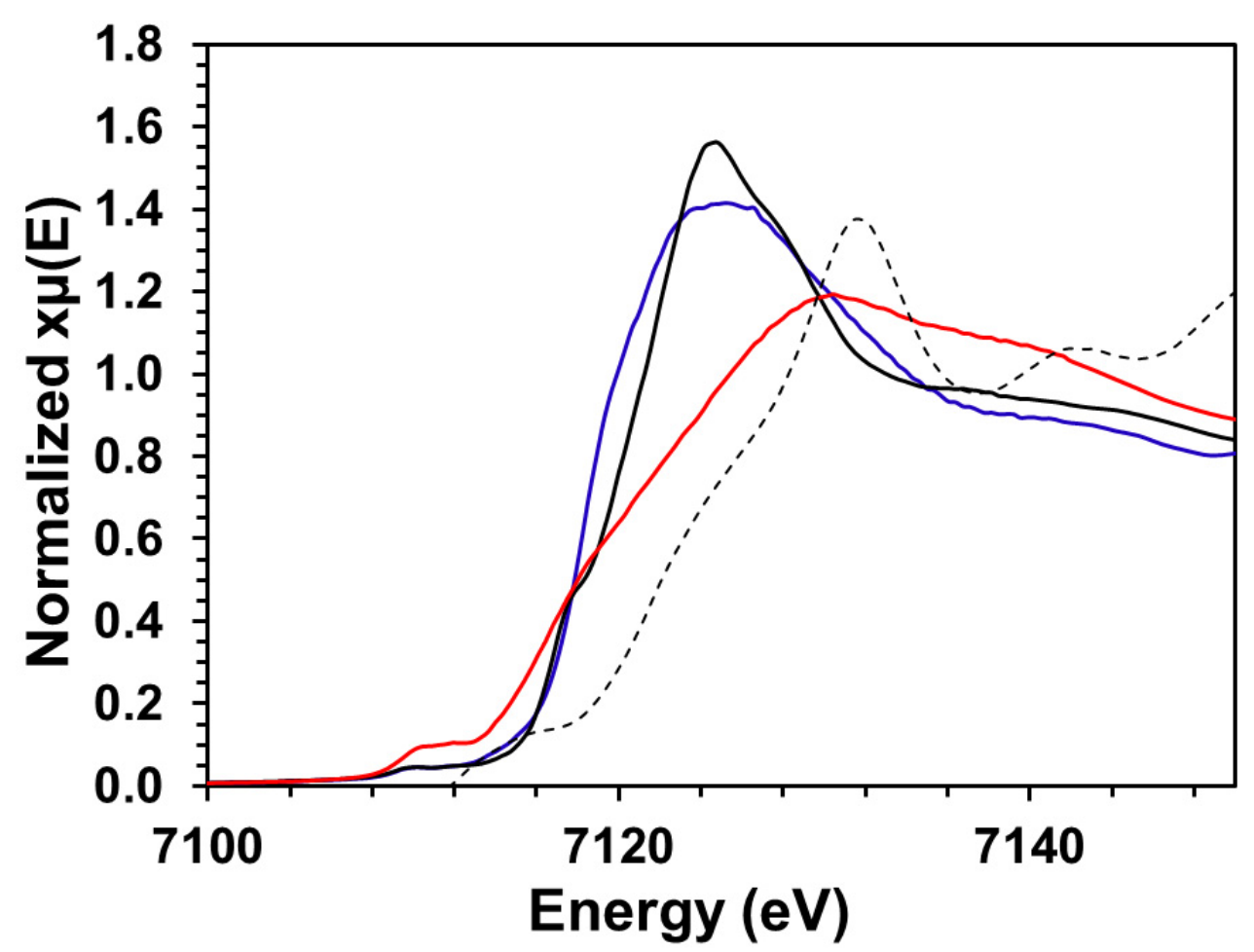

Figure S40. XAS of 1-Fe, 3-Fe, $\mathrm{Fe}(\mathrm{MeCN})_{2}(\mathrm{OTf})_{2}$, and the $\mathrm{Fe}(0)$ foil. Inflection points (eV): 1$\mathbf{F e}$ (7118), 3-Fe (7116), $\mathrm{Fe}(\mathrm{MeCN})_{2}(\mathrm{OTf})_{2}$ (7116), and $\mathrm{Fe}(0)$ foil (7112). 


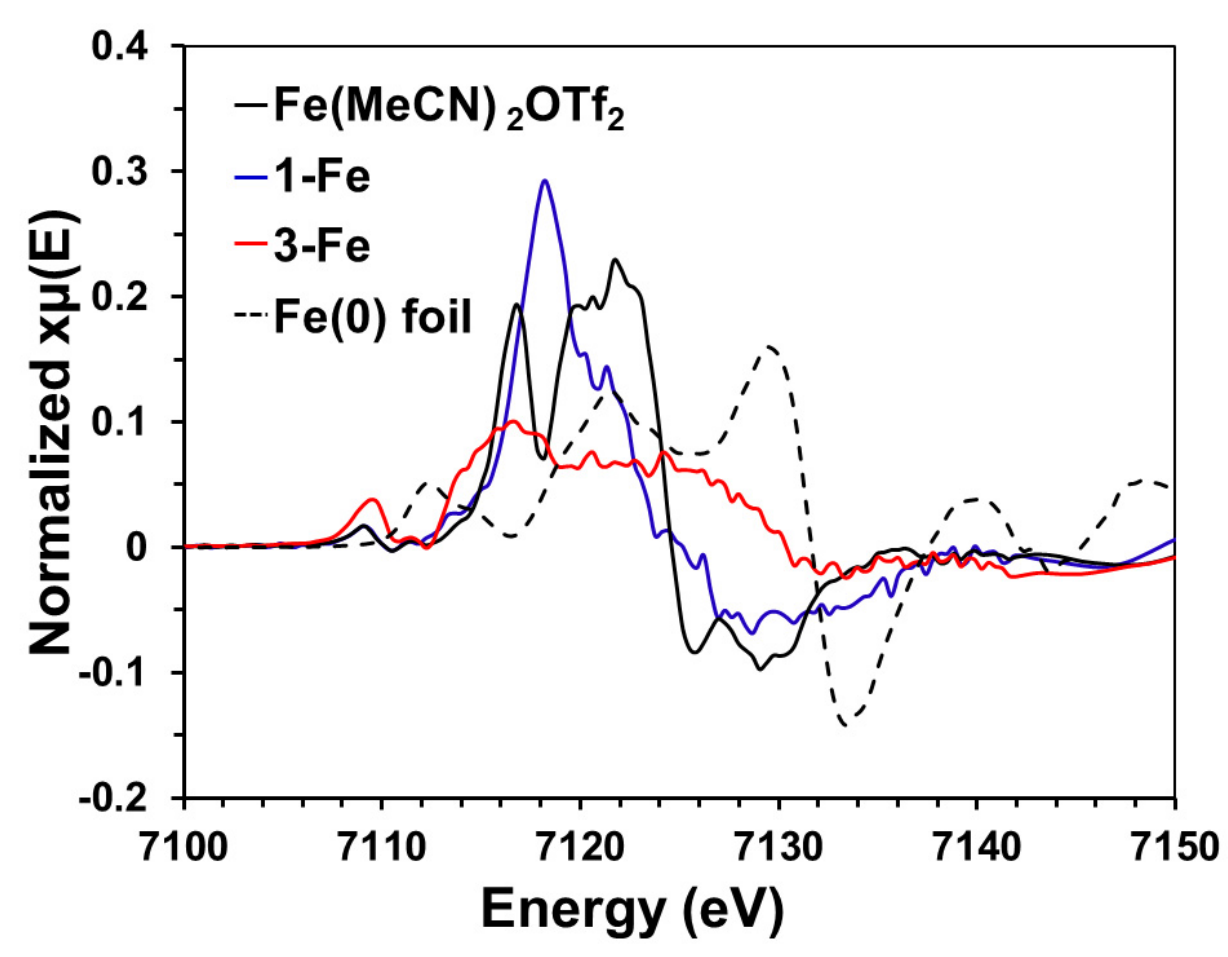

Figure S41. XAS K-edge derivative plot of 1-Fe, 3-Fe, $\mathrm{Fe}(\mathrm{MeCN})_{2}(\mathrm{OTf})_{2}$, and the $\mathrm{Fe}(0)$ foil. Inflection points (eV): 1-Fe (7118), 3-Fe (7116), $\mathrm{Fe}(\mathrm{MeCN})_{2}(\mathrm{OTf})_{2}(7116)$, and $\mathrm{Fe}(0)$ foil (7112).

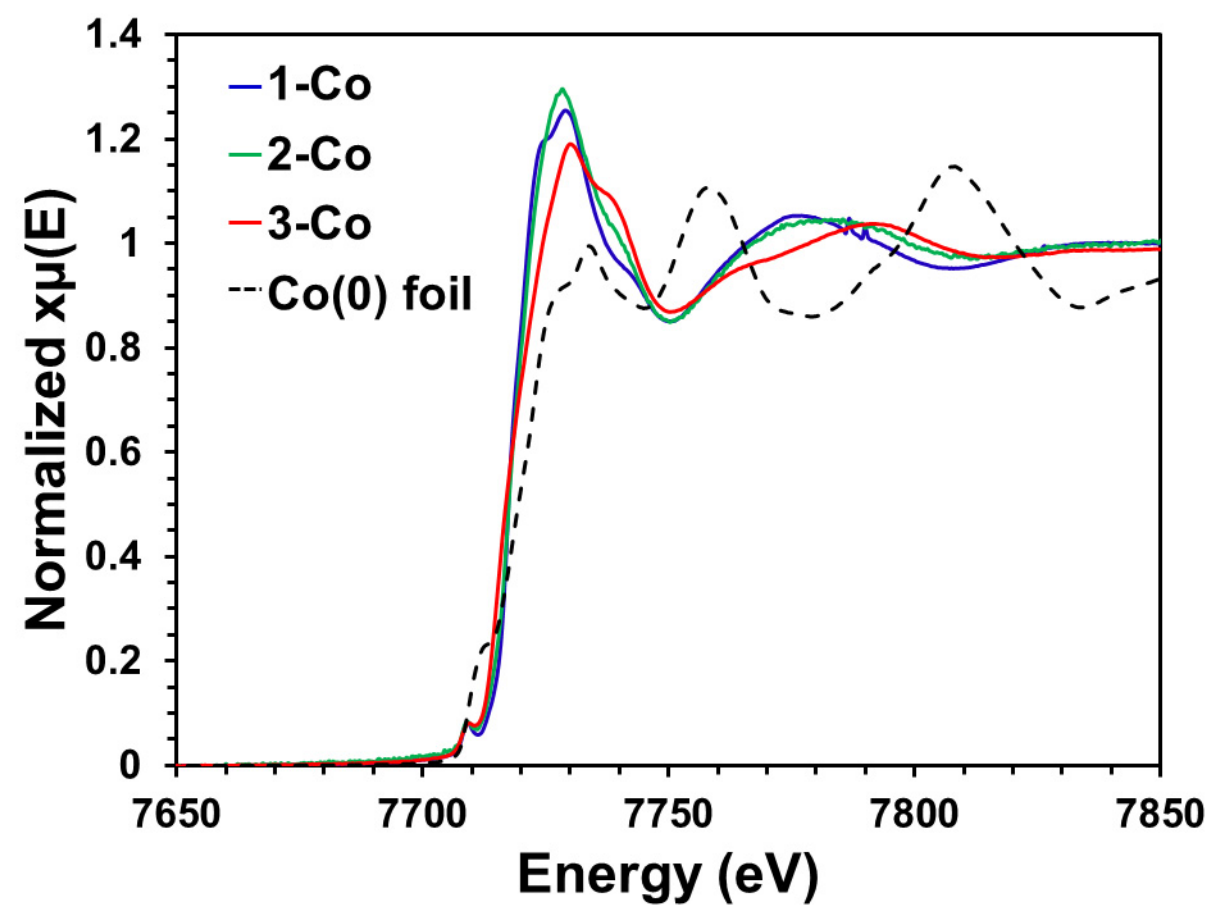

Figure S42. XAS of 1-Co, 2-Co, 3-Co and the $\mathrm{Co}(0)$ foil. Inflection points (eV): 1-Co (7717), 2-Co (7717), 3-Co (7716), and Co(0) foil (7709). 


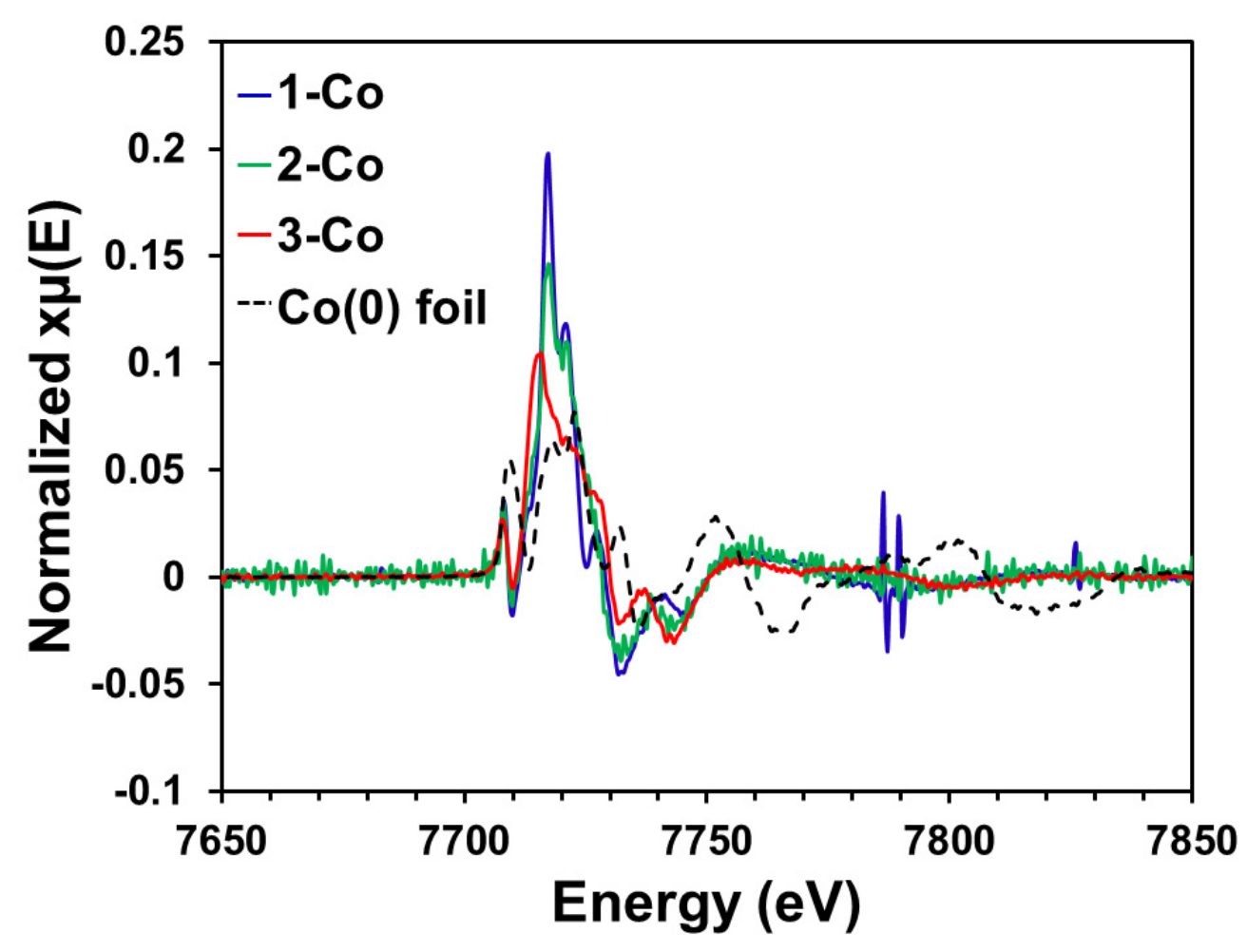

Figure S43. XAS K-edge derivative plot of 1-Co, 2-Co, 3-Co and the $\mathrm{Co}(0)$ foil. Inflection points (eV): 1-Co (7717), 2-Co (7717), 3-Co (7716), and Co(0) foil (7709).

\section{SXRD}

\section{General Description}

Suitable crystals reported in this manuscript were mounted on a cryo-loop and transferred into the cold nitrogen stream of a Bruker D8 Venture diffractometer. Crystal structure of complex 1-Fe (CCDC 189232) and 3-Co (CCDC 1898231) were collected at The Advanced Photon Source at Argonne National Laboratory (beamline 15-ID-B,C,D). The diffraction data were measured at 100 $\mathrm{K}$ using synchrotron X-ray radiation with a wavelength of $\lambda=0.41328 \AA$. Data were collected using $\phi$ scans. Data reduction and integration were performed with the Bruker APEX $3^{2}$ software package. Data were scaled and corrected for absorption effects using the multi-scan procedure as implemented in SADABS. ${ }^{3}$ The structure was solved by SHELXT ${ }^{4}$ and refined by a full-matrix least-squares procedure using $\operatorname{OLEX}^{5}\left(\mathrm{XL}\right.$ refinement program $\left.{ }^{6}\right)$. The crystallographic data of 1Co (CCDC 1898228), 1-Co and [Co(neocuproine)(OTf) $2 \mathrm{MeCN}$ ] (CCDC 1898233), 2-Co (CCDC $1898229)$ and 3-Fe (CCDC 1898230) were collected by using Mo $\mathrm{K}_{\alpha}$ radiation $(0.71073 \AA$ ). The final unit cell was obtained from the xyz centroids of 19263 (1-Co), 16878 (1-Co and [Co(neocuproine)(OTf) $2 \mathrm{MeCN}]), 8164$ (2-Co), 7799 (3-Co), 15933 (1-Fe), and 8042 (3-Fe) reflections after integration. Intensity data were corrected for Lorentz and polarization effects, scale variation for decay and absorption: a multiscan absorption correction was applied, based on the intensities of symmetry-related reflections measured at different angular setting (SADABS). ${ }^{7}$ The structures were solved by direct methods using the program $S H E L X S^{8}$ integrated in Olex $2 .{ }^{9}$ 
Most of the hydrogen atoms were generated by geometrical considerations and constrained to idealized geometries and allowed to ride on their carrier atoms with an isotropic displacement parameter related to the equivalent displacement parameter of their carrier atoms. Structure refinement was performed with the program package $S H E L X L^{7}$ integrated in Olex $2 .{ }^{10}$ Crystallographic data are presented in the table below.

B-level alerts are present for 8042 (3-Fe) and 7799 (3-Co). This is a direct reflection of the low quality of data that could be obtained for these single crystals despite multiple collection attempts in house and at Argonne National Lab using synchrotron radiation. The limitations of the collected data should be considered in any analyses of the aforementioned crystal structures and we have discussed the data in the text cautiously to reflect the data quality.

Table S3. Crystallographic Data

\begin{tabular}{|c|c|c|c|}
\hline & 1-Fe & 1-Co & $\begin{array}{l}\text { 1-Co and } \\
{\left[\mathrm{Co}(\text { neocuproine })(\mathrm{OTf})_{2}\right.} \\
\mathrm{MeCN}]\end{array}$ \\
\hline Empirical formula & $\mathrm{C}_{64} \mathrm{H}_{58} \mathrm{~F}_{12} \mathrm{Fe}_{2} \mathrm{~N}_{8} \mathrm{O}_{13} \mathrm{~S}_{4}$ & $\mathrm{C}_{64} \mathrm{H}_{57.66} \mathrm{Co}_{2} \mathrm{~F}_{12} \mathrm{~N}_{8} \mathrm{O}_{13} \mathrm{~S}_{4}$ & $\mathrm{C}_{48} \mathrm{H}_{39} \mathrm{Co}_{2} \mathrm{~F}_{12} \mathrm{~N}_{7} \mathrm{O}_{12} \mathrm{~S}_{4}$ \\
\hline Formula weight & 1615.12 & 1620.94 & 1379.96 \\
\hline Temperature/K & $100(2)$ & $100(2)$ & $100(2)$ \\
\hline Crystal system & monoclinic & monoclinic & monoclinic \\
\hline Space group & $\mathrm{P} 2{ }_{1} / \mathrm{c}$ & $\mathrm{P} 2_{1} / \mathrm{c}$ & $\mathrm{P} 2{ }_{1} / \mathrm{c}$ \\
\hline $\mathrm{a} / \AA$ & $15.5650(16)$ & $15.5656(10)$ & $17.7028(12)$ \\
\hline $\mathrm{b} / \AA$ & $31.997(3)$ & $31.720(2)$ & $18.0869(13)$ \\
\hline $\mathrm{c} / \AA$ & $14.5894(14)$ & $14.5502(9)$ & $17.8196(12)$ \\
\hline$\alpha /^{\circ}$ & 90 & 90 & 90 \\
\hline$\beta /{ }^{\circ}$ & $108.194(2)$ & $107.712(2)$ & $106.615(2)$ \\
\hline$\gamma /{ }^{\circ}$ & 90 & 90 & 90 \\
\hline Volume $/ \AA^{3}$ & $6902.8(12)$ & $6843.4(8)$ & $5467.4(7)$ \\
\hline $\mathrm{Z}$ & 4 & 4 & 4 \\
\hline$\rho_{\text {calc }} \mathrm{g} / \mathrm{cm}^{3}$ & 1.554 & 1.573 & 1.676 \\
\hline$\mu / \mathrm{mm}^{-1}$ & 0.155 & 0.708 & 0.868 \\
\hline $\mathrm{F}(000)$ & 3304 & 3311 & 2792 \\
\hline Crystal size $/ \mathrm{mm}^{3}$ & $0.5 \times 0.2 \times 0.1$ & $0.48 \times 0.18 \times 0.09$ & $0.3 \times 0.2 \times 0.2$ \\
\hline Radiation & $\begin{array}{l}\text { synchrotron } \quad(\lambda= \\
0.41328)\end{array}$ & $\operatorname{MoK} \alpha(\lambda=0.71073)$ & $\operatorname{MoK} \alpha(\lambda=0.71073)$ \\
\hline $\begin{array}{l}2 \Theta \text { range for data } \\
\text { collection/ }{ }^{\circ}\end{array}$ & 1.48 to 31.418 & 4.226 to 59.56 & 4.45 to 63.892 \\
\hline Index ranges & $\begin{array}{l}-20 \leq \mathrm{h} \leq 20,-41 \leq \mathrm{k} \leq \\
41,-18 \leq 1 \leq 18\end{array}$ & $\begin{array}{l}-21 \leq \mathrm{h} \leq 21,-44 \leq \mathrm{k} \leq 42,-20 \\
\leq 1 \leq 19\end{array}$ & $\begin{array}{l}-26 \leq \mathrm{h} \leq 26,-24 \leq \mathrm{k} \leq 24, \\
-26 \leq 1 \leq 24\end{array}$ \\
\hline $\begin{array}{l}\text { Reflections } \\
\text { collected }\end{array}$ & 175890 & 155696 & 98889 \\
\hline
\end{tabular}




\begin{tabular}{|c|c|c|c|}
\hline $\begin{array}{l}\text { Independent } \\
\text { reflections }\end{array}$ & $\begin{array}{l}15933\left[\mathrm{R}_{\text {int }}=0.0763,\right. \\
\left.\mathrm{R}_{\text {sigma }}=0.0280\right]\end{array}$ & $\begin{array}{l}19263\left[R_{\text {int }}=0.0469, R_{\text {sigma }}=\right. \\
0.0374]\end{array}$ & $\begin{array}{l}16878\left[\mathrm{R}_{\text {int }}=0.0440,\right. \\
\left.\mathrm{R}_{\text {sigma }}=0.0371\right]\end{array}$ \\
\hline $\begin{array}{l}\text { Data/restraints/pa } \\
\text { rameters }\end{array}$ & $15933 / 0 / 957$ & $19263 / 0 / 957$ & $16878 / 0 / 855$ \\
\hline $\begin{array}{l}\text { Goodness-of-fit } \\
\text { on } \mathrm{F}^{2}\end{array}$ & 1.029 & 1.065 & 1.03 \\
\hline $\begin{array}{l}\text { Final } R \text { indexes } \\
{[I>=2 \sigma(I)]}\end{array}$ & $\begin{array}{l}\mathrm{R}_{1}=0.0548, \quad \mathrm{wR}_{2}= \\
0.1410\end{array}$ & $\mathrm{R}_{1}=0.0580, \mathrm{wR}_{2}=0.1278$ & $\begin{array}{l}\mathrm{R}_{1}=0.0411, \quad \mathrm{wR}_{2}= \\
0.0975\end{array}$ \\
\hline $\begin{array}{l}\text { Final } \mathrm{R} \text { indexes } \\
\text { [all data] }\end{array}$ & $\begin{array}{l}\mathrm{R}_{1}=0.0618, \quad \mathrm{wR}_{2}= \\
0.1452\end{array}$ & $\mathrm{R}_{1}=0.0888, \mathrm{wR}_{2}=0.1414$ & $\begin{array}{l}\mathrm{R}_{1}=0.0620, \quad \mathrm{wR}_{2}= \\
0.1058\end{array}$ \\
\hline $\begin{array}{l}\text { Largest diff. } \\
\text { peak/hole / e } \AA^{-3}\end{array}$ & $1.34 /-1.08$ & $1.07 /-0.99$ & $1.08 /-0.59$ \\
\hline
\end{tabular}

Table S3. Crystallographic Data (Cont.)

\begin{tabular}{|c|c|c|c|}
\hline & 2-Co & 3-Fe & 3-Co \\
\hline Empirical formula & $\mathrm{C} 29 \mathrm{H} 24 \mathrm{CoF} 3 \mathrm{~N} 4 \mathrm{O} 3 \mathrm{~S}$ & $\mathrm{C} 28 \mathrm{H} 24 \mathrm{FeN} 4$ & $\mathrm{C} 28 \mathrm{H} 24 \mathrm{CoN} 4$ \\
\hline Formula weight & 624.51 & 472.36 & 475.44 \\
\hline Temperature/K & $100(2)$ & $100(2)$ & $100(2)$ \\
\hline Crystal system & monoclinic & tetragonal & monoclinic \\
\hline Space group & $\mathrm{P} 21 / \mathrm{n}$ & $\mathrm{P} 41212$ & $\mathrm{C} 2 / \mathrm{c}$ \\
\hline $\mathrm{a} / \AA$ & $11.4765(5)$ & $16.0367(17)$ & $22.723(2)$ \\
\hline $\mathrm{b} / \AA \AA$ & $11.0667(5)$ & $16.0367(17)$ & $22.757(2)$ \\
\hline $\mathrm{c} / \AA ̊$ & $21.0321(10)$ & $34.722(4)$ & $18.3309(19)$ \\
\hline$\alpha{ }^{\circ}$ & 90 & 90 & 90 \\
\hline$\beta /{ }^{\circ}$ & $98.187(2)$ & 90 & $107.775(2)$ \\
\hline$\gamma /{ }^{\circ}$ & 90 & 90 & 90 \\
\hline Volume/Å3 & $2644.0(2)$ & $8930(2)$ & $9026.3(16)$ \\
\hline Z & 4 & 16 & 16 \\
\hline$\rho c a l c g / c m 3$ & 1.569 & 1.405 & 1.399 \\
\hline$\mu / \mathrm{mm}-1$ & 0.79 & 0.7 & 0.188 \\
\hline $\mathrm{F}(000)$ & 1280 & 3936 & 3952 \\
\hline Crystal size/mm3 & $0.47 \times 0.45 \times 0.28$ & $0.28 \times 0.18 \times 0.14$ & $0.01 \times 0.002 \times 0$ \\
\hline Radiation & $\operatorname{MoK} \alpha(\lambda=0.71073)$ & $\operatorname{MoK} \alpha(\lambda=0.71073)$ & synchrotron $(\lambda=0.41328)$ \\
\hline $\begin{array}{l}2 \Theta \text { range for data } \\
\text { collection/ }{ }^{\circ}\end{array}$ & 4.322 to 63.868 & 4.29 to 50.402 & 1.51 to 28.34 \\
\hline Index ranges & $\begin{array}{l}-16 \leq \mathrm{h} \leq 17,-16 \leq \mathrm{k} \leq \\
15,-28 \leq 1 \leq 30\end{array}$ & $\begin{array}{l}-19 \leq \mathrm{h} \leq 19,-19 \leq \mathrm{k} \leq 19, \\
-41 \leq 1 \leq 41\end{array}$ & $\begin{array}{l}-26 \leq \mathrm{h} \leq 26,-26 \leq \mathrm{k} \leq 26,-21 \leq \\
1 \leq 21\end{array}$ \\
\hline $\begin{array}{l}\text { Reflections } \\
\text { collected }\end{array}$ & 46539 & 75194 & 91673 \\
\hline $\begin{array}{l}\text { Independent } \\
\text { reflections }\end{array}$ & $\begin{array}{l}8164[\text { Rint }=0.0269, \\
\text { Rsigma }=0.0254]\end{array}$ & $\begin{array}{l}8042 \quad[\text { Rint }= \\
\text { Rsigma }=0.1167]\end{array}$ & $\begin{array}{l}7799[\text { Rint }=0.1507, \text { Rsigma }= \\
0.0740]\end{array}$ \\
\hline $\begin{array}{l}\text { Data/restraints/par } \\
\text { ameters }\end{array}$ & $8164 / 0 / 374$ & $8042 / 1080 / 605$ & $7799 / 1086 / 604$ \\
\hline $\begin{array}{l}\text { Goodness-of-fit } \\
\text { on F2 }\end{array}$ & 1.039 & 1.084 & 1.166 \\
\hline $\begin{array}{l}\text { Final } R \text { indexes } \\
{[I>=2 \sigma(I)]}\end{array}$ & $\begin{array}{l}\mathrm{R} 1=0.0375, \mathrm{wR} 2= \\
0.0866\end{array}$ & $\begin{array}{l}\mathrm{R} 1=\quad 0.1361, \quad w \mathrm{w} 2= \\
0.3045\end{array}$ & $\mathrm{R} 1=0.1616, \mathrm{wR} 2=0.3721$ \\
\hline $\begin{array}{l}\text { Final } \mathrm{R} \text { indexes } \\
\text { [all data] }\end{array}$ & $\begin{array}{l}\mathrm{R} 1=0.0513, \mathrm{wR} 2= \\
0.0924\end{array}$ & $\begin{array}{l}\mathrm{R} 1=0.2004, \quad w R 2= \\
0.3403\end{array}$ & $\mathrm{R} 1=0.1666, w \mathrm{R} 2=0.3743$ \\
\hline
\end{tabular}



\begin{tabular}{l|l} 
Largest diff. & $0.61 /-0.43$ \\
peak/hole / e $\AA-3$ &
\end{tabular}
$2.21 /-0.97$
$2.96 /-1.44$

\section{DFT}

\section{General Description}

Geometry optimization calculations were performed with $\mathrm{ORCA}^{10}$ software suite using density functional theory (DFT). Geometries were fully optimized starting from coordinates generated from a molecular model built in Avogadro. The B3P functional was used with a basis set of def2SVP on $\mathrm{H}$, def2-TZVPP on Co and $\mathrm{N}$, and def2-TZVP on $\mathrm{C}$ atoms. The resulting structures were confirmed to be minima on the potential energy surface by frequency calculations using ORCA ${ }^{10}$. Frequency calculations were also conducted using the B3P functional and previously listed basis sets for each atom type. Single point broken symmetry calculations using flipspin were then run to obtain the final spin density plots and Mullikan spin densities.

\section{2-Co}

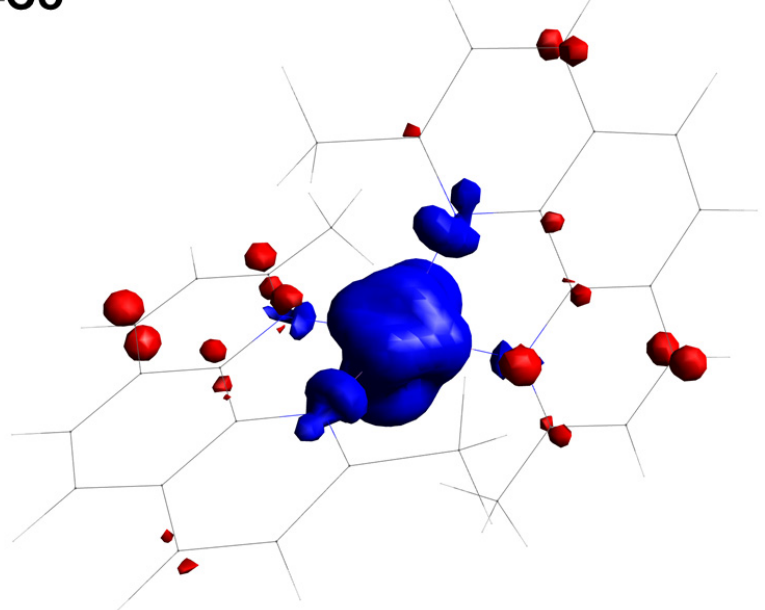

\section{3-Co}

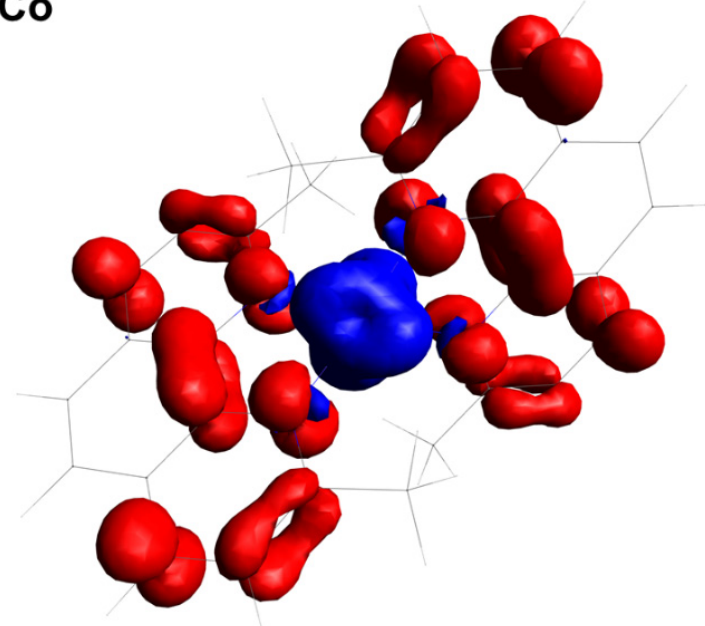

Figure S44. Spin density plots of 2-Co and 3-Co at an iso value of 0.003. Mulliken spin density (Co, ligands): 2-Co: $2.25,-0.25,3-C o: 2.41,-1.54$. Plots were generated in ORCA using orca_plot as gaussian cube files with a grid density of $100 \times 100$ x 100 then modeled in Avogadro.

Table S4. Mulliken Spin Density on Ligand vs. Cobalt

\begin{tabular}{l|ll} 
& 2-Co & 3-Co \\
\hline Spin density on Co & 2.246546 & 2.411682 \\
Spin density on ligands & -0.24655 & -1.54113 \\
Spin density on ligands - Spin density on N & -0.02311 & -0.37009
\end{tabular}

Table S5. Corresponding Orbital Overlap from Broken Symmetry Calculations

\begin{tabular}{c|c|c} 
& 2-Co & 3-Co \\
\hline Orbital & overlap & overlap \\
\hline $0: 00$ & 1 & 1
\end{tabular}




\begin{tabular}{|c|c|}
\hline $1: 00$ & 1 \\
\hline $2: 00$ & 1 \\
\hline $3: 00$ & 1 \\
\hline 4:00 & 1 \\
\hline $5: 00$ & 1 \\
\hline $6: 00$ & 1 \\
\hline $7: 00$ & 1 \\
\hline $8: 00$ & 1 \\
\hline 9:00 & 1 \\
\hline 10:00 & 1 \\
\hline 11:00 & 1 \\
\hline $12: 00$ & 1 \\
\hline $13: 00$ & 1 \\
\hline $14: 00$ & 1 \\
\hline $15: 00$ & 1 \\
\hline $16: 00$ & 1 \\
\hline $17: 00$ & 1 \\
\hline 18:00 & 1 \\
\hline $19: 00$ & 1 \\
\hline $20: 00$ & 1 \\
\hline 21:00 & 1 \\
\hline $22: 00$ & 1 \\
\hline 23:00 & 1 \\
\hline $24: 00: 00$ & 1 \\
\hline $25: 00: 00$ & 1 \\
\hline $26: 00: 00$ & 1 \\
\hline $27: 00: 00$ & 1 \\
\hline 28:00:00 & 1 \\
\hline 29:00:00 & 1 \\
\hline $30: 00: 00$ & 1 \\
\hline $31: 00: 00$ & 1 \\
\hline $32: 00: 00$ & 1 \\
\hline $33: 00: 00$ & 1 \\
\hline $34: 00: 00$ & 1 \\
\hline $35: 00: 00$ & 1 \\
\hline $36: 00: 00$ & 1 \\
\hline $37: 00: 00$ & 1 \\
\hline $38: 00: 00$ & 1 \\
\hline 39:00:00 & 1 \\
\hline 40:00:00 & 1 \\
\hline $41: 00: 00$ & 1 \\
\hline 42:00:00 & 1 \\
\hline 43:00:00 & 1 \\
\hline $44: 00: 00$ & 1 \\
\hline $45: 00: 00$ & 1 \\
\hline
\end{tabular}




\begin{tabular}{|c|c|}
\hline $46: 00: 00$ & 1 \\
\hline 47:00:00 & 1 \\
\hline $48: 00: 00$ & 1 \\
\hline 49:00:00 & 1 \\
\hline $50: 00: 00$ & 1 \\
\hline $51: 00: 00$ & 1 \\
\hline $52: 00: 00$ & 1 \\
\hline $53: 00: 00$ & 1 \\
\hline $54: 00: 00$ & 1 \\
\hline $55: 00: 00$ & 1 \\
\hline $56: 00: 00$ & 1 \\
\hline $57: 00: 00$ & 1 \\
\hline $58: 00: 00$ & 1 \\
\hline $59: 00: 00$ & 1 \\
\hline $60: 00: 00$ & 1 \\
\hline $61: 00: 00$ & 1 \\
\hline $62: 00: 00$ & 1 \\
\hline $63: 00: 00$ & 1 \\
\hline $64: 00: 00$ & 1 \\
\hline $65: 00: 00$ & 1 \\
\hline $66: 00: 00$ & 1 \\
\hline $67: 00: 00$ & 1 \\
\hline 68:00:00 & 1 \\
\hline 69:00:00 & 1 \\
\hline $70: 00: 00$ & 1 \\
\hline $71: 00: 00$ & 1 \\
\hline $72: 00: 00$ & 1 \\
\hline $73: 00: 00$ & 1 \\
\hline $74: 00: 00$ & 1 \\
\hline $75: 00: 00$ & 1 \\
\hline $76: 00: 00$ & 1 \\
\hline $77: 00: 00$ & 1 \\
\hline 78:00:00 & 1 \\
\hline $79: 00: 00$ & 1 \\
\hline $80: 00: 00$ & 1 \\
\hline $81: 00: 00$ & 1 \\
\hline $82: 00: 00$ & 1 \\
\hline $83: 00: 00$ & 1 \\
\hline $84: 00: 00$ & 1 \\
\hline $85: 00: 00$ & 1 \\
\hline $86: 00: 00$ & 1 \\
\hline $87: 00: 00$ & 1 \\
\hline $88: 00: 00$ & 1 \\
\hline $89: 00: 00$ & 1 \\
\hline 90:00:00 & 1 \\
\hline
\end{tabular}




\begin{tabular}{|c|c|c|}
\hline 91:00:00 & 1 & 0.99999 \\
\hline 92:00:00 & 1 & 0.99999 \\
\hline 93:00:00 & 1 & 0.99999 \\
\hline 94:00:00 & 1 & 0.99999 \\
\hline 95:00:00 & 1 & 0.99999 \\
\hline $96: 00: 00$ & 1 & 0.99999 \\
\hline 97:00:00 & 1 & 0.99999 \\
\hline 98:00:00 & 1 & 0.99999 \\
\hline 99:00:00 & 1 & 0.99999 \\
\hline 100:00:00 & 1 & 0.99998 \\
\hline 101:00:00 & 1 & 0.99998 \\
\hline 102:00:00 & 1 & \\
\hline 103:00:00 & 1 & 0.9999 \\
\hline 104:00:00 & 1 & 0.9999 \\
\hline 105:00:00 & 0.99999 & 0.9999 \\
\hline 106:00:00 & 0.99999 & 0.9999 \\
\hline 107:00:00 & 0.99999 & \\
\hline 108:00:00 & 0.99999 & 0.9999 \\
\hline 109:00:00 & 0.99998 & 0.9999 \\
\hline 110:00:00 & 0.99998 & 0.9998 \\
\hline 111:00:00 & 0.99997 & 0.9998 \\
\hline 112:00:00 & & \\
\hline 113:00:00 & 0.99997 & 0.9997 \\
\hline 114:00:00 & 0.99996 & 0.9997 \\
\hline 115:00:00 & 0.99994 & 0.9997 \\
\hline 116:00:00 & 0.99992 & 0.9996 \\
\hline 117:00:00 & 0.99982 & 0.99962 \\
\hline 118:00:00 & 0.99892 & 0.9994 \\
\hline 119:00:00 & 0.99764 & 0.9984 \\
\hline 120:00:00 & 0.99344 & 0.9950 \\
\hline 121:00:00 & 0.89337 & 0.6061 \\
\hline 122:00:00 & 0 & 0.5409 \\
\hline 123:00:00 & 0 & 0 \\
\hline
\end{tabular}

\section{Optimized Coordinates}

$\begin{array}{cccc}\text { 2-Co } & & & \\ \text { C } & 5.920407 & 7.859000 & 4.281296 \\ \text { C } & 6.075995 & 6.456177 & 4.070344 \\ \text { C } & 5.098653 & 5.585557 & 4.425935 \\ \text { C } & 3.882298 & 6.049797 & 5.011957 \\ \text { C } & 3.689315 & 7.431072 & 5.202436 \\ \text { C } & 4.723189 & 8.349408 & 4.836342 \\ \text { H } & 7.000478 & 6.096116 & 3.629753\end{array}$

$\begin{array}{cccc}\mathrm{H} & 5.229257 & 4.518453 & 4.274210 \\ \mathrm{C} & 1.592612 & 7.122920 & 6.153937 \\ \mathrm{C} & 1.721161 & 5.733823 & 6.003519 \\ \mathrm{C} & 2.849053 & 5.196166 & 5.431691 \\ \mathrm{C} & 5.465888 & 10.544234 & 4.804538 \\ \mathrm{C} & 6.690543 & 10.128511 & 4.253508 \\ \mathrm{C} & 6.914598 & 8.803633 & 3.978322 \\ \mathrm{C} & 0.363121 & 7.725634 & 6.750654 \\ \mathrm{H} & -0.231558 & 8.228963 & 5.979346 \\ \mathrm{H} & 0.627001 & 8.477849 & 7.499883\end{array}$




$\begin{array}{cccc}\mathrm{H} & -0.262537 & 6.965277 & 7.221761 \\ \mathrm{C} & 5.232300 & 11.977917 & 5.145287 \\ \mathrm{H} & 5.885234 & 12.634070 & 4.568219 \\ \mathrm{H} & 5.440149 & 12.149821 & 6.207546 \\ \mathrm{H} & 4.188671 & 12.251188 & 4.970884 \\ \mathrm{~N} & 4.495450 & 9.668916 & 5.063577 \\ \mathrm{~N} & 2.563122 & 7.952711 & 5.759809 \\ \mathrm{H} & 7.451411 & 10.871688 & 4.042564 \\ \mathrm{H} & 7.853641 & 8.477432 & 3.541889 \\ \mathrm{H} & 0.914835 & 5.092082 & 6.341340 \\ \mathrm{H} & 2.950849 & 4.122264 & 5.306869 \\ \mathrm{Co} & 2.539470 & 9.964125 & 5.676234 \\ \mathrm{~N} & 1.511773 & 11.604903 & 5.087393 \\ \mathrm{~N} & 2.344394 & 10.852546 & 7.525611 \\ \mathrm{C} & 1.439608 & 11.862781 & 7.461036 \\ \mathrm{C} & 0.976902 & 12.248495 & 6.163176 \\ \mathrm{C} & 0.965697 & 12.544459 & 8.598734 \\ \mathrm{C} & -0.015087 & 13.571369 & 8.449361 \\ \mathrm{C} & -0.469914 & 13.920717 & 7.221773 \\ \mathrm{C} & 0.028206 & 13.281444 & 6.045716 \\ \mathrm{C} & 2.866244 & 10.529520 & 8.708747 \\ \mathrm{C} & 2.459845 & 11.180683 & 9.885340 \\ \mathrm{C} & 1.505904 & 12.167447 & 9.838016 \\ \mathrm{C} & -0.364917 & 13.644618 & 4.749336 \\ \mathrm{C} & 1.130574 & 11.976760 & 3.860659 \\ \mathrm{C} & 0.189650 & 12.999882 & 3.670266 \\ \mathrm{H} & -0.091708 & 13.276722 & 2.660448 \\ \mathrm{H} & -1.093749 & 14.436628 & 4.607328 \\ \mathrm{H} & -0.384866 & 14.069751 & 9.339672 \\ \mathrm{H} & -1.211063 & 14.705848 & 7.109206 \\ \mathrm{H} & 2.902016 & 10.881536 & 10.828928 \\ \mathrm{H} & 1.170370 & 12.662435 & 10.744240 \\ \mathrm{C} & 3.910874 & 9.465757 & 8.741925 \\ \mathrm{H} & 3.631564 & 8.639799 & 8.083472 \\ \mathrm{H} & 4.070643 & 9.091125 & 9.754014 \\ \mathrm{H} & 4.861924 & 9.867673 & 8.374926 \\ \mathrm{C} & 1.745643 & 11.273930 & 2.696672 \\ \mathrm{H} & 2.833338 & 11.405280 & 2.703420 \\ \mathrm{H} & 1.357075 & 11.659234 & 1.753707 \\ \mathrm{H} & 1.539594 & 10.198833 & 2.740117 \\ & & & \end{array}$

\section{3-Co}

$\begin{array}{llll}\mathrm{C} & 5.911765 & 7.877729 & 4.138619 \\ \mathrm{C} & 5.985969 & 6.469294 & 3.894071 \\ \mathrm{C} & 4.990439 & 5.634226 & 4.279567\end{array}$

$\begin{array}{lccc}\mathrm{C} & 3.815357 & 6.129541 & 4.929821 \\ \mathrm{C} & 3.712114 & 7.524763 & 5.154597 \\ \mathrm{C} & 4.757734 & 8.387725 & 4.784303 \\ \mathrm{H} & 6.869626 & 6.078611 & 3.397077 \\ \mathrm{H} & 5.067167 & 4.565805 & 4.096961 \\ \mathrm{C} & 1.611656 & 7.285655 & 6.168536 \\ \mathrm{C} & 1.673474 & 5.910850 & 5.998080 \\ \mathrm{C} & 2.769414 & 5.321827 & 5.364633 \\ \mathrm{C} & 5.602273 & 10.571795 & 4.742703 \\ \mathrm{C} & 6.746083 & 10.129988 & 4.093638 \\ \mathrm{C} & 6.908344 & 8.779836 & 3.781347 \\ \mathrm{C} & 0.430728 & 7.938545 & 6.810756 \\ \mathrm{H} & -0.119252 & 8.544701 & 6.080723 \\ \mathrm{H} & 0.747789 & 8.616793 & 7.609509 \\ \mathrm{H} & -0.250328 & 7.195061 & 7.230150 \\ \mathrm{C} & 5.428484 & 12.005804 & 5.123197 \\ \mathrm{H} & 6.236772 & 12.620078 & 4.722275 \\ \mathrm{H} & 5.413421 & 12.114262 & 6.213533 \\ \mathrm{H} & 4.473153 & 12.393219 & 4.752944 \\ \mathrm{~N} & 4.605433 & 9.726816 & 5.077608 \\ \mathrm{~N} & 2.606574 & 8.096832 & 5.748885 \\ \mathrm{H} & 7.513822 & 10.850015 & 3.834143 \\ \mathrm{H} & 7.803232 & 8.429422 & 3.276727 \\ \mathrm{H} & 0.850494 & 5.300517 & 6.353799 \\ \mathrm{H} & 2.811509 & 4.247532 & 5.212350 \\ \mathrm{Co} & 2.791626 & 10.074740 & 5.851898 \\ \mathrm{~N} & 1.571343 & 11.497779 & 5.167042 \\ \mathrm{~N} & 2.402668 & 10.900933 & 7.628350 \\ \mathrm{C} & 1.426288 & 11.864644 & 7.514212 \\ \mathrm{C} & 0.995246 & 12.188881 & 6.216715 \\ \mathrm{C} & 0.860095 & 12.506356 & 8.644587 \\ \mathrm{C} & -0.152446 & 13.494463 & 8.428290 \\ \mathrm{C} & -0.557857 & 13.817377 & 7.176666 \\ \mathrm{C} & 0.003918 & 13.181171 & 6.023066 \\ \mathrm{C} & 2.838910 & 10.567591 & 8.858487 \\ \mathrm{C} & 2.318222 & 11.158987 & 10.000137 \\ \mathrm{C} & 1.322244 & 12.132421 & 9.901554 \\ \mathrm{H} & 1.185254 & 11.817280 & 3.910811 \\ \mathrm{H} & 0.237346 & 12.798313 & 3.663887 \\ \mathrm{H} & 13.020861 & 2.637904 \\ \mathrm{H} & 14.239910 & 4.528291 \\ \mathrm{H} & 13.981978 & 9.294273\end{array}$




$\begin{array}{lrllllll}\mathrm{H} & -1.324745 & 14.571474 & 7.023159 & \mathrm{H} & 4.801523 & 9.875290 & 8.384869 \\ \mathrm{H} & 2.699505 & 10.852938 & 10.967841 & \mathrm{C} & 1.825009 & 11.061220 & 2.794289 \\ \mathrm{H} & 0.908525 & 12.598008 & 10.790828 & \mathrm{H} & 2.910908 & 11.210852 & 2.799286 \\ \mathrm{C} & 3.910805 & 9.531237 & 8.923019 & \mathrm{H} & 1.434036 & 11.383547 & 1.827968 \\ \mathrm{H} & 3.580473 & 8.607548 & 8.434538 & \mathrm{H} & 1.644180 & 9.985199 & 2.902736 \\ \mathrm{H} & 4.189279 & 9.304083 & 9.953302 & & & & \end{array}$

\section{References}

[1] Ravel, B., Newville, M., ATHENA, ARTEMIS, HEPHAESTUS: data analysis for X-ray absorption spectroscopy using IFEFFIT. J. Synchr. Radn., 2005, 12, 537-541; Newville, M., IFEFFIT: interactive EXAFS analysis and FEFF fitting. J. Synchr. Radn. 2001, 8, 322-324; Rehr, J. J.; Albers, R. C. Rev. Mod. Phys. 2000, 72, 621-654.

[2] Bruker AXS, version 2015.5-2, 2015.

[3] Bruker AXS, version 2014/5, Krause, Herbst-Irmer, Sheldrick \& Stalke, J. Appl. Cryst. 2015, $48,3-10$.

[4] Version 2018/2: Sheldrick, G. M. Acta Crystallogr. 2015, A71, 3-8.

[5] Version 1.2.10; O. V. Dolomanov, L. J. Bourhis, R. J. Gildea, J. A. K. Howard and H. Puschmann. J. Appl. Crystallogr. 2009, 42, 339-34.

[6] Version 2018/3, Sheldrick, G. M. Acta Crystallogr. 2015, C71, 3-8.

[7] Bruker. APEX3 (Version 2015.9-0), SAINT (Version 8.37A) and SADABS (Version 2016/2). Bruker AXS Inc., Madison, Wisconsin, USA, 2015.

[8] G. Sheldrick, Acta Cryst. A 2008, 64, 112-122.

[9] O. V. Dolomanov, L. J. Bourhis, R. J. Gildea, J. A. K. Howard, H. Puschmann, J. Appl. Cryst. 2009, 42, 339-341.

[10] Fenn, T. D., Schnieders, M. J. \& Brunger, A. T. Acta Crystallogr. 2010, D66, 1024-1031. [11] Neese, F. "The Orca Program System" Wiley Interdisciplinary Reviews: Computational Molecular Science 2012, 2, 73-78.; H - Kr: A. Schaefer, H. Horn and R. Ahlrichs, J. Chem. Phys. 1992, 97, 2571; Rb - Xe: A. Schaefer, C. Huber and R. Ahlrichs, J. Chem. Phys. 1994 100, 5829; F. Weigend, R. Ahlrichs, Phys. Chem. Chem. Phys. 2005, 7, 3297. 